\title{
Regulation of glucose - 6 -phosphate dehydrogenase by polyunsaturated fatty acids in cultured rat hepatocytes
}

\author{
Laura Petrosky Stabile \\ West Virginia University
}

Follow this and additional works at: https://researchrepository.wvu.edu/etd

\section{Recommended Citation}

Stabile, Laura Petrosky, "Regulation of glucose -6 -phosphate dehydrogenase by polyunsaturated fatty acids in cultured rat hepatocytes" (1999). Graduate Theses, Dissertations, and Problem Reports. 1051. https://researchrepository.wvu.edu/etd/1051

This Dissertation is protected by copyright and/or related rights. It has been brought to you by the The Research Repository @ WVU with permission from the rights-holder(s). You are free to use this Dissertation in any way that is permitted by the copyright and related rights legislation that applies to your use. For other uses you must obtain permission from the rights-holder(s) directly, unless additional rights are indicated by a Creative Commons license in the record and/ or on the work itself. This Dissertation has been accepted for inclusion in WVU Graduate Theses, Dissertations, and Problem Reports collection by an authorized administrator of The Research Repository @ WVU.

For more information, please contact researchrepository@mail.wvu.edu. 


\title{
REGULATION OF GLUCOSE-6-PHOSPHATE DEHYDROGENASE BY POLYUNSATURATED FATTY ACIDS IN CULTURED RAT HEPATOCYTES
}

Laura P. Stabile, M.S.

\author{
Dissertation submitted to the School of Medicine \\ of West Virginia University \\ in partial fulfillment of the requirements \\ for the degree of \\ Doctor of Philosophy \\ in \\ Biochemistry
}

\author{
Lisa M. Salati, Ph.D., Chair \\ Diana Beattie, Ph.D. \\ Marilyn Evans, Ph.D. \\ Robert Goodman, Ph.D. \\ Jeannine Strobl, Ph.D.
}

Department of Biochemistry

Morgantown, West Virginia

1999

Keywords: gene regulation, nutrition, polyunsaturated fatty acids 


\begin{abstract}
REGULATION OF GLUCOSE-6-PHOSPHATE DEHYDROGENASE BY POLYUNSATURATED FATTY ACIDS IN CULTURED RAT HEPATOCYTES
\end{abstract}

\author{
Laura P. Stabile
}

The goal of this research is to understand the molecular mechanism(s) by which polyunsaturated fatty acids inhibit gene expression of the lipogenic enzymes. The model enzyme that we are using to study this phenomenon is liver glucose-6-phosphate dehydrogenase (G6PD). In order to determine if regulation of G6PD occurred at a transcriptional or a posttranscriptional step in rat hepatocytes, enzyme activity, mRNA accumulation and transcriptional activity of the G6PD gene were measured in the presence and absence of a polyunsaturated fatty acid, arachidonic acid. Insulin and glucose stimulated a 5- to 7-fold increase in G6PD activity and mRNA. This increase was attenuated by $60 \%$ due to the addition of arachidonic acid to the medium of primary rat hepatocytes in culture. Transcriptional activity of the G6PD gene was measured using nuclear run-on assays. The changes in mRNA accumulation occurred in the absence of changes in transcription. To more precisely define the regulated step, the abundance of G6PD mRNA both in the nucleus and in total RNA was measured using a ribonuclease protection assay with probes designed to cross intron-exon boundaries. Amounts of precursor mRNAs for G6PD in the nucleus changed in parallel with the amount of mature mRNA. The decrease in pre-mRNA accumulation was only caused by long chain polyunsaturated fatty acids not monounsaturated fatty acids. Further, this decrease was not due to toxicity of the cells as a result of fatty acid oxidation. Thus, regulation occurs at a nuclear posttranscriptional step and represents a novel form of regulation by fatty acids. Our hypothesis is that regulation of G6PD occurs very early in the processing pathway through the interaction of a trans-acting factor with a cis-acting element within the precursor mRNA for the gene. Using transient transfection analysis of a mouse G6PD cDNA construct in rat hepatocytes, a putative fatty acid response element has been localized within $2.3 \mathrm{~kb}$ of the G6PD mature sequences. Identification of the pathway involved in the inhibition of de novo fatty acid synthesis by polyunsaturated fat will help understand the molecular basis for diseases associated with the consumption of fat, such as diabetes, obesity and atherosclerotic disease. 


\section{ACKNOWLEDGMENTS}

First, I would like to express my sincere gratitude to my advisor, Dr. Lisa Salati, for her guidance, encouragement and patience throughout my graduate career. Second, I would like to thank all of the members of my committee, Dr. Diana Beattie, Dr. Marilyn

Evans, Dr. Robert Goodman, and Dr. Jeannine Strobl for their valuable suggestions on this project.

I would also like to thank the members of the Salati laboratory, both past and present, and all of the other graduate students in the Biochemistry Department for both professional assistance and friendship which made these years at WVU an enjoyable experience.

Most of all, I wish to thank my family for the encouragement to continue my education. Without their love and support, none of this would have been possible. 


\section{TABLE OF CONTENTS}

PAGE

LIST OF ILLUSTRATIONS

vii

ABBREVIATIONS

CHAPTER 1. LITERATURE REVIEW

Introduction

Regulation of G6PD by nutritional and hormonal factors

Hormonal factors

Nutritional factors

Structural characterization of the G6PD gene

Tissue specificity of G6PD regulation

Mechanisms of G6PD regulation

Regulation of lipogenic/glycolytic enzymes by nutrients

and hormones

Acetyl-CoA carboxylase

ATP-citrate lyase

Fatty acid synthase

Malic enzyme

Spot 14

Stearoyl-CoA desaturase

Pyruvate kinase

Summary

Posttranscriptional regulatory mechanisms

Capping

Splicing

25

Poly(A) tail

26

Pre-mRNA instability

Nuclear matrix

Nonsense-mediated decay

Iron response elements

Coding region stability determinants

Adenylate/Uridylate rich elements

Summary and conclusions 
CHAPTER 2. POLYUNSATURATED FATTY ACIDS INHIBIT

THE EXPRESSION OF THE GLUCOSE-6-PHOSPHATE

DEHYDROGENASE GENE IN PRIMARY RAT HEPATOCYTES BY

A NUCLEAR POSTTRANSCRIPTIONAL MECHANISM

Introduction 54

Materials and methods $\quad 55$

Materials $\quad 55$

Animal care and cell culture $\quad 56$

Thiobarbituric acid assay $\quad 56$

Measurement of G6PD activity $\quad 57$

Isolation of total RNA and Northern analysis $\quad 57$

Isolation of nuclear RNA $\quad 57$

Nuclear run-on assays and DNA probes $\quad 57$

Probe design for ribonuclease protection assay 58

Ribonuclease protection assay $\quad 60$

Results $\quad 60$

Effect of starvation and refeeding on transcriptional activity of $\quad 60$ G6PD in rat

Regulation of enzyme activity and mRNA accumulation by $\quad 64$ glucose, insulin, and fatty acids in rat hepatocytes in primary culture

Time course of the effect of arachidonic acid on G6PD mRNA 67 accumulation

G6PD is regulated at a posttranscriptional step in the nucleus of 70 rat hepatocytes

Effect of monounsaturated versus polyunsaturated fatty acids on 73 G6PD expression

Discussion $\quad 76$

References $\quad 81$

CHAPTER 3. LOCALIZATION OF A FATTY ACID RESPONSE 86

ELEMENT WITHIN THE G6PD MATURE SEQUENCE

Introduction 86

$\begin{array}{ll}\text { Materials and methods } & 87\end{array}$

$\begin{array}{ll}\text { Materials } & 87\end{array}$

Animal care and cell culture $\quad 88$

Plasmid construction $\quad 88$

Transient transfection of primary hepatocytes $\quad 92$ 
Ribonuclease protection assay $\quad 92$

Preparation of cell extracts and $\beta$-galactosidase assay 95

Cellular fractionation $\quad 96$

Isolation of total RNA and Northern analysis $\quad 98$

Lithium chloride treatment of RNA 98

DNase I treatment of RNA 98

Results 99

Assays to measure transgene and endogenous gene expression 99

CMV promoter is not regulated by fatty acids $\quad 101$

pcDNA transgene mRNA is found in the same nuclear fractions 104

as the endogenous G6PD mRNA

G6PD mature sequences contain a fatty acid response element 107

$\begin{array}{ll}\text { Discussion } & 110\end{array}$

$\begin{array}{ll}\text { References } & 115\end{array}$

$\begin{array}{ll}\text { APPENDIX } & 119\end{array}$

$\begin{array}{lr}\text { Hepatocyte isolation } & 119\end{array}$

pcDNA deletion constructs 121

$\begin{array}{lr}\text { Letter of permission } & 123\end{array}$

$\begin{array}{lr}\text { Curriculum Vitae } & 124\end{array}$ 


\section{LIST OF ILLUSTRATIONS}

Chapter 1

PAGE

Figure 1: Outline of lipogenic pathway 2

Figure 2: G6PD reaction 4

Figure 3: Structure of the G6PD gene 8

\section{Chapter 2}

Figure 1: Probes and predicted fragments for the ribonuclease protection 59 assay

Figure 2: Effect of starvation and refeeding on the expression of G6PD 62 in the rat

Figure 3: Effect of insulin, glucose, and arachidonic acid on G6PD

enzyme activity and mRNA accumulation in cultured rat hepatocytes

Figure 4: Time course of the inhibition of G6PD mRNA accumulation 68 arachidonic acid

Figure 5: G6PD is regulated at a posttranscriptional step in rat hepatocytes

Figure 6: Posttranscriptional regulation of G6PD by arachidonic acid occurs in the nucleus

Figure 7: Effects of polyunsaturated fatty acids and monounsaturated fatty acids on inhibition of G6PD pre-mRNA accumulation

\section{Chapter 3}

Figure 1A: Parent vectors for designing chimeric constructs

Figure 1B: cDNA and 3'-UTR constructs

Figure 2A: Mouse and rat probes

Figure 2B: The 3'-end of exon 13 is different in mice and rats

Figure 3: Cellular fractionation scheme 
Figure 4: Assay to distinguish between the transgene and endogenous G6PD mRNA

Figure 5: The CMV promoter is not regulated by arachidonic acid

Figure 6: The pcDNA transgene colocalizes with the endogenous gene in subcellular fractions

Figure 7: The mature G6PD mRNA sequences contain a putative fatty acid response element

Figure 8: Proposed model for G6PD regulation by polyunsaturated fatty acid

\section{APPENDIX}

Figure 1: pcDNA deletion constructs 


\section{ABBREVIATIONS}

ACC

AURE

bp

CAT

CHX

CMV

DEPC

DHFR

DNase

EGF

FABP

FAS

GAPDH

G6PD

HepG2

HNF-4

HS

IRE

IRP

$\mathrm{kb}$

ME

$\mathrm{NADP}^{+}$

NAPDH

NF-1

nt

PI

PII

PIII

PBS

PCR

pC3

PEPCK

pFAS-17

PK

pmalb-2

PMSF

PPAR

pPCK10

pre-mRNA

pRGAPDH1

PUFA
Acetyl-CoA Carboxylase

Adenylate-Uridylate Rich Element

base pair

Chloramphenicol Acetyl Transferase

Cycloheximide

Cytomegalovirus

Diethyl-Phenyl Carboxykinase

Dihydrofolate Reductase

Deoxyribonuclease

Epidermal Growth Factor

Fatty Acid Binding Protein

Fatty Acid Synthase

Glyceraldehyde-3-Phosphate Dehydrogenase

Glucose-6-Phosphate Dehydrogenase

Human hepatoma cell line

Hepatocyte Nuclear Factor-4

Hypersensitive Site

Iron Response Element

Iron Regulatory Protein

kilo basepairs

Malic Enzyme

Nicotinamide Adenine Dinucleotide Phosphate, oxidized

Nicotinamide Adenine Dinucleotide Phosphate, reduced

Nuclear Factor-1

nucleotide

Promoter I

Promoter II

Promoter III

Phosphate Buffered Saline

Polymerase Chain Reaction

mouse stearoyl-CoA desaturase cDNA subclone

Phosphoenolpyruvate Carboxykinase

rat fatty acid synthase subclone

Pyruvate Kinase

mouse albumin cDNA subclone

Phenylmethylsulphonyl Fluoride

Peroxisome Proliferator Activated Receptor

rat PEPCK cDNA subclone

precursor mRNA

rat GAPDH cDNA subclone

Polyunsaturated fatty acid 


$\begin{array}{ll}\text { RLU } & \text { Relative Light Units } \\ \text { RNase } & \text { Ribonuclease } \\ \text { RPA } & \text { Ribonuclease Protection Assay } \\ \text { RSB } & \text { Reticulocyte Suspension Buffer } \\ \text { SCD } & \text { Stearoyl-CoA Desaturase } \\ \text { SR } & \text { Serine-Arginine } \\ \text { SREBP } & \text { Stearoyl Regulatory Element Binding Protein } \\ \text { S14 } & \text { Spot } 14 \\ \text { sxl } & \text { sex lethal gene } \\ \text { T3 } & \text { Thyroid Hormone } \\ \text { TBA } & \text { Thiobarbituric Acid } \\ \text { TPI } & \text { Triosphosphate Isomerase } \\ \text { tra } & \text { transformer gene } \\ \text { URE } & \text { Uridylate-Rich Element } \\ \text { UTR } & \text { Untranslated Region }\end{array}$




\section{CHAPTER 1. LITERATURE REVIEW}

\section{Introduction}

Atherosclerotic heart disease is a major cause of illness and death in the United States. For many years, the American public has been encouraged to decrease their consumption of dietary fat to less than $30 \%$ of their daily caloric intake and to increase to 2:1 the ratio of polyunsaturated to saturated fatty acids in their diet. These health recommendations have been based solely on correlation between increased risk of atherosclerotic disease, level of circulating serum lipids and consumption of dietary fat. The molecular basis for these dietary health recommendations is not known.

Fatty acids play important roles in cell structure and cellular metabolism. They are components of phospholipids which provide structural support to cell membranes. In addition, they are involved in various intracellular signaling pathways including activation of $\mathrm{Ca}^{2+}$-dependent protein kinase (1), growth factor signaling (2) and G-protein signaling (3). Polyunsaturated fatty acids are also the precursors to the prostaglandins, thromboxanes, and leukotrienes which are potent intracellular mediators that control a variety of complex processes such as inflammatory response, regulation of blood pressure, and induction of blood clotting. Another very important role is that fats, in the form of triacylglycerols, are a highly efficient form of metabolic energy storage in adipocytes. This is because fats are less oxidized than either carbohydrates or proteins and thus yield significantly more energy upon oxidation. Fat can be obtained from a variety of sources including de novo synthesis, diet and release from adipose tissue stores.

The addition of polyunsaturated fat to a high-carbohydrate diet has been shown to decrease the expression of many of the lipogenic genes (4). Lipogenesis is defined as the conversion of carbon from glucose or amino acids to triacylglycerol (Fig. 1). The reactions of glycolysis, the citric acid cycle and fatty acid synthesis give rise to the carbon backbone of the fatty acids and glycerol. The reactions that generate NADPH provide hydrogen atoms for the fatty acids. Members of the family of fatty acid biosynthetic enzymes include malic enzyme, glucose-6-phosphate dehydrogenase (G6PD), acetyl-CoA carboxylase (ACC), ATP-citrate lyase and fatty acid synthase (FAS). We are interested in elucidating the mechanism(s) by which polyunsaturated fatty acids inhibit the expression of the genes for the lipogenic enzymes; that is, how dietary fat decreases the de novo production of fat in the body. The model enzyme that we are using to study this phenomenon is liver G6PD. G6PD catalyzes the first step in the pentose phosphate pathway, producing ribose sugars necessary for nucleotide biosynthesis and reducing 


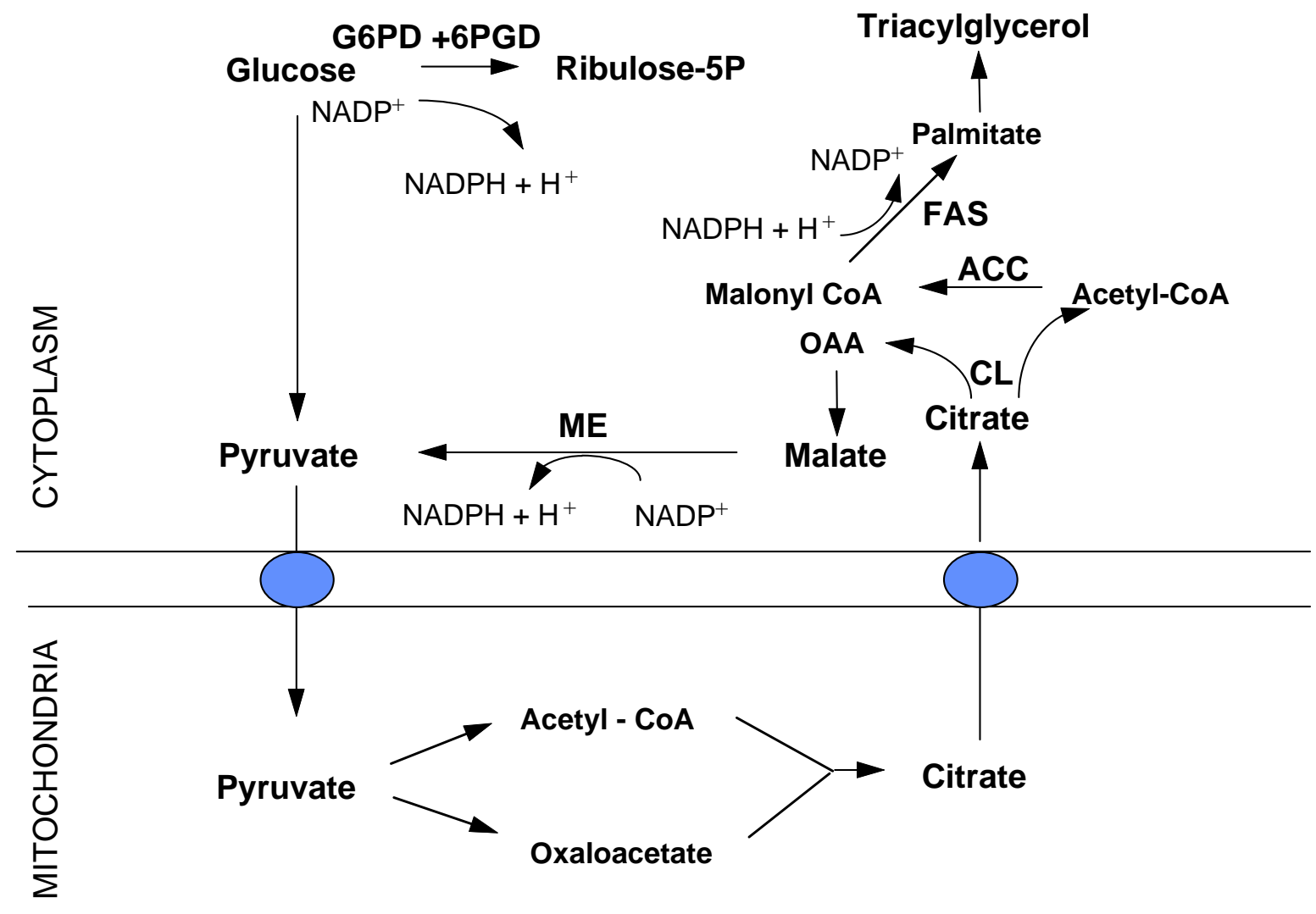

Figure 1. Schematic outline of fat biosynthesis. G6PD, glucose-6-phosphate dehydrogenase; 6PGD, 6-phosphogluconate dehydrogenase; CL, ATP-citrate lyase; ACC, acetyl-CoA carboxylase; ME, malic enzyme; FAS, fatty acid synthase. 
equivalents in the form of NADPH (Fig. 2). In addition to fatty acid biosynthesis, the reducing equivalents are used for other biosynthetic reductive reactions such as the regeneration of glutathione by acting as a hydrogen donor for glutathione reductase. The later function of NADPH ensures the integrity of erythrocyte membranes by protection from oxidative damage. Thus, G6PD has several major physiological roles consisting of lipogenesis in the liver and adipose tissue, synthesis of nucleic acids for growing cells, and protection from oxidative stress. The liver is our target organ since this is the major organ that makes fatty acids and then secretes them into the bloodstream packaged in lipoprotein particles.

The discovery that fatty acids can affect lipogenic gene expression and thus modulate a cell's metabolic state is essential in understanding responses to dietary changes. Identification of the pathway involved in the inhibition of de novo fatty acid synthesis by dietary polyunsaturated fatty acids (PUFA) will help understand the molecular basis for diseases associated with consumption of fat, such as diabetes, obesity and atherosclerotic disease. This may give insight into new diet recommendations or drug intervention as well as understanding novel mechanisms of gene regulation. The goal of my research is to characterize a cell culture model which mimics the regulation of G6PD observed in the intact animal and to use this model to identify cis-acting sequences within the G6PD precursor mRNA (pre-mRNA) which may be responsible for mediating the inhibition by fatty acids.

\section{Regulation of G6PD by hormonal and nutritional factors}

The members of the lipogenic family of enzymes are coordinately regulated by a variety of nutritional and hormonal factors (5). Carbohydrate and polyunsaturated fats are the two primary nutritional factors that act to either stimulate or inhibit lipogenic enzyme activity, respectively. Hormonal factors which alter lipogenic enzyme activity include insulin, thyroid hormone (T3), glucocorticoids and glucagon. Insulin, T3 and glucocorticoids are positive regulators whereas glucagon is a negative regulator of

lipogenic activity. First, I will discuss the hormonal effectors followed by a discussion of the nutritional factors in both the intact animal and in cells in culture specifically for G6PD.

\section{Hormonal factors}

Like other lipogenic enzymes, G6PD activity in the livers of starved rats is low and increases when rats are fed a high-carbohydrate, fat-free diet (6-8). This starvation- 


\section{Glucose-6-Phosphate Dehydrogenase Reaction}

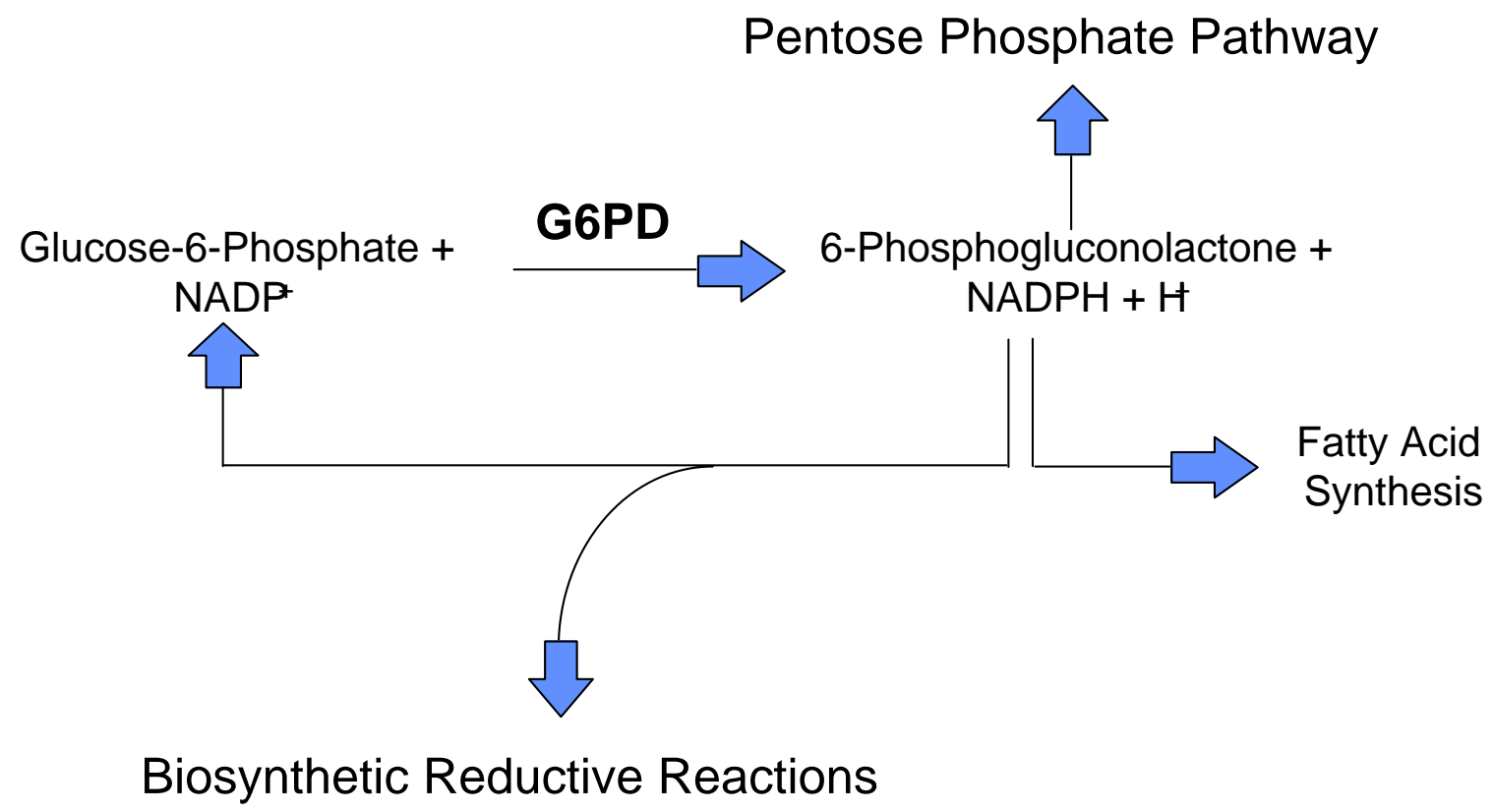

Figure 2. Physiological role of the glucose-6-phosphate dehydrogenase (G6PD) reaction. G6PD catalyzes the conversion of glucose-6-phosphate to 6-phosphogluconolactone with the concomitant production of NADPH from NADP ${ }^{+}$. 6-phosphogluconolactone is an intermediate of the pentose phosphate pathway. NADPH is the coenzyme used for many biosynthetic reductive reactions and also provides the reducing equivalents for fatty acid synthesis. 
refeeding paradigm is commonly used to increase hepatic lipogenesis and results in a dramatic increase, or "overshoot", in the activity of the lipogenic enzymes followed by a decrease in activity to a new steady-state amount $(9,10)$. The diet-induced changes seem to be dependent on the levels of circulating insulin and glucocorticoids, and the level of carbohydrates in the diet. These conclusions were based upon endocrine gland ablation/replacement therapy experiments. Rats that were either adrenalectomized or treated with streptozotocin which destroys the pancreatic $\beta$-cells thereby stopping insulin production failed to induce G6PD activity upon refeeding (11). However, when the rats were treated with glucocorticoids or insulin replacement therapy, respectively, G6PD activity increased above control samples.

The positive regulatory effect of insulin and glucocorticoids observed in the intact animal has also been observed in primary rat hepatocytes. Primary culture systems provide a chemically-defined environment to allow the examination of a combination of hormonal and nutritional regulators of enzymatic and metabolic activities. Several investigators have used this approach to study the role of insulin and glucocorticoids on the expression of G6PD. Kurtz and Wells (12) were the first to show that insulin induced G6PD activity in primary rat hepatocytes. Others have since confirmed this effect $(8,13-$ 15). Glucocorticoids have also been shown to be positive regulators of G6PD in both the intact animal and in the primary culture system. Glucocorticoids and insulin by themselves stimulate G6PD mRNA levels (16). When both are present at the same time, the levels increase in an additive manner. The molecular mechanism causing the change in RNA levels has not been determined.

Glucagon and T3 also alter G6PD activity, although the results are confounded due to discrepancies between results obtained in the intact animal versus those obtained in cell culture experiments. Injecting a rat with glucagon, the hormone most associated with the starved state, has been shown to decrease G6PD activity (6). In contrast, injecting a rat with $\mathrm{T} 3$ has been shown to increase G6PD activity (17). However, neither glucagon nor cAMP decrease G6PD activity in cultured rat hepatocytes. In addition, T3 does not increase G6PD activity in cultured cells (8). Thus in the intact animal, glucagon and T3 may be changing the accumulation of another metabolite or cellular factor which is not present in cultured hepatocytes.

\section{Nutritional factors}

In rats that have been fasted and then refed a high-carbohydrate, fat-free diet, G6PD activity has been shown to increase approximately 16-fold, reaching the highest value after the rats were on the diet for 48 to $72 \mathrm{~h}$ (18). While part of this response may 
be due to changes in insulin concentrations in the blood, the type of carbohydrate in the diet is also important. Diets with fructose as the carbohydrate source result in greater increases in the rates of fatty acid synthesis and the increases in the activities of the lipogenic enzymes than when glucose is the primary carbohydrate source (19). In addition, fructose increases G6PD activity independently of hormonal stimuli. In this regard, the refeeding induced increase in G6PD activity can be maintained in diabetic rats by feeding fructose (19). The increase in activity in whole animals due to carbohydrate in the diet is related to an increase in enzyme synthesis and a decrease in degradation rates (20-22).

The role of carbohydrates in regulating G6PD activity in primary rat hepatocytes is not clear due to discrepancies in the increase due to glucose among various investigators. Some studies have shown an effect of monosaccharides such as glucose on enzyme activity (14) while others have not $(12,23)$. These differences may be due to varying contents of gluconeogenic amino acids present in the media used in these studies. In this respect, an intermediary metabolite of glucose or fructose is thought to activate glucose responsive genes (24-27). Therefore, variations in the content of gluconeogenic amino acids in the different tissue culture media could cause the accumulation of this putative metabolite, regardless of the addition of exogenous glucose.

In contrast to the stimulatory effect of carbohydrates, polyunsaturated fat inhibits G6PD activity. Several lines of evidence indicate that the inhibition by dietary fat is specifically due to PUFA in the diet (28). First, when the carbohydrate intake of each rat is held constant and fat is added in addition, the activity of the lipogenic enzymes is inhibited in the rats receiving the fat (29). Second, saturated and monounsaturated fats do not inhibit G6PD activity (29). In rats that were fed a high-carbohydrate, fat-free diet supplemented with palmitate (16:0), stearate (18:0) or oleate (18:1) G6PD activity was not inhibited whereas dietary supplementation with linoleate (18:2) and linolenate (18:3) did result in a decrease in G6PD activity. Third, the inhibition has been shown to be independent of essential fatty acid status. Rats deficient in essential fatty acids have increased rates of lipogenesis and these rates are decreased when essential fatty acids are given (28). However, the addition of more PUFA to a diet already adequate in essential fatty acids further inhibits activity. Finally, the inhibition is not a result of a change in the protein to calorie ratio of the diet (30). In rats, supplementation of the diet with $20 \%$ additional energy as safflower oil inhibits the activity of G6PD better than supplementation of the diet with $20 \%$ additional energy as beef tallow, a saturated source of fat. 
The decrease in G6PD activity by PUFA in the intact animal has also been shown in primary rat hepatocytes (14); primary mouse hepatocytes are unresponsive to this treatment (31). The effects of PUFA in primary rat hepatocytes have been shown to be specific to polyunsaturated fats, not monounsaturated or saturated fats. In addition, the decrease in G6PD activity is not due to a generalized toxicity of the cells due to lipid oxidation as assessed by measurement of thiobarbituric acid-reactive substances in the medium (32) and ATP concentrations (14). It has been hypothesized that eicosanoids may be the metabolite of fatty acids that is responsible for mediating the inhibition. However, use of specific inhibitors to block arachidonic acid and linoleic acid metabolism does not consistently block the inhibition of lipogenic enzymes by PUFA $(7,33,34)$. A second hypothesis is that PUFA action is via activation of peroxisome proliferator activated receptors (PPARs) which then bind along with their heterodimeric partner, retinoid $\mathrm{X}$ receptor, to peroxisome proliferator responsive elements. PPARs are members of the steroid-like receptor superfamily and are located in the nucleus of a number of tissues, including liver and adipocytes. This also has led to inconsistent results based on recent in vivo and in vitro studies. First the PUFA response elements that have been identified do not contain a PPAR response element nor do they bind PPAR $(35,36)$. Second saturated, monounsaturated and polyunsaturated fats all have equal potency as activators of PPAR to induce PPAR-mediated gene transcription $(37,38)$. Thus, they do not exhibit the selectivity of regulation to explain PUFA control of gene expression. A third hypothesis is that PUFA may interfere with other hormone action, such as insulin action, by modifying membrane lipid composition thereby altering hormone release and signaling. Some evidence supports this hypothesis $(35,39)$ but other studies do not $(40)$ which suggests that such a PUFA-insulin interaction may not be universal. A final hypothesis is that the effect is direct through a PUFA-specific mechanism. In support of this hypothesis, several PUFA response elements have been identified $(40,41)$ which are distinct from the insulin response elements in the same genes. It may be unlikely that any one mechanism can fully account for the nuclear actions of PUFA.

\section{Structural characterization of the G6PD gene}

The mouse G6PD gene is $18 \mathrm{~kb}$ long and contains 13 exons. The second intron makes up almost half of the gene (Fig. 3). The G6PD gene is an X-linked gene which undergoes transcriptional silencing in one of the 2 alleles resulting in expression of only a single copy of the gene per cell. Its promoter is embedded in a $\mathrm{CpG}$ island which is conserved from mice to humans (42). G6PD has a promoter with two GC-boxes and a non-canonical TATA box, TTAAAT, but no CAAT element. These GC-boxes are 


\section{Structure of the G6PD gene}

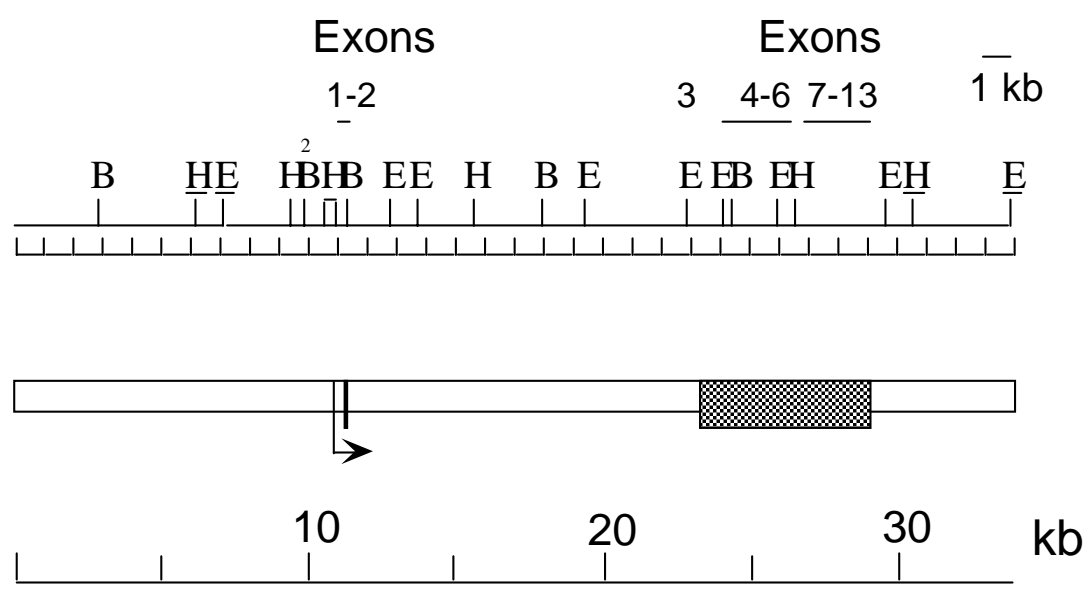

Figure 3. Structure of the G6PD gene. The G6PD gene is $18 \mathrm{~kb}$ in length and contains 13 exons. The transcription start site is indicated with an arrow. Exons 1 and 2 are represented by a narrow solid box. Exons 3-13 are represented by a shaded box. Intron 2 comprises almost half of the gene structure. Restriction sites are listed on the top line: $\mathrm{B}$, BamHI; H, HindIII; E, EcoRI. 
essential for the expression of transiently expressed constructs in HeLA and HepG2 cells. The transcription factors Sp-1 and AP-2 have been shown to bind to the GC-boxes (43). The rat, human and mouse transcriptional start sites have all been mapped. The primary start site in mouse (44) is located 3 bases downstream of that used in human (45) and rat (46). The reason for these slight differences is most likely due to experimental variation and probably does not represent the presence of two separate start sites. The translational start codon is located in exon 2. The number of exons, locations of the introns in the coding sequence and the size and sequence of the exons are conserved between species. However, exon 13 has been found to contain many sequence differences between species. In contrast, intron size and sequence are not conserved $(47,48)$. The 3'-UTR is approximately $600 \mathrm{bp}$ in length and contains a single poly(A) site (L. P. Stabile and L. M. Salati, unpublished).

\section{Tissue specificity of G6PD regulation}

G6PD is essential to all tissues to provide the ribose sugars for nucleotide biosynthesis and NADPH for reductive biosynthetic reactions. Because of its biochemical role and because it is found in all organisms analyzed thus far, G6PD is regarded as a typical housekeeping gene. Regulation by the various hormonal and nutritional factors discussed previously occurs primarily in the liver and adipose tissue (49). The amount of G6PD activity varies between tissues (50) as well as the amount of G6PD mRNA (44). For example, kidney contains 2 times the amount of activity found in cardiac muscle (50) and 2.6 times the amount of mRNA (44). In addition, Corcoran et al. (51) generated transgenic mice expressing $20 \mathrm{~kb}$ of the human G6PD gene which included $2.5 \mathrm{~kb}$ of 5 '-flanking DNA and $2 \mathrm{~kb}$ of downstream sequences and found a similar pattern of tissue-specific distribution and level of expression of the transgene as the endogenous gene. Therefore, the tissue-specific expression of G6PD is pretranslational.

For some genes, tissue-specific regulation is achieved via alternate promoter usage between tissues, such as with the glucokinase (52) and acetyl-CoA carboxylase (53) genes. Hodge et al. (44) has shown by S1 nuclease analysis and primer extension analysis of G6PD mRNA that the same transcriptional start site is used in liver, kidney and adipose tissue, thus this gene has a single promoter. Therefore, the tissue-specific regulation is not a consequence of alternate promoter usage. A second possibility is that there are differences in the composition of the basal transcriptional machinery between tissues. Nuclease hypersensitive sites are often regions of the DNA that interact with transcription factors, such as with the S14 gene where different hypersensitive sites 
correlate with differential tissue-specific expression (54) and changes in expression during development (55). A nuclease hypersensitivity analysis of the 5'-end of the gene revealed three hypersensitive sites (HS): HS1, HS2, and HS3 (44). To measure expression in different tissues, the amount of nuclear pre-mRNA for G6PD was measured. The abundance of G6PD pre-mRNA was 3- to 4-fold higher in liver than in heart or kidney and was associated with the disappearance of HS3 in the heart and kidney. These results are consistent with tissue-specific regulation being regulated at a transcriptional level, but this has not been demonstrated directly. HS1 and HS2 may be required for basal expression of the gene whereas HS3 may be involved in the tissuespecific regulation. Further analysis of these hypersensitive regions is necessary to fully understand the mechanisms behind the tissue-specific differences in the amount of G6PD expression and differences in regulation. The mechanisms by which various tissues differentially express G6PD activity most likely will vary with each cell type and with the functional requirement for NADPH in the cell.

G6PD expression is also regulated in mammary glands. G6PD expression is increased in lactating mammary tissue versus non-lactating controls, presumably due to an increased need for the lipid component of milk (56). G6PD is also regulated by nutritional factors in this tissue. For example, dietary carbohydrate has been shown to stimulate G6PD activity in this tissue (57).

Oxidative stress is another important regulator of G6PD. This type of regulation occurs primarily in the lung and liver $(58,59)$. G6PD activity increases in addition to various other antioxidant enzymes when rat alveolar type II cells are exposed to hyperoxic conditions, suggesting a direct correlation between increased G6PD activity and increased oxidative stress (58). In primary rat hepatocytes, ethanol increases G6PD activity, which may be a consequence of an induction of oxidative stress (59). This increased activity is due to increased G6PD protein synthesis and mRNA accumulation. Signaling is thought to occur through the metabolism of ethanol to acetaldehyde. Free radicals are then generated through the metabolism of acetaldehyde by acetaldehyde oxidase. In support of this idea, the addition of acetaldehyde to primary rat hepatocytes increases G6PD activity and mRNA but has no effect on lipid biosynthesis (60). In addition, Pandolfi et al. (61) has shown by targeted disruption of the G6PD gene that G6PD is essential to protect cells against even mild oxidative stress.

G6PD activity has also been reported to be stimulated by cell growth (61). In this regard, G6PD activity is increased with the addition of epidermal growth factor (EGF) to primary rat hepatocytes (62). This effect appeared to be disconnected from lipogenesis since EGF repressed both the induction of malic enzyme and the insulin stimulated 
incorporation of acetate into triglycerides. EGF was shown to increase the relative rate of synthesis of G6PD and the mRNA accumulation. This growth effect may not be tissuespecific since tumor cells from various tissues have been reported to have increased G6PD activity (63). The increase in G6PD activity due to cellular growth may reflect an adaptation to an increased need for nucleic acids and NADPH.

\section{Mechanisms of G6PD regulation}

Expression of a gene can be controlled at many levels including transcription of the DNA into the primary transcript, processing of the primary transcript into the mature message, transport of the mature message into the cytoplasm, mRNA stability, translation of the message into a protein and posttranslational events such as protein stability and modification. Regulation at each of these steps can be very complex and can involve many accessory factors. The majority of studies to date have focused on transcriptional control mechanisms, but the importance of posttranscriptional mechanisms in regulating gene expression is becoming increasingly clear.

The exact regulatory step involved in the regulation of G6PD by nutritional and hormonal factors is still not entirely known. The nutritionally- and hormonally-induced changes in G6PD enzyme activity are accompanied by comparable changes in the concentration of the G6PD protein not changes in catalytic efficiency of the enzyme. To determine if the total amount of G6PD protein was altered in response to dietary factors, antibodies against G6PD were used in immunoprecipitation experiments on liver supernatants from rats that were either fed a high-carbohydrate diet $(64,65)$ or a high-fat diet (66). In both cases, changes in G6PD enzyme activity paralleled changes in the amount of the enzyme. Glucagon has also been shown to regulate G6PD enzyme activity by decreasing G6PD concentration (6). Thus, both increases and decreases in activity can be accounted for by changes in the amount of G6PD protein.

Changes in the concentration of the protein can be due to changes in the rate of protein synthesis or changes in the rate of protein degradation. The relative rate of G6PD synthesis was measured by incubating hepatocytes with ${ }^{3} \mathrm{H}$-leucine followed by immunoprecipitation of G6PD with a specific antiserum (67). The amount of radiolabeled G6PD was compared to ${ }^{3} \mathrm{H}$-leucine incorporated into total protein to calculate the relative rate of synthesis of the enzyme. In another study, Winberry and Holten (68) measured the amount of ${ }^{125}$ I-anti-G6PD bound to liver polysomes. The amount of ${ }^{125} \mathrm{I}$-anti-G6PD bound to the polysomes under saturating conditions directly correlates with the rate of synthesis of the protein. The results from both of these 
experiments demonstrated that the changes in activity and amount of the enzyme could be accounted for by changes in the rate of synthesis of G6PD.

The changes in the rate of synthesis can be caused by changes in translational efficiency of the mRNA or by changes in mRNA abundance. To distinguish between these possibilities, an in vitro rabbit reticulocyte translation system was used to measure mRNA abundance (17). All of the changes observed in the rate of G6PD synthesis were accounted for by changes in the amount of mRNA. This was the first report to suggest that regulation of G6PD occurred at a pretranslational step. Following the isolation of G6PD genomic and cDNA clones, further work was done to corroborate these findings. Using a rat liver G6PD cDNA to measure mRNA levels in response to refeeding a highcarbohydrate diet, G6PD mRNA levels increased 13-fold, accounting for the changes observed in enzyme activity (69).

Changes in mRNA accumulation can be due to changes in transcription or to changes in posttrancriptional regulatory processes, such as mRNA stability or processing. To test if the transcriptional activity of the gene was regulated in response to a highcarbohydrate diet or a diet containing PUFA, nuclear run-on assays were performed. Our laboratory has shown that regulation of G6PD by both dietary carbohydrate and dietary fat occurs exclusively at a posttranscriptional step in mice (15). Multiple controls were used to verify that the absence of transcriptional regulation was real (15). The G6PD probes did not contain repetitive elements, the probes were authentic G6PD sequences (both cDNA and genomic probes), and the transcription signals reflected hybridization to only the transcribed strand of the G6PD gene. Transcription was measured at multiple positions along the gene so as to exclude elongation of transcription as a regulated step. In addition, both positive and negative controls were included (i.e. fatty acid synthase, stearoyl-CoA desaturase, and phosphoenolpyruvate carboxykinase) and they all exhibited the expected transcriptional changes.

In order to determine more specifically the step involved in this posttranscriptional regulatory mechanism, Hodge and Salati (70) used ribonuclease protection assays to measure the amount of pre-mRNA in the nucleus after feeding mice a high-fat diet. An 80\% decrease in G6PD mRNA in total cellular RNA was accompanied by an $80 \%$ decrease in nuclear pre-mRNA. Regulation of pre-mRNA in the nucleus could result from a change in the rate of processing of the pre-mRNA, stability of premRNA or mature mRNA in the nucleus, or a block in transport of mRNA from the nucleus to the cytoplasm. Further characterization of the regulation of G6PD indicates that transport of the mRNA from the nucleus to the cytoplasm is not regulated. In this regard, the rate of accumulation of G6PD pre-mRNA in the nucleus paralleled the rate of 
accumulation of mature mRNA in the cytoplasm and changes in the nucleus preceded changes in cytoplasmic accumulation. In addition, splicing of the primary transcript and changes in the rate of stability did not appear to be regulated. Deadenylation of mRNA is also known to be involved in normal turnover (71). However, selective disappearance of the 3'-most portion of the pre-mRNA with dietary treatment was not observed, suggesting that this mechanism is unlikely. Thus, regulation of the amount of G6PD pre-mRNA probably occurs in the nucleus very soon after transcription of the primary transcript. Regulation of pre-mRNA accumulation by PUFA has not been previously described and thus represents a novel mechanism for control of gene expression by dietary fat. Further identification of the cis-acting elements and trans-acting factors involved in regulation of this gene are currently underway.

\section{Regulation of lipogenic/glycolytic enzymes by nutrients and hormones}

Dietary manipulation results in coordinated changes in the concentrations of several lipogenic enzymes, suggesting common regulatory mechanisms. In each case the primary mechanism involves changes in mRNA abundance. Most of the observed changes are due to changes in transcription although more and more examples of posttranscriptional mechanisms have been reported. Cis-acting DNA sequences have been identified in many of these genes using cell culture and transfection techniques as well as the factors that bind to these sequences. Each enzyme is discussed separately because there are both similarities and differences in the mechanisms by which they are regulated.

\section{Acetyl-CoA carboxylase}

Acetyl-CoA carboxylase catalyzes the first committed step and key regulatory step in fatty acid synthesis which is the conversion of acetyl-CoA to malonyl-CoA. Malonyl$\mathrm{CoA}$ is the substrate used by fatty acid synthase as the 2 carbon source in each round of fatty acid synthesis. ACC exists in 2 isozymic forms that are attributed to transcription from two separate genes, ACC- $\alpha$ and ACC- $\beta$ (72,73). In rats, ACC- $\alpha$ gives rise to a 265 $\mathrm{kDa}$ isozyme which is expressed in all cell types; however, its activity is the greatest in liver, adipose tissue and lactating mammary gland. ACC- $\beta$ gives rise to a $275-280 \mathrm{kDa}$ isozyme which is mainly expressed in the skeletal and heart muscle and is thought to function in the regulation of fatty acid $\beta$-oxidation in the mitochondria (73-75). These two isoforms of ACC control the amount of fatty acids in the cell. Expression of the ACC- $\alpha$ form is regulated by diet and hormonal factors and thus will be the only one discussed. 
ACC- $\alpha$ is regulated by both short- and long-term regulatory mechanisms. Shortterm regulation involves allosteric interactions by citrate and long-chain acyl-CoAs, phosphorylation and dephosphorylation, and changes in the size of the enzyme. The enzyme exists in two different states, an inactive protomer consisting of two monomeric subunits, and an active polymer. The active polymer forms a filamentous structure that is made up of many protomers which is subject to short-term regulation by the factors mentioned above. Long-term regulatory mechanisms include regulation by nutritional and hormonal factors. ACC is increased by insulin, dexamethasone and dietary carbohydrate. Conversely, fatty acids inhibit the hormonal induction (76).

Transcription of the rodent ACC- $\alpha$ gene is initiated from two promoters, promoter I (PI) and promoter II (PII), which are located $12 \mathrm{~kb}$ apart $(77,78)$. The first four exons are alternatively spliced to form a heterogeneous population of mRNAs differing in their 5'-UTRs. These mRNAs encode the same protein product because exon 5, which contains the start codon for translation, is present in all ACC- $\alpha$ transcripts. Alternative promoter usage and splicing are two of the mechanisms by which the expression of ACC is regulated. Alternative promoter usage is involved in tissue-specific expression of the mRNA in response to starvation-refeeding. When rats are fed a standard chow diet, expression of ACC is primarily due to transcriptional initiation at PI in epididymal fat tissue. Starvation followed by refeeding a fat-free diet greatly stimulates transcriptional activity at the ACC PI in this tissue. This is followed by a large increase in ACC mRNA accumulation (79). PII is not active under these conditions. In liver, both promoters are active in response to feeding. When rats are fed a standard chow diet, low basal transcription activity is only seen from PII. Refeeding a purified fat-free diet after $72 \mathrm{~h}$ of starvation causes increased transcriptional initiation from both promoters with activity at PI being higher (80). In the chick, nutritional changes of ACC, which also may have multiple promoters, are mediated by changes in the rate of transcription of the gene (81).

Regulation of ACC by polyunsaturated fat has been studied in both primary rat hepatocytes and primary chick embryo hepatocytes. Incubation of rat hepatocytes in media containing palmitate (16:0), oleate (18:1), linoleate $(18: 2)$, arachidonate $(20: 4)$ or docosahexanoate (22:6) resulted in a $30-35 \%$ decrease in the hormonal induction of ACC (76). This inhibition was the same with all chain lengths and degrees of unsaturation. In chick hepatocytes, palmitate $(16: 0)$, hexanoate $(6: 0)$, octanoate $(8: 0)$, oleate $(18: 1)$, and arachidonate (20:4) all decreased activity. However, only the medium-chain fatty acids (6:0 or 8:0) and arachidonic acid inhibited transcription of the gene suggesting that a metabolite of hexanoate or octanoate, possibly 6 or 8 carbon acyl-CoA, plays a role in this effect (82). 
PI and PII in the rat have very different structures. PI contains TATA and CAAT boxes, 2 fatty acyl-CoA elements and a dinucleotide repeat repressor element $(83,84)$. The repressor element may be responsible for the low level of expression of PI under normal conditions in the liver. PII contains multiple Sp-1 sites, an AP-2 site, a glucose response element, and a tumor necrosis factor response element (85). Both contain insulin response elements (80). The physiological significance of this tissue-specific promoter usage and transcript diversity is unclear at this time. It has been hypothesized that there is a physical and metabolic compartmentalization of ACC molecules which is related to the increasingly diverse functions of fatty acids in physiological processes such as the specialization of adipocytes for fat storage and the synthesis of fatty acids for incorporation into cell membranes. In support of this hypothesis, Barber et al. (86) have demonstrated the existence of a third promoter, PIII, in the ACC- $\alpha$ gene that results in tissue-specific expression of a novel ACC mRNA isoform which is $259 \mathrm{kDa}$. Thus, ACC is very complex and the mechanisms involved in regulation of this gene will most likely prove to be very complicated.

\section{ATP-citrate lyase}

Acetyl-CoA is generated in mitochondria by pyruvate dehydrogenase or by the oxidation of fatty acids. When the need for ATP synthesis is low such that oxidation of acetyl-CoA via the citric acid cycle and oxidative phosphorylation is also low, this mitochondrial acetyl-CoA may be stored as fat. A problem arises because fat biosynthesis occurs in the cytosol but the mitochondrial membrane is impermeable to acetyl-CoA. To solve this problem, acetyl-CoA enters the cytosol in the form of citrate. ATP-citrate lyase catalyzes the formation of acetyl-CoA and oxaloacetate from citrate and CoA with the concomitant hydrolysis of ATP to ADP and phosphate. The product of this reaction, acetyl-CoA, is important in several biosynthetic pathways, including lipogenesis and cholesterogenesis. Thus, ATP-citrate lyase is a member of the lipogenic family of enzymes. Starvation, feeding a high-carbohydrate diet, feeding a high-fat diet, insulin and glucagon all regulate the amount of ATP-citrate lyase in liver and adipose tissue.

Gene expression of ATP-citrate lyase is increased in the livers of rats fed a fatfree, high-carbohydrate diet and decreased in the livers of rats that have been starved (13). In contrast, ATP-citrate lyase expression is decreased in the livers of rats fed a diet high in polyunsaturated fat. These changes in gene expression are accompanied by comparable changes in the rate of transcription of the gene. Another study suggests that regulation by starvation and refeeding occurs by both transcriptional and posttranscriptional mechanisms (87). In this regard, in rats that have been starved and 
then refed a high-carbohydrate diet, transcriptional activity of the gene increased to a maximum of 24-fold at $12 \mathrm{~h}$. Transcriptional activity continued through $48 \mathrm{~h}$ with a 17 fold increase over starved animals. Conversely, ATP-citrate lyase mRNA levels increased after $6 \mathrm{~h}$ of refeeding, peaked at $12 \mathrm{~h}$ and then decreased to low levels by $48 \mathrm{~h}$. This suggests that changes in the transcriptional activity of the ATP-citrate lyase gene account for the early responses to refeeding but that decreased stability of the message predominates as the control mechanism at later times.

Regulatory sequences have been identified in primary rat hepatocytes using transient transfection of plasmids containing the 5'-flanking region of the rat ATP-citrate lyase gene fused to the chloramphenicol acetyltransferase gene (CAT). The region from -104 to -20 of the ATP-citrate lyase gene was shown to be responsible for regulation due to insulin and PUFAs. The region from -61 to -49 was shown to have sequence similarity to the insulin-responsive regions of fatty acid synthase and acetyl-CoA carboxylase genes (88). Unfortunately, these analyses were done only with minimal regions of the ATPcitrate lyase promoter. The limits of the flanking DNA used in the transfection studies were not established using techniques such as DNase I hypersensitivity. DNase I hypersensitive sites often correlate with regions of regulatory significance thus this type of experiment would give an indication if there were more regulatory sequences upstream of the region that was tested. Thus, in the absence of corroboration by others these results are very preliminary.

\section{Fatty acid synthase}

Fatty acid synthase plays a central role in de novo lipogenesis in mammals, catalyzing all reaction steps in the conversion of acetyl-CoA and malonyl-CoA into palmitate. The production of palmitate involves a series of seven enzymatic reactions for each 2 carbon addition, until the final 16 carbon product is produced. In animals, this enzyme is the product of a single gene and is a $500 \mathrm{kDa}$ multifunctional enzyme because all seven enzymatic activities are located on a single peptide. Regulation of FAS by nutritional factors, such as carbohydrate and PUFA, have been shown to occur primarily at the level of transcription, although some posttranscriptional components have been reported (40,89-91).

In birds, mice, and rats, mRNA amounts and transcription rate of fatty acid synthase are low in the livers of starved animals and increase with refeeding $(89,92-94)$. Changes in the rate of fatty acid synthase gene transcription can account for most of the changes in mRNA accumulation and enzyme activity $(89,92,93,95)$. The increase in expression due to refeeding can be blocked by injection of cAMP or glucagon (94). In 
addition, in both rats and mice, the activity and mRNA abundance of FAS is low in livers of diabetic animals and increases 10-fold or more with insulin treatment (94-97). In parallel, FAS transcription is low in the livers of diabetic mice and insulin increases the mRNA abundance and transcription of FAS by 19- and 7-fold, respectively (94). In rat hepatocytes, insulin increases the activity and mRNA accumulation for FAS $(13,98)$. The effect of insulin on mRNA accumulation is dose-dependent and the induction by insulin requires glucose. In HepG2 cells, a human hepatoma cell line, glucose alone increases the accumulation of FAS mRNA 2.7- to 5.4-fold $(91,99)$. This effect of glucose is accompanied by an increase in stability of fatty acid synthase mRNA but not a change in the transcriptional activity of the gene. The half-life for FAS mRNA was $30 \mathrm{~h}$ in the presence of glucose and $4.4 \mathrm{~h}$ in the absence of glucose. Whether or not the insulin response is direct or indirect remains a controversial issue.

In chickens, T3 and not insulin is the primary inducer of FAS gene expression by increasing the rate of transcription of the gene (100,101). Neither cAMP nor glucagon cause a decrease in the transcription rate of the gene, even though the transcriptional rate is inhibited by starvation in birds (89). The addition of glucagon or dibutyryl cyclic AMP to insulin and T3 stimulated chick hepatocytes results in a 70-80\% decrease in FAS activity, a $60 \%$ decrease in mRNA abundance, and no effect on transcriptional activity of the gene. The mechanism of this posttranscriptional regulation by glucagon and cAMP has not been elucidated.

Regulation of FAS by PUFA has been studied in both the intact animal and in cells in culture. This occurs primarily at the transcriptional level. Regulation of FAS by fatty acids is dependent on the length and the amount of desaturation of the fatty acids. Suppression of FAS requires that the fatty acid contain at least 18 carbons and 2 double bonds (103). In rats fed menhaden oil (20:5/22:6), hepatic FAS mRNA decreased 80\% whereas the transcription rate was reduced by $94 \%(40,103)$. Thus, alterations in transcription account for all of the regulation of FAS by PUFA.

The molecular mechanisms by which FAS is positively regulated by glucose and insulin has been studied. A glucose response element and an insulin response element have been localized to +283 to +303 and -71 to -51 , respectively $(104,105)$. The upstream stimulatory factor, USF, family of transcription factors have been shown to bind to both sites $(106,107)$. Recently, a novel factor has been reported to bind to the insulin response element, not the glucose response element, but the identity of this protein has not yet been made (108). The molecular mechanisms of FAS regulation by PUFA has not yet been elucidated. One possible trans-acting factor which has been implicated in PUFA mechanism is sterol regulatory element binding protein (SREBP). This protein belongs to 
a novel family of membrane-bound transcription factors that regulate multiple enzymes required for cholesterol and fatty acid synthesis. SREBPs directly activate FAS expression along with several other genes involved in fatty acid synthesis (109). However, the exact role of SREBP in PUFA regulation remains to be demonstrated.

\section{Malic enzyme}

Malic enzyme catalyzes the conversion of malate to pyruvate with the production of NADPH from NADP ${ }^{+}$. Malic enzyme provides a source of NADPH for fatty acid synthesis in addition to the enzymes of the pentose phosphate pathway, G6PD and 6phosphogluconate dehydrogenase. The contributions of NADPH from malic enzyme and from the pentose phosphate pathway are variable in different species. For example, in birds, the pentose phosphate pathway is less active thus malic enzyme provides most of the NADPH needed for fatty acid synthesis in the liver (110). In contrast, in the rodent liver and adipose tissue, there is an equal contribution from these two different pathways $(111,112)$.

Regulation of malic enzyme by thyroid hormone has been studied extensively. Treatment of euthyroid rats with T3 has been shown to stimulate hepatic malic enzyme mRNA accumulation 10- to 15-fold, whereas transcriptional activity increased only 3 - to 4-fold with this treatment $(113,114)$. This suggests that at least some component of the increase is due to posttranscriptional regulation. This posttranscriptional regulation was shown to occur in the nucleus since the accumulation of malic enzyme nuclear premRNA increased 10- to 15-fold in response to T3. The increase of nuclear pre-mRNA paralleled the increase seen in malic enzyme mRNA in the cytoplasm (115). Thus regulation of malic enzyme by $\mathrm{T} 3$ is due to both changes in the transcriptional activity of the gene as well as by regulation of nuclear stability.

In rodent and avian liver, the activity, amount and rate of synthesis of malic enzyme is low during periods of starvation. Refeeding starved animals a highcarbohydrate, low-fat diet results in a 20- to 30-fold increase in the synthesis of malic enzyme (116-118). The contributions of transcriptional versus posttranscriptional processes to the accumulation of malic enzyme mRNA varies between species and with various treatments. For example, in birds and chick embryo hepatocytes, regulation of malic enzyme is mediated by changes in transcription of the gene (119). In contrast, in rodents, regulation of malic enzyme occurs by both transcriptional and posttranscriptional processes (120). When euthyroid rats are fed a high-carbohydrate diet, malic enzyme mRNA accumulation increases 7- to 8-fold. Transcriptional activity of the gene and nuclear RNA concentration do not increase which suggests that changes in stability of the 
cytoplasmic message are responsible for the regulation of malic enzyme gene expression. Additional evidence for posttranscriptional regulation was observed in mice where changes in mRNA accumulation for malic enzyme due to starvation and refeeding were greater than the changes in the transcriptional activity of the gene (121).

Both saturated and unsaturated fatty acids have been shown to regulate malic enzyme expression at a pretranslational step. Medium chain saturated fatty acids, hexanoate (6:0) and octanoate (8:0) inhibit the T3-induced increases in malic enzyme gene transcription in chick embryo hepatocytes (122). However, longer chain fatty acids do not have this inhibitory effect. PUFA have been shown to regulate malic enzyme expression both in the intact animal and in cells in culture. Feeding meal trained rats a high-carbohydrate diet supplemented with 10\% menhaden oil (20:5/22:6) decreases malic enzyme mRNA accumulation (5). Similar results were obtained in cultured rat hepatocytes. Addition of linoleic acid (18:2) or arachidonic acid (20:4) inhibits the stimulation of dexamethasone, insulin and glucose (13). Further elucidation of this pretranslational mechanism has not been described.

One study demonstrated evidence for posttranscriptional regulation by fat. Increases in the carbohydrate to fat ratio in the diet increases the amount of cytoplasmic RNA 7- to 8-fold in the absence of changes in transcription or nuclear mRNA accumulation (115). The mechanisms of posttranscriptional regulation of malic enzyme by PUFA have not yet been elucidated.

\section{Spot 14}

Spot $14(\mathrm{~S} 14)$ is a small $(17 \mathrm{kDa})$ acidic protein with no similarity to other known mammalian gene products. Although the specific function of the protein is not yet clear, the responses of this mRNA to a number of stimuli are similar to those of the lipogenic enzymes (123). The protein has been localized to the nucleus suggesting that it may act as a transcription factor (124). Recently, Moncur et al. (125) has reported the localization of the human S14 gene to the long arm of chromosome 11 (11q13.5). The S14 gene is specifically expressed in tissues that produce lipids for use as metabolic fuel such as lactating mammary, white and brown adipose tissue, and liver (126). In liver, its expression is increased by thyroid hormone, glucose and insulin. Conversely, S14 expression is inhibited by glucagon and PUFA.

S14 mRNA accumulation changes rapidly in response to stimuli that modulate fatty acid formation. S14 protein levels have been shown to parallel those of its mRNA. Induction of S14 mRNA by carbohydrate feeding results from an increase in the rate of gene transcription (127). This has been mimicked in cultured hepatocytes by keeping the 
insulin level constant and altering the glucose level. Insulin is necessary for the carbohydrate response but it does not appear to be a direct effector. Using transient transfection to define sequences mediating carbohydrate regulation, a $30 \mathrm{bp}$ segment $(-1457$ to -1428$)$ in the 5 '-flanking region of the gene has been shown to be essential for the glucose response (128). In addition, 5'-deletions in other parts of the S14 gene led to significant loss of carbohydrate response. Therefore, there must be other elements in the 5 '-flanking region that influence the response to glucose and interact with this identified response element $(129,130)$. Multiple trans-acting proteins have been found to be important in this regulation although there is still conflicting evidence as to the identity of these factors. Comparison of the L-pyruvate kinase and S14 carbohydrate regulatory regions revealed a sequence with 9 out of 10 bp identity, suggesting that a common nuclear factor is involved the regulation of both of these genes (128).

Insulin has been shown to increase hepatic S14 mRNA levels in streptozotocininduced diabetic rats $(131,132)$. Less than half of this induction could be accounted for by an increase in transcription, thus insulin regulates $\mathrm{S} 14$ by both transcriptional and posttranscriptional mechanisms. In this regard, insulin increases the ratio of mature to precursor S14 mRNA which is due to an increase in splicing efficiency of S14 premRNA, suggesting a role for insulin in the processing of lipogenic genes (133). This posttranscriptional mechanism has also been observed with dietary sucrose (134).

The increases in S14 by glucose is synergistically enhanced by T3. In this regard, injection of T3 into hypothyroid rats increases S14 mRNA levels 15- to 20-fold. When these rats are starved overnight and then treated with T3, little change is observed in S14 mRNA levels (135). Three distinct T3 response elements are found between -2718 and 2558 of the 5'-flanking region (136). The mechanism for the synergism with the carbohydrate response element has not been determined.

Regulation of S14 gene expression by PUFA in both adult and weaning rats occurs by inhibition of S14 gene transcription. For example, feeding rats a highcarbohydrate diet supplemented with menhaden oil (20:5/22:6) inhibited S14 mRNA accumulation and gene transcription by $50 \%$ (40). Using S14-CAT chimeric fusion constructs and transient transfection in primary rat hepatocytes, a cis-acting region for PUFA control has been localized to -220 to $-80 \mathrm{bp}$ (39). This region is distinct from either the carbohydrate or T3 response element of the gene. A trans-acting PUFAregulated protein has not yet been identified. Thus, the mechanism is still unclear at this time. 


\section{Stearoyl-CoA desaturase}

Stearoyl-CoA desaturase catalyzes the $\Delta 9$-cis desaturation of long chain fatty acids. The preferred substrates are palmitoyl (16:0)- and stearoyl (18:0)-CoA which are converted to palmitoleoyl (16:1)- and oleoyl (18:1)-CoA, respectively. Palmitoleic and oleic acids are the major constituents of membrane phospholipids and triacylglycerol stores in adipocytes. The ratio of stearic acid to oleic acid is an important factor which influences cell membrane fluidity. Alteration of this ratio may play a role in aging and several diseases such as cancer, diabetes, obesity, hypertension and neurological and heart diseases.

Two genes encode stearoyl-CoA desaturase activity, SCD1 and SCD2 $(137,138)$. Cloned DNAs encoding both SCD1 and SCD2 have been isolated and characterized from both rat and mouse. The tissue-specific expression of these two genes is quite different. Under normal conditions, mouse and rat SCD1 mRNAs are expressed constitutively in adipose tissue but not in liver $(138,139)$. The expression is induced in liver upon feeding a fat-free, high-carbohydrate diet, and to a lesser extent in the kidney, lung, spleen, and heart. SCD1 mRNA is also negatively regulated in the liver by supplementing a highcarbohydrate diet with PUFA (140). Conversely, SCD2 is expressed constitutively in the brain and induced in the kidney, lung, spleen and adipose tissue in response to a highcarbohydrate diet. SCD2 is not expressed in liver under either condition $(139,141)$. The mechanisms responsible for the differences in the tissue-specific expression and dietary induction of expression of each of these genes have not been elucidated.

SCD is regulated by the same nutritional and hormonal factors as other lipogenic enzymes. Hepatic SCD1 levels in rats and mice are increased 40-fold by refeeding a fatfree, high-carbohydrate diet to starved animals (142). Insulin, T3, estradiol and dexamethasone all have been shown to stimulate the activity of SCD in both animal and cell culture studies (98,143-146). Changes in hepatic SCD expression are due to changes in the transcriptional activity of the gene (140). Recently, Waters et al. (147) have localized a T3 response region to a 70 bp sequence in the SCD1 promoter. In addition, they have demonstrated specific binding of nuclear protein from mouse liver nuclear extract to a 43 bp sequence. Response elements for the other stimulatory factors have not been identified.

Regulation of SCD by PUFA has been well characterized in mouse liver $(140,148)$, primary hepatocytes (149), rat adipose tissue (150) and 3T3-L1 adipocytes (151). Mouse liver SCD1 mRNA was decreased $95 \%$ by PUFA accompanied by a $75 \%$ decrease in transcription. Waters et al. (41) localized a PUFA response region to a $60 \mathrm{bp}$ fragment in the SCD1 5'-flanking region in HepG2 cells which shows specific binding to 
nuclear proteins. A homologous region in the SCD2 promoter also mediates PUFA specific repression in transfection experiments. This suggests that there may be a common transcriptional mechanism in both liver and adipose tissue for the inhibition by PUFA. The inhibition by PUFA has been shown to be insulin-independent (148). In support of this result, an insulin response region has been mapped to a region distinct from the PUFA response region. Further characterization of the nuclear factor(s) involved in the PUFA response has not been reported. This PUFA response region has no sequence similarity to the other identified PUFA response elements.

The effect of PUFA was also examined on the expression of the SCD1 gene in mature adipocytes. In contrast to the results obtained in liver tissue, PUFAs regulated the expression of the adipocyte SCD1 gene by regulating stability of mRNA transcripts. Treatment of 3T3-L1 adipocytes with arachidonic acid decreased SCD1 enzyme activity and mRNA accumulation (151). However, arachidonic acid did not alter the transcription of the gene whereas the half-life of the SCD1 mRNA was reduced form $25.1 \mathrm{~h}$ to $8.5 \mathrm{~h}$. The interpretation of these results in view of the similar PUFA response element in SCD1 and SCD2 has not been reconciled.

\section{Pyruvate kinase}

Pyruvate kinase is a rate-controlling glycolytic enzyme which catalyzes the formation of pyruvate and ATP from phosphoenolpyruvate and ADP. It also is a control point in regulating flux of glucose to fatty acids. There are 2 genes for pyruvate kinase, $P K-L$ and $P K-M$ for the liver and muscle types, respectively. $P K-L$ encodes 2 isoenzymes, R- and L-types, by alternate promoter usage $(152,153)$. The term "L-PK gene" refers to the gene for the L-type isoenzyme in the $P K-L$ gene and this gene is regulated by dietary and hormonal control.

Hepatic L-PK activity (154) and mRNA expression $(155,156)$ are decreased as a result of starvation or diabetes and are increased with a high-carbohydrate diet or insulin administration, respectively, to diabetic rats. Glucagon inhibits the accumulation of hepatic L-PK mRNA and the increase in transcription by insulin via cAMP through both pre- and post-translational mechanisms $(157,158)$. cAMP increases the phosphorylation of L-PK by protein kinase A to decrease enzyme activity (159) whereas insulin increases L-PK activity by stimulating dephosphorylation of L-PK (160). The increase in mRNA due to glucose or insulin is due to an increase in gene transcription in rats $(157,161)$. In hepatocytes, glucose and insulin have been shown to increase L-PK gene transcription and also to increase the stability of mRNA (158). The reasons for the differences in transcriptional versus posttranscriptional mechanisms in these two systems is unclear. 
L-PK activity and mRNA are decreased by 60 and 70\%, respectively, in the livers of rats by the addition of PUFA to a high-carbohydrate diet $(5,35,162)$. This effect has been shown to be specific to PUFA since oleic acid (18:1) does not elicit this response. In addition, PUFAs decrease the increases in enzyme activity, mRNA levels and transcriptional activity of L-PK by insulin and glucose in primary rat hepatocytes in culture (35).

In order to further characterize the regulation of L-PK, both positive and negative cis-acting regulatory elements have been identified in the rat L-PK promoter using CAT reporter assays in cultured cells or transgenic approaches. Three positive regulatory regions were identified which are designated L-I (-94 to -76), L-II (-149 to -126), and LIII (-170 to -150) $(163,164)$. Both the L-II and L-III elements are required for stimulation of L-PK gene transcription by carbohydrates as well as for cell-type specific expression $(165,166)$. The LIII element itself possesses responsiveness to carbohydrate whereas the LII element acts as an accessory element in this regulation. As noted earlier, comparison of the segments of the 5'-flanking regions of the S14 and L-PK genes conferring the glucose response shows a region with 9 out of 10 identity (128). Hepatocyte nuclear factor 4 (HNF-4) and proteins of the nuclear factor-1 (NF-1) family have been shown to bind to LII. The LIII element binding protein is still unclear because there is conflicting evidence for the binding proteins involved $(163,167,168)$.

Transient transfection of L-PK-CAT fusion constructs in primary cultured hepatocytes demonstrates that the PUFA response element is on the L-II element (35). Examination of the PUFA responsive regions in S14 and L-PK genes revealed a region with $80 \%$ sequence identity. PPAR has been reported to be involved in PUFA regulation of L-PK gene expression, as it was suggested for other lipogenic enzymes. In support of PPAR as a mediator in this response, the retinoid $\mathrm{X}$ receptor-PPAR heterodimer is able to recognize HNF-4 binding sequence which is found in LII (the location of the PUFA response element) (169). One piece of evidence against PPAR is that PUFA-mediated repression of L-PK gene expression is observed in PPAR deficient mice (170). Thus, the mechanism of PUFA mediated regulation for this gene is still unclear. HNF-4 has been speculated to be involved because recently fatty acyl-CoA thioesters have been shown to be ligands of HNF-4 in the human apolipoprotein CIII gene promoter (171). Thus, long chain fatty acids may modulate the transcriptional activity of HNF-4 by binding as their acyl-CoA thioesters to the ligand binding domain of HNF-4. This in turn may alter the affinity of HNF-4 for its cognate promoter element. In this manner, fatty acids may indirectly alter the expression of HNF-4 controlled genes. 


\section{Summary}

Enzymes involved in de novo fatty acid biosynthesis are coordinately regulated by a variety of hormonal and nutritional factors; however, this regulation is achieved through a variety of mechanisms within a liver cell with examples of both transcriptional

and posttranscriptional mechanisms. Transcriptional regulation of lipogenic enzymes has been better characterized than the posttranscriptional control mechanisms. G6PD is unique in that regulation by dietary carbohydrate and PUFA is mediated exclusively at a posttranscriptional level in the nucleus.

The reasons for the exclusive regulation of G6PD by a posttranscriptional mechanism while other lipogenic enzymes are primarily regulated by transcriptional mechanisms (or a combination of both) is unclear. One possible reason for posttranscriptional regulation is that G6PD participates in many aspects of intracellular metabolism, not just lipogenesis, whereas other lipogenic enzymes are more exclusive to this pathway. A posttranscriptional mechanism might permit increased expression of G6PD in liver when the needs for lipogenesis are great but maintain uniform expression in all cells for its roles in cellular detoxification and nucleotide biosynthesis. Even though G6PD does not use the intracellular pathway related to transcriptional regulation by diet, the mechanisms involved in posttranscriptional regulation of G6PD by diet may be common to all lipogenic enzymes. The additional posttranscriptional regulation of genes controlled by transcriptional mechanisms would permit more rapid changes in the expression of these genes in response to changes in nutritional status. G6PD provides an ideal model to study this regulation because of the absence of transcriptional regulation which would otherwise confound the interpretation of such experiments.

\section{Posttranscriptional regulatory mechanisms}

Posttranscriptional regulation can occur at many stages during the processing of a primary transcript through its translation in the cytoplasm. Regulation can occur in the nucleus or in the cytoplasm. Nuclear regulation can involve capping, polyadenylation, splicing, nonsense-mediated decay, nuclear pre-mRNA stability, or regulated processing. There are many cis-acting elements within a transcript which may be involved in regulating a message at the posttranscriptional level. The trans-acting factors which interact with these sequences have been identified in some cases. Some elements are relevant for all mRNAs whereas others are unique to individual transcripts. Gene regulation is a very complex process and there are many examples of genes that are regulated at each of these steps. I will discuss at least one example of regulation at the major points in posttranscriptional control. 


\section{Capping}

The 5' cap structure on mRNA plays multiple roles in gene expression and its regulation. It enhances splicing, RNA stabilization and translation. Most nuclear functions of the cap are mediated through protein factors which recognize the cap structure. A nuclear cap binding complex has been described which specifically recognizes the cap structure (172). Immunodepletion of this nuclear cap binding complex from nuclear splicing extracts efficiently inhibited splicing of an adenovirus mRNA (173). Further analysis revealed that an early step of the spliceosome assembly was inhibited by the lack of this protein complex. In yeast, the cap affects stability of certain messages via a deadenylation dependent-decay mechanism $(174,175)$ which means that the poly(A) tail must be shortened to an oligo(A) tail before removal of the cap. Once decapping has occurred, the transcript is then exonucleolytically degraded by specific 5 ' to 3' nucleases. A specific decapping enzyme along with a 5' to 3' exonuclease, XRN1, has been identified in yeast $(176,177)$. Disruption of the XRN1 gene results in accumulation of deadenylated transcripts lacking caps (178). Mammalian mRNAs without caps have been shown to be 4-fold less stable than their capped counterparts (71). A similar decay mechanism may be involved in mammalian cells since a 5' to 3' exonuclease has also been discovered in mammals (179). Finally, the cap is important in efficient translational activity (180). In translation, the cap is recognized by the cap binding protein, eIF-4E, which is part of a multi-protein complex (eIF-4F) required for translational initiation.

\section{Splicing}

Alternative splicing of pre-mRNAs is the most common way that splicing functions to regulate gene expression. This is a powerful and versatile regulatory mechanism that can affect the quantitative control of gene expression as well as the functional diversification of proteins. It can involve skipping or including a particular exon, choosing a single exon or multiple exons from a series, or alternative use of adjacent 5' or 3' splice sites. Alternative splicing is regulatory in a wide spectrum of processes. For example, the expression and function of a large number of genes involved in programmed cell death are regulated by alternative splicing, including death receptors and intracellular components of the death machinery (181). Alternative splicing also affects neuronal processes such as the ability of neurons to communicate electrical and chemical signals and to develop synaptic connections (182). In addition, a wide range of 
alternative splicing examples are found in genes involved in developmental processes (183).

The most well characterized example of alternative splicing is for sex determination in Drosophila. In Drosophila, the default sex is male. Female-specific expression of the sex lethal $(S x l)$ gene and the transformer (tra) gene results in repression of the male state and expression of female-specific genes through a cascade of regulated splicing events that dictate sexual identity (184). $S x l$ acts at the top of the cascade to regulate the splicing of tra RNA as well as its own transcripts. The male Sxl mRNA encodes a truncated, nonfunctional protein due to the inclusion of a male-specific exon with a stop codon. This exon is skipped in females and results in the production of a functional RNA-binding protein (185). This process is regulated by the Sxl protein itself which binds to a U-rich sequence both upstream and downstream of the male-specific exon thus preventing recognition of this exon by the splicing machinery $(186,187)$. The roles of alternative splicing of the other genes involved in this cascade have also been identified using genetic and biochemical approaches $(188,189)$. Some factors which regulate this process include constitutive splicing factors, such as serine-arginine (SR) rich proteins, as well as RNA secondary structure and steric constraints.

The metabolism of the spliced introns has also been suggested to be critical for regulation of gene expression. For example, the rate of intron turnover may influence the levels of nucleotide available for further rounds of transcription or it may affect the availability of splicing factors and other posttranscriptional events. Clement et al. (190) recently reported the first calculated half-life for an intron from a higher eukaryotic cell, an intron from the constant region of the mouse T-cell receptor- $\beta$ gene. Using a tetracycline-regulated promoter, the spliced intron and its pre-mRNA had half-lives of 6.0 $\pm 1.4 \mathrm{~min}$ and $3.7 \pm 1.0 \mathrm{~min}$, respectively. Analysis of the function of spliced introns in nuclear metabolism will most likely lead to novel mechanisms involved in the regulation of gene expression.

\section{$\operatorname{Poly}($ A) tail}

The poly(A) tail found at the 3' end of most mRNAs has been implicated as an early step in the degradation of many mRNAs (191) and also is important in the developmental regulation of mRNA translation (192). Transfected mRNAs which lack a poly(A) tail and mRNAs synthesized in culture with 3'-deoxyadenosine have been shown to be degraded more rapidly than their adenylated counterparts $(193,194)$. In eukaryotes, most, if not all, of the functions of the poly(A) tail are mediated via its association with the multifunctional poly(A) binding protein. Depletion of this protein results in rapid 
degradation of the mRNA (193). The exact mechanism for how poly(A) tail removal enhances degradation is still unclear. It is thought that following deadenylation, degradation of the body of the transcript occurs by removal of the 5' methyl cap and subsequent 5' to 3' exonucleolytic digestion of the mRNA (174). A variation of this pathway has also been demonstrated to occur in which transcripts undergo 3' to 5' exonucleolytic decay subsequent to poly(A) tail shortening (195). Several cis-acting sequence elements have been identified which promote rapid decay via poly(A) tail shortening such as the adenylate/uridylate-rich sequences found in the 3'-UTR of c-fos (194). Thus, the poly(A) tail plays a protective role in cells.

The majority of eukaryotic gene transcription units possess a single polyadenylation signal. Recently, there have been many reported examples of transcription units with multiple poly(A) sites which result in more than one RNA species (196). Use of alternative poly(A) sites can positively or negatively impact the final amount of protein product per unit precursor RNA transcribed. The current examples are mainly a result of different stages of development or growth state of the cell or tissue. Dihydrofolate reductase (DHFR) is an extreme example of a gene with multiple poly(A) sites, with seven sites spread over a $5 \mathrm{~kb}$ sequence. Transcription proceeds through all seven and terminates $1 \mathrm{~kb}$ downstream of the last one (197). Thus, multiple forms of the mRNA arise by alternative polyadenylation sites, not a result of transcription termination between the sites. A different distribution of these DHFR mRNAs is observed in growing versus resting cells (198). It is thought that different mRNAs which are the result of alternative poly(A) site usage may influence protein expression through differences in stability or translation efficiency of the individual transcripts.

\section{Pre-mRNA instability}

Another example of nuclear posttranscriptional regulation involves nuclear stability of the pre-mRNA or processed transcript. Fibronectin is regulated in this manner. Fibronectins are large glycoproteins that play roles in cell adhesion, cell morphology, wound healing, cellular migration and oncogenic transformation. Downregulation of fibronectin protein and mRNA levels by transformation of TE- 85 cells, a human osteosarcoma cell line, with H-ras (199) or up-regulation by treatment of a human fibrosarcoma cell line, HT-1080, with dexamethasone (200) occurs by changes in the accumulation of nuclear pre-mRNA in the absence of transcription. Mechanisms that would result in changes in accumulation of nuclear RNA include alteration in RNA processing (splicing or polyadenylation) or alterations in the stability of the transcript in the nucleus. The length of the poly(A) tail or the site of polyadenylation were not 
affected by either treatment. In addition, altered splicing was ruled out as a potential mechanism. These results suggest that decreased stability of the processed nuclear fibronectin RNA is involved in the regulation by H-ras, whereas increased stability of the unprocessed nuclear fibronectin RNA is involved in regulation by dexamethasone.

To further characterize this mechanism of regulation, a search for cis-acting sequences mediating the dexamethasone induction was done using transfection analysis with minigene constructs. The cis-acting sequences mediating the dexamethasone induction are thought to reside in intronic regions of the gene since no elements were found in the $8 \mathrm{~kb}$ mRNA. Experiments to identify elements mediating the H-ras inhibitory effect have not been done. This type of nuclear regulation is not unique to fibronectins. Another example of regulation in this manner is the estrogen downregulation of the peptidylglycine $\alpha$-amidating monooxygenase gene which is a bifunctional enzyme involved in the posttranslational processing of many prohormones and neuropeptides (201). The precise mechanism by which the stability of this nuclear RNA is controlled has not been established. It is hypothesized that a putative destabilizing protein binds to either a specific sequence or secondary structure in these transcripts. These cis-and trans-acting factors have not been identified.

\section{Nuclear matrix}

There is an emerging recognition that gene regulatory mechanisms are functionally linked to nuclear architecture. In this regard, the nuclear matrix is thought to be involved in gene regulation. In 1974, Berezney and Coffey coined the term "nuclear matrix" and speculated on its function (202). The nuclear matrix is a structural component of the cell which is composed of proteins and RNA which form tube-like structures. These structures have been hypothesized not only to function as an anchor for actively transcribed chromatin via matrix attachment regions, but also to direct newly synthesized RNA into the pathway for processing and transport into the cytoplasm. This idea is based on immunocytochemical studies which demonstrate the co-localization of key processing proteins to the specific nuclear domains referred to as "speckles" or interchromatin granules (203-205). Using fluorescently-tagged antibodies and probes, splicing accessory proteins associate with both the matrix and the hyperphosphorylated Cterminal domain of RNA polymerase II (205).

Association of the nascent transcript to the nuclear matrix, the site of its processing, and then transport to the nuclear membrane following processing is a potential site for regulation. Regulation of the alkaline phosphatase gene is thought to be stimulated in this manner by retinoic acid (206). The liver/bone/kidney isoform of this 
enzyme is found mainly in osteoblast cells and is likely to be involved in bone mineralization. Tissue-specific regulation (207) or regulation by retinoic acid (206) of the liver/bone/kidney alkaline phosphatase gene involves changes in the amount of nuclear pre-mRNA without significant changes in transcriptional activity. In order to determine the influence of retinoic acid on the nuclear processing of alkaline phosphatase, Zhou et al. (206) fractionated the nuclear compartment to isolate RNA from the nuclear matrix, DNase I/high salt eluate, and nuclear membrane of rat pre-osteoblastic UMR 201 cells. The results demonstrate that mature (spliced) alkaline phosphatase mRNA accumulated in the non-matrix fractions of retinoic acid-treated cells at a 100-fold greater level than in control cells. This suggests that nuclear processing of the pre-mRNA only occurred in retinoic acid treated cells, thus processing of alkaline phosphatase pre-mRNA is enhanced by retinoic acid. It is thought that enhanced stability of the nuclear RNA on the nuclear matrix is involved, however, this was not formally tested. More recently, it was demonstrated that regulation of other genes affected by retinoic acid such as the osteopontin gene, a phosphorylated glycoprotein secreted by osteoblasts and osteoclasts, occurs through the same type of mechanism (208). The key to understanding these findings is determining if the RNA transcript is blocked from association with the nuclear matrix and thereby the processing reactions versus if the transcripts undergo selective decay during processing. These experiments remain to be done.

The emerging concept that regulatory components of gene expression must be at the right place in the nucleus at the right time in order to mediate the proper control seems to be gaining supportive evidence. Recent advancements in high resolution in situ hybridization techniques and immunofluorescence analysis will provide new insights into the intranuclear distribution of genes and regulatory factors to more fully understand this concept. It is unclear if this will be a common organizational principle of efficient gene expression or if it will be gene-specific.

\section{Nonsense-mediated decay}

mRNAs can also be destabilized by the presence of nonsense codons. Nonsense codon recognition takes place during protein synthesis and involves cytoplasmic ribosomes. Thus, mRNA turnover and translation appear to be directly linked. This type of mRNA decay is initiated by deadenylation-independent decapping and subsequent 5' to 3' decay of the transcript. Nonsense-mediated decay occurs in all eukaryotes however the enzymes involved have only been identified in yeast (209-211). It appears that there are two potential cellular pathways that degrade nonsense-containing mRNAs (212). Results from studies in yeast and mammalian cells are consistent with the hypothesis that 
accelerated turnover of nonsense-containing mRNAs is attributed to cytoplasmic events that are concurrent with mRNA translation (213,214). A second decay pathway exists in mammalian cells in which certain mRNAs are degraded in the nucleus due to the presence of nonsense codons. The degradation of nonsense-containing mRNAs synthesized from the human triose phosphate isomerase (TPI) gene, T-cell receptor- $\beta$ gene, the hamster dihydrofolate reductase gene, the v-src gene, the mouse major urinary protein and the human $\beta$-globin gene is consistent with the hypothesis that their degradation is associated with the nucleus. Thus, it appears on the surface that there are two independent nonsense-mediated mRNA decay pathways, nuclear and cytoplasmic. The results reported in yeast versus mammalian cells can be rectified if in mammalian cells, following mRNA export to the cytoplasm but still on the outside of the nucleus, the nonsense-containing transcript forms an aberrant ribonucleoprotein particle (RNP) that is susceptible to decay. The biochemical fractionation of these mRNAs with the nuclear component may reflect a tight association of mRNPs with the outside of the nucleus.

The effect of nonsense mutations on nuclear-localized decay of TPI has been analyzed in the greatest detail. An anemia-inducing mutation which converts a CGA arginine codon to a TGA nonsense codon is responsible for this decay (215). The presence of this nonsense codon causes premature translation termination and also results in a 5-fold decrease in TPI mRNA. Furthermore, the results of inhibiting RNA synthesis with actinomycin D demonstrated that the half-life of a TPI mRNA with a normal termination codon versus one with a premature nonsense codon was not different. This suggests that the decrease in amount of TPI mRNA with a premature termination codon is not attributable to an increase in the rate of cytoplasmic mRNA decay (216). Instead, it was shown to be characteristic of both nuclear and cytoplasmic mRNA fractions of the cell (217). In addition, changes in gene transcription or splicing were not observed. Nucleus-associated RNA can be located within the nucleoplasm, associated with the pore or almost fully exported and not yet released from the nucleus. The exact location of the nucleus-associated mRNA has not been determined.

Three models have been proposed to account for how premature stop codons are recognized while nucleus-associated (212). All the models require that RNA containing premature termination codons be "marked" in some manner. The first model is a translational translocation model which suggests that translation begins as soon as the mRNA coding region emerges from the nucleus. The translating ribosomes facilitate splicing of the remaining portion of the pre-mRNA and enhance export. Premature stop codons may slow this process thereby degrading some of the pre-mRNA. The second model assumes that the fully spliced mRNA is translated as it emerges from the nucleus, 
the 5'-end first. The presence of a premature stop codon would interfere with this process and promote rapid decay of nucleus-associated mRNA. The final model is a nuclear scanning model in which an unidentified scanning process within the nucleus recognizes and degrades mRNAs containing premature stop codons. It is unclear whether every mRNA with a nonsense codon is degraded in the same manner. The pathway of nonsense-mediated decay may depend on the cell type where this is occurring or the actual gene product itself.

The model that has the most supporting evidence is the nuclear scanning model. Evidence from experiments done using the TPI gene have led to support of this model. In this respect, at least one intron is required which implicates nuclear splicing as an effector of translation (218). The most convincing explanation of this model that has been proposed is that all exon-exon junctions within a mRNA from a multi-intron gene may be "marked" with a remnant of the splicing machinery. The decision whether translation termination occurred prematurely is made by the putative scanning complex. The scanner then must interact with a properly positioned downstream "marked" junction. The proposed nuclear scanning mechanism may be some component of the translation termination complex or it may be a completely distinct complex. The scanner appears to have limits to the distance to which it can scan and recognize mRNAs which are marked for decay. In this respect, nonsense mediated decay requires the "marked" intron to reside at least $50 \mathrm{nt}$ downstream but less than $550 \mathrm{nt}$ downstream of the nonsense codon (219). The identification of trans-acting factors will be required to resolve the details of this mechanism. Splicing factors have been implicated in this model since several factors have been shown to shuttle from the nucleus to the cytoplasm $(220,221)$.

This mechanism was originally thought to eliminate "imperfect messages" which contain premature translation termination codons which can code for nonfunctional or harmful polypeptides. In support of this hypothesis, there are well over 200 genetic disorders that result from premature translation termination (222). However, recent evidence suggests that this path may contribute to the regulation of mRNA half-life for normal mRNAs, such has been reported for mRNAs involved in normal telomere chromatin function and/or telomere control length (223).

\section{Iron response elements}

There are many well characterized examples of posttranscriptional regulation in the cytoplasm. An intriguing system showing posttranscriptional gene control is the regulation of cellular iron metabolism in higher eukaryotes. Excess iron leads to an increase in translation of ferritin mRNA and a decrease in stability of the transferrin 
receptor mRNA mediated by cytosolic proteins called iron response element binding proteins (IRBP). The opposing effects aid in controlling iron homeostasis in the cell. The IRBPs bind to iron response elements (IRE) in the 5' -UTR of ferritin mRNA and in the 3'-UTR of transferrin receptor mRNA (224-226). The IRP has been shown to interact with ferritin and transferrin receptor transcripts, via a "sulfhydryl switch" mechanism (227). According to this model, iron concentrations in the cell are able to alter the available sulfhydryl groups in the IRP that are involved in binding to the IRE. The switch occurs when an iron-sulfur cluster in the protein becomes saturated with iron when iron is abundant. This in turn leads to a protein conformational change which prevents binding to the response element. On the other hand, when iron concentration is low, the ironsulfur cluster disassembles and allows a protein conformation which has strong affinity for the IRE. This mechanism was proposed after the discovery of two forms of the IRBP, a high affinity reduced form and a low affinity oxidized form. Additional evidence comes from the finding that sulfur was required in experiments to demonstrate IRBP binding to the IRE $(228,229)$.

Endonucleolytic cleavage of some mRNAs is regulated by RNA-binding proteins that bind in the vicinity of the cleavage sites and render them inaccessible to nucleolytic attack. This type of control is also observed in iron metabolism. For example, five IREs are located within a $678 \mathrm{nt}$ fragment of the 3'-UTR of transferrin receptor mRNA and a functional endonucleolytic cleavage site is situated between each of the IREs (230). The binding of the IRBP to the IRE prevents access of the nuclease to the cleavage site. When iron concentration is increased, the IRE-IRBP interaction decreases and the endonucleolytic cleavage can then occur in the transferrin receptor transcript, resulting in

a decrease in stability. This mechanism is not unique to iron regulation. Endonucleolytic cleavage sites have also been identified in coding region sequences of c-myc and Xenopus laevis albumin mRNA in addition to those identified in the 3'-UTR of transferrin receptor $(231,232)$.

\section{Coding region stability determinants}

Sequences within coding regions have been identified in many genes to regulate stability such as in the c-fos, c-myc, human interferon, and $\beta$-tubulin genes. A common sequence motif among these examples has not been identified. In some cases these sequences do not bind to trans-acting factors. Additionally, most examples of genes with coding region stability determinants also have additional stability factors in other areas of the gene. This is the case for c-fos and c-myc. c-myc and c-fos contain stability 
determinants in the 3'-UTRs of their messages in addition to those found in the coding region.

The identification of coding region determinants in c-fos and c-myc was shown by deletion and/or replacement of the 3'-UTRs of these genes with an unrelated sequence $(233,234)$. The 3 '-UTRs of these genes are known to contain the adenylate/uridylate rich instability determinants. The presence of a heterologous UTR did not result in an increase in half-life of the mRNA which suggested the presence of additional instability determinants besides those in the 3'-UTR. To further identify the additional regulatory sequence in c-fos, the coding region of c-fos was inserted into the globin mRNA which is very stable with a half-life of greater than $8 \mathrm{~h}$. This resulted in a new half-life of less than $30 \mathrm{~min}$ (235). This $320 \mathrm{bp}$ coding region determinant is 391 to $709 \mathrm{nt}$ downstream of the translation initiation codon. In addition, gel mobility shift assays and UV-crosslinking assays have identified two cellular proteins which bind specifically to this region (236). The c-myc mRNA coding region determinant has been identified more precisely to a 180 nt fragment (237). A trans-acting protein has also been shown to bind to this C-terminal coding region in vitro (238). This protein may function as a stabilizing factor by binding to the c-myc coding region determinant and protecting the RNA from attack by ribonucleases. Thus, it appears that mRNAs can contain two or more well separated stability determinants, each of which most likely specifies a distinct decay pathway or a distinct response to a regulatory factor.

\section{Adenylate/Uridylate rich elements}

Adenylate/Uridylate-rich elements (AUREs) found in the 3'-UTR of many labile cytokine, transcription factor, and proto-oncogene mRNAs represent the most common RNA stability determinant in mammalian cells. AUREs play a critical role in regulation of gene expression. AUUUA is a common sequence motif that is repeated several times but the presence of this sequence alone is insufficient to cause decay. Many AUREcontaining mRNAs are degraded by a sequential pathway involving removal of the poly(A) tail followed by degradation of the mRNA transcript (239). Destabilization is thought to occur in c-fos (240). c-fos mRNA is one of the least stable mammalian messages $\left(\mathrm{t}_{1 / 2}=30 \mathrm{~min}\right)$. When the ARE from c-fos is replaced within the 3'-UTR of a stable mRNA, the normally stable transcript is destabilized. In a different type of experiment, point mutations or deletion of these ARE sequences results in stabilization of the c-fos mRNA. In addition, deletion of the AURE in the 3'-UTR of c-fos increases its oncogenic power (241) suggesting that this element may play a role in cellular 
transformation due to the stability effect. Since AURE-mediated decay is linked to cell transformation and oncogenesis, elucidation of its mechanism of action is important.

A detailed understanding of how AUREs function requires the identification of trans-acting proteins that interact with the AURE. Many such factors have already been identified and is this list is constantly growing. Recently, a family of ARE-binding proteins have been identified which bind to AUREs on many mRNAs to decrease their stability (242). This family is formed by alternative splicing of a single gene and functions as part of a multi-subunit complex to promote turnover (242). Other examples of AUREs which function as RNA destabilizing elements have been identified in c-myc, $\beta$-interferon and human granulocyte-monocyte colony-stimulating factor (243-245).

AUREs affect mRNA half-lives in different ways by interacting with different regulatory factors whose expression, in turn, depends on treatment. Thus, the signal transduction pathway that affects protein binding to the AUREs are probably distinct for each gene.

A variation of the AUREs is a class of elements referred to as uridine-rich elements (URE). A URE has been identified in the c-fos gene in addition to the AURE, which has been shown to promote rapid deadenylation. In c-fos, four different URE binding proteins have been identified which bind to these U-rich sequences. The pathways for AURE-mediated decay and URE-mediated decay have begun to be identified which show that deadenylation is the first critical step in the decay of mRNAs containing these elements (246). However, deadenylation occurs by two distinct pathways because mRNAs containing AUREs have different decay intermediates than those containing UREs. AURE-mediated mRNA decay results in intermediates with poly(A) tails of 30-60 nt whereas URE-mediated decay results in poly(A) minus decay intermediates. It is thought that differences in organization of some sequence features, such as the spacing between AUUUA sequences and U-rich sequences, could result in the binding of different RNA-protein complexes or different ways of organizing the same factors. These distinct complexes could directly influence or modulate the processivity of a ribonuclease or recruit kinetically distinct ribonucleases for each of these pathways. cfos has both of these types of elements in addition to a coding region stability determinant therefore this gene may use distinct pathways in response to different factors. Thus, the stability of a given mRNA can be controlled by specific intrinsic nucleotide sequences and globally regulated by RNA binding proteins that either bind many RNAs or that are RNA-specific. 


\section{Summary and conclusions}

G6PD expression occurs by a nuclear posttranscriptional event. While dietary fat coordinately inhibits multiple enzymes in intermediary metabolism at a pre-translational step (5), the mechanisms involved vary significantly between genes. Regulation of G6PD expression at a posttranscriptional step would permit enhanced expression in tissues such as liver when the need for lipogenesis increases, and uniform expression in all cells for its role in cellular detoxification and nucleotide biosynthesis. Regulation of G6PD at an exclusively posttranscriptional step is quite unique compared to the other lipogenic enzymes which seem to have both transcriptional and posttranscriptional components to their regulation.

Posttranscriptional control of mRNA is an integral component of regulated gene expression and there are many ways in which the amount of a specific transcript can be affected by these pathways. The stability of a given mRNA can be controlled by specific intrinsic cis-acting RNA sequences and regulated by trans-acting RNA binding proteins that are either mRNA specific or bind to many RNAs. Furthermore, the half-life of many mRNAs can fluctuate in response to developmental or environmental stimuli such as nutritional or hormonal factors, cytokines and viral infection. Identification of the regulatory mechanism involved in the regulation of G6PD by dietary fat will aid in our knowledge of novel posttranscriptional mechanisms as well as understanding the molecular basis for many diseases associated with the consumption of dietary fat. This may lead to the engineering of new "low-fat" foods or new targets for drug discovery.

\section{References}

1. McPhail, L. C., C. C. Clayton, and R. Snyderman. 1984. A potential second messenger role for unsaturated fatty acids: Activation of $\mathrm{Ca}^{2+}$-dependent protein kinase. Science. 224: 622-625.

2. James G., and E. N. Olson. 1990. Fatty acylated proteins as components of intracellular signaling pathways. Biochemistry. 29: 2623-2634.

3. Glick, J., G. Santoyo, and P. J. Casey. 1996. Arachidonate and related unsaturated fatty acids selectively inactivate the guanine nucleotide-binding regulatory protein, Gz. $J$. Biol. Chem. 271: 2949-2954.

4. Clarke, S. D., and D. B. Jump. 1996. Polyunsaturated fatty acid regulation of hepatic gene transcription. Lipids. 31: S7-S11.

5. Jump, D. B., S. D. Clarke, A. Thelen, and M. Liimata. 1994. Coordinate regulation of glycolytic and lipogenic gene expression by polyunsaturated fatty acids. J. Lipid Res. 35: 1076-1084. 
6. Garcia, D. R., and D. Holten. 1975. Inhibition of rat liver glucose-6-phosphate dehydrogenase synthesis by glucagon. J. Biol. Chem. 250: 3960-3965.

7. Szepesi, B., A. K. Kamara, and S. D. Clarke. 1989. Lack of specificity of polyunsaturated fats in the inhibition of rat liver glucose-6-phosphate dehydrogenase. $J$. Nutr. 119: 161-165.

8. Yoshimoto, K., T. Nakamura, S. Niimi, and A. Ichihara. 1983. Hormonal regulation of translatable mRNA of glucose-6-phosphate dehydrogenase in primary cultures of adult rat hepatocytes. Biochim. Biophys. Acta. 741: 143-149.

9. McDonald, B. E., and B. C. Johnson. 1965. Metabolic response to realimentation following chronic starvation in the adult male rat. J. Nutr. 87: 161-167.

10. Wurdeman, R., C. D. Berdanier, and R. B. Tobin. 1978. Enzyme overshoot in starved-refed rats: Role of adrenal glucocorticoid. J. Nutr. 108: 1457-1461.

11. Berdanier, C.D., and D. Shubeck. 1979. Interaction of glucocorticoid and insulin in the responses to starvation-refeeding. J. Nutr. 109: 1766-1771.

12. Kurtz, J. W., and W. W. Wells. 1981. Induction of glucose-6-phosphate dehydrogenase in primary cultures of adult rat hepatocytes. Requirement for insulin and dexamethasone. J. Biol. Chem. 26: 10870-10875.

13. Fukuda, H., A. Katsurada, and N. Iritani. 1992. Nutritional and hormonal regulation of mRNA levels of lipogenic enzymes in primary cultures of rat hepatocytes. J. Biochem. 111: $25-30$.

14. Salati, L. M., B. Adkins-Finke, and S. D. Clarke. 1988. Free fatty acid inhibition of the insulin induction of glucose-6-phosphate dehydrogenase in rat hepatocyte monolayers. Lipids. 23: 36-41.

15. Stabile, L. P, D. L. Hodge, S. A Klautky, and L. M. Salati. 1996. Posttranscriptional regulation of glucose-6-phosphate dehydrogenase by dietary polyunsaturated fat. Arch. Biochem. Biophys. 332: 269-279.

16. Stumpo, D. J., and R. F. Kletzien. 1984. Regulation of glucose-6-phosphate dehydrogenase mRNA by insulin and the glucocorticoids in primary cultures of rat hepatocytes. Eur. J. Biochem. 144: 497-502.

17. Miksicek, R. F., and H. C. Towle. 1982. Changes in the rates of synthesis and messenger RNA levels of hepatic glucose-6-phosphate and 6-phosphogluconate dehydrogenases following induction by diet or thyroid hormone. J. Biol. Chem. 257: 11829-11835.

18. Prostko, C. R., R. S. Fritz, and R. F. Kletzien. 1989. Nutritional regulation of hepatic glucose-6-phosphate dehydrogenase. Transient activation of transcription. Biochem. J. 258: 295-299.

19. Freedland, R. A., S. Murad, and A. I. Hurvitz. 1968. Relationship of nutritional and hormonal influences on liver enzyme activity. Fed. Proc. 27: 1217-1222.

20. Tepperman, J., and H. M. Tepperman. 1958. Effects of antecedent food intake pattern on hepatic lipogenesis. Am. J. Physiol. 193: 55-64. 
21. Winberry, L., and D. Holten. 1977. Rat liver glucose-6-P dehydrogenase. Dietary regulation of the rate of synthesis. J. Biol. Chem. 252: 7796-7801.

22. Peavy, D. E., and R. J. Hansen. 1979. Influence of diet on the in vivo turnover of glucose-6-phosphate dehydrogenase. Transient activation of transcription. Biochem. J. 258: $295-299$.

23. Manos, P., R. Nakayama, and D. Holten. 1991. Regulation of glucose-6-phosphate dehydrogenase synthesis and mRNA abundance in cultured rat hepatocytes. Biochem $J$. 276: $245-250$.

24. Mariash, C. N., and J. H. Oppenheimer. 1983. Stimulation of malic enzyme formation in hepatocyte culture by metabolites: Evidence favoring a nonglycolytic metabolite induction signal. Metabolism. 33: 545-552.

25. Foufelle, F., B. Gouhot, J. P. Pegorier, D. Perdereau, J. Girard, and P. Ferre. 1992. Glucose stimulation of lipogenic enzyme gene expression in cultured white adipose tissue. A role for glucose 6-phosphate. J. Biol. Chem. 267: 20543-20546.

26. Lawson, J. W., and K. Uyeda. 1987. Effects of insulin and work on fructose 2,6bisphosphate content and phosphofructokinase activity in perfused rat hearts. J. Biol. Chem. 262: 3165-3173.

27. Mourrieras, F., F. Foufelle, M. Foretz, J. Morin, S. Bouche, and P. Ferre. 1997. Induction of fatty acid synthase and S14 gene expression by glucose, xylitol and dihydroxyacetone in cultured rat hepatocytes is closely correlated with glucose 6phosphate concentrations. Biochem. J. 326: 345-349.

28. Clarke, S. D., D. R. Romsos, and G. A. Leveille. 1976. Specific inhibition of hepatic fatty acid synthesis exerted by dietary linoleate and linolenate in essential fatty acid adequate rats. Lipids 11: 485-490.

29. Clarke, S. D., D. R. Romsos, and G. A. Leveille. 1977. Differential effects of dietary methyl esthers of long-chain saturated and polyunsaturated fatty acids on rat liver and adipose tissue lipogenesis. J. Nutr. 107: 1170-1181.

30. Clarke, S. D., and J. Hembree. 1990. Inhibition of triiodothyronine's induction of rat liver lipogenic enzymes by dietary fat. J. Nutr. 120: 625-630.

31. Hillard, L. A., C. Y. Lin, and S. Abraham. 1988. Lipogenic enzyme activities in primary cultures of adult mouse hepatocytes. Lipids. 23: 242-247.

32. Stabile, L. P, S. A. Klautky, S. M. Minor, and L. M. Salati. 1998. Polyunsaturated fatty acids inhibit the expression of the glucose-6-phosphate dehydrogenase gene in primary rat hepatocytes by a nuclear posttranscriptional mechanism. J. Lipid Res. 39: 1951-1963.

33. Clarke, B. A., and S. D. Clarke. 1982. Suppression of rat liver fatty acid synthesis by eicosa-5,8,11,14- tetraynoic acid without a reduction in lipogenic enzymes. J. Nutr. 112: $1212-1219$. 
34. Szepesi, B. 1983. Reversal of the effects of exogenous fats on the activities of rat liver NADP-linked dehydrogenases by eicosa- 5,8,11,14- tetraynoic acid. Nutr. Rep. Int. 28: $1219-1299$.

35. Liimatta, M., H. C. Towle, S. Clarke, and D. B Jump. 1994. Dietary polyunsaturated fatty acids interfere with the insulin/glucose activation of L-type pyruvate kinase gene transcription. Mol. Endocrinol. 8: 1147-1153.

36. Jump, D. B., B. Ren, S. D. Clarke, and A. Thelen. 1995. Effects of fatty acids on hepatic gene expression. Prostaglandin Leukotr. Essent. Fatty Acids. 52: 107-111.

37. Gottlicher, M., E. Widmark, Q. Li, and J. A. Gustafsson. 1992. Fatty acids activate a chimera of the clofibric acid-activated receptor and the glucocorticoid receptor. Proc. Natl. Acad. Sci. USA. 89: 4653-4657.

38. Keller, H., C. Deyer, J. Medin, A. Nahfoudi, K. Ozato, and W. Wahli. 1993. Fatty acids and retinoids control lipid metabolism through activation of peroxisome proliferator-activated receptor-retinoid X receptor heterodimers. Proc. Natl. Acad. Sci. 90: $2160-2164$.

39. Jump, D. B., S. D. Clarke, O. A. MacDougald, and A. Thelen. 1993. Polyunsaturated fatty acids inhibit S14 gene transcription in rat liver and cultured hepatocytes. Proc. Natl. Acad. Sci. USA. 90: 8454-8458.

40. Blake, W. L., and S. D. Clarke. 1990. Suppression of rat hepatic fatty acid synthase and S14 gene transcription by dietary polyunsaturated fat. J. Nutr. 120: 1727-1729.

41. Waters, K. M., C. W. Miller, and J. M. Ntambi. 1997. Localization of a polyunsaturated fatty acid response region in stearoyl-CoA desaturase gene 1. Biochem. Biophys. Acta. 1349: 33-42.

42. Toniolo, D., M. Filippi, R. Dono, T. Lettieri, and G. Martini. 1991. The CpG island in the 5' region of the G6PD gene of man and mouse. Gene. 102: 197-203.

43. Philippe, M., Y. Larondelle, F. Lemaigre, B. Mariame, H. Delhez, P. Mason, L. Luzzatto, and G. Rousseau. 1994. Promoter function of the human glucose-6-phosphate dehydrogenase gene depends of two GC boxes that are cell specifically controlled. Eur. J. Biochem. 226: 377-384.

44. Hodge, D. L., T. Charron, L. P. Stabile, S. A. Klautky, and L. M. Salati. 1998. Structural characterization and tissue-specific expression of the mouse glucose-6phosphate dehydrogenase gene. DNA \& Cell Biol. 17: 283-291.

45. Martini, G., D. Toniolo, T. Vulliamy, L. Luzzatto, R. Dono, G. Viglietto, G. Paonessa, M. D’Urso, and M. G. Persico. 1986. Structural analysis of the X-linked gene encoding human glucose-6-phosphate dehydrogenase. EMBO J. 5: 1849-1855.

46. Rank, K., P. Harris, L. Ginsberg, and S. Stapleton. 1994. Isolation and sequence of a rat glucose-6-phosphate dehydrogenase promoter. Biochem. Biophys. Acta. 1217: 9092.

47. Kletzien, R. F., and C. D. Berdanier. 1993. Glucose-6-phosphate dehydrogenase: diet and hormonal influences on de novo enzyme synthesis. In Nutrition and Gene 
Expression. (Berdanier, C. D., and J. L. Hargrove, eds.) pp. 187-206. CRC Press. Boca Raton.

48. Chen E., A. Chang, A. Lee, W. Kuang, and L. Hillier. 1992. Sequence of human glucose-6-phosphate dehydrogenase cloned in plasmids and a yeast artificial chromosome (YAC). Genomics. 10: 792-800.

49. Kletzien, R. F., P. K. W. Harris, and L. A. Foellmi. 1994. Glucose-6-phosphate dehydrogenase: a "housekeeping" enzyme subject to tissue-specific regulation by hormones, nutrients and oxidative stress. FASEB J. 8: 174-180.

50. Glock, G. E., and P. McLean. 1955. A preliminary investigation of the hormonal control of hexose monophosphate oxidative pathway. Biochem J. 61: 390.

51. Cocoran, C. M., P. Fraser, G. Martini, L. Luzzato, and P. J. Mason. 1996. Highlevel regulated expression of the human G6PD gene in transgenic mice. Gene. 173: 241-246.

52. Magnuson, M. A., and K. D. Shelton. 1989. An alternate promoter in the glucokinase gene is active in the pancreatic $\beta$ cell. J. Biol. Chem. 264: 15936-15942.

53. Kim, K.-H., and H.-J. Tae. 1994. Pattern and regulation of acetyl-CoA carboxylase gene expression. J. Nutr. 124: 1273S-1283S.

54. Jump, D. B., N. C. W. Wong, and J. H. Oppenheimer. 1987. Chromatin structure and methylation state of a thyroid hormone-responsive gene in rat liver. J. Biol. Chem. 262: $778-784$.

55. Jump, D., A. Veit, V. Santiago, G. Lepar, and L. Herberholz. 1988. Transcriptional activation of the rat liver S14 gene during postnatal development. J. Biol. Chem. 263: 7254-7260.

56. Martins, R. N., P. E. Hartmann, and G. B. Stokes. 1985. Comparative profiles of hexose monophosphate dehydrogenases in rat tissues over the lactation cycle. Aust. J. Biol. Sci. 3: 295-303.

57. Grigor, M. R., and K. R. Gain. 1983. The effect of starvation and refeeding on lipogenic enzymes in mammary glands and livers of lactating rats. Biochem J. 216: 515518.

58. Kennedy, K. A., L. S. Crouch, and J. B. Warshaw. 1989. Effect of hypeoxia on antioxidants in neonatal rat type II cells in vitro and in vivo. Pediatr. Res. 26: 400-403.

59. Stumpo, D. J., and R. F. Kletzien. 1985. The effect of ethanol, alone and in combination with the glucocorticoids and insulin, on glucose-6-phosphate dehydrogenase synthesis and mRNA in primary cultures of hepatocytes. Biochem J. 226: 123-130.

60. Stapleton, S. R., G. J. Stevens, J. F. Teel, K. B. Rank, E. A. Berg, J. Y. Wu, L. C. Ginsberg, and R. F. Kletzien. 1993. Effects of acetaldehyde on glucose-6-phosphate dehydrogenase activity and mRNA levels in primary rat hepatocytes in culture. Biochim. 75: $971-976$.

61. Pandolfi, P. P., F. Sonati, R. Rivi, P. Mason, F. Grosveld, and L. Luzzatto. 1995. Targeted disruption of the housekeeping gene encoding glucose-6-phosphate 
dehydrogenase (G6PD): G6PD is dispensable for pentose synthesis but essential for defense against oxidative stress. EMBO J. 14: 5209-5215.

62. Yoshimoto, K., T. Nakamura, and A. Ichihara. 1983. Reciprocal effects of epidermal growth factor on key lipogenic enzymes in primary cultures of adult rat hepatocytes. Induction of glucose-6-phosphate dehydrogenase and suppression of malic enzyme and lipogenesis. J. Biol. Chem. 258: 12355-12360.

63. Weber, G. 1987. In Modulation of Liver Cell Expression (Reutter, W., H. Popper, I. M. Arias, P. C. Heirich, D. Keppler, and L. Landmann, eds.) 43: 303-314. MTP Press Ltd., Lancaster, PA.

64. Watanabe, A., and K. Taketa. 1973. Immunological studies on glucose-6-phosphate dehydrogenase of rat liver. Arch. Biochem. Biophys. 158: 43-52.

65. Peavy, D. E., and R. J. Hansen. 1975. Immunological titration of rat liver glucose-6phosphate dehydrogenase from animals fed high and low carbohydrate diets. Biochem. Biophys. Res. Comm. 66: 1106-1111.

66. Gozukara, E. M., M. Frolich, and D. Holten. 1972. The effect of unsaturated fatty acids on the rate of synthesis of rat liver glucose-6-phosphate dehydrogenase. Biochim. Biophys. Acta. 286: 155-163.

67. Wolfe, R. C., and D. Holten. 1978. The effect of dietary fat or cholesterol and cholic acid on the rate of synthesis of rat liver glucose-6-P dehydrogenase. J. Nutr. 108: 17081717.

68. Winberry, L. and D. Holten. 1977. Rat liver glucose-6-P dehydrogenase. Dietary regulation of the rate of synthesis. J. Biol. Chem. 252: 7796-7801.

69. Kletzien, R. F., C. R. Prostko, D. J. Stumpo, J. K. McClung, and K. L. Dreher. 1985. Molecular cloning of DNA sequences complementary to rat liver glucose-6-phosphate dehydrogenase mRNA. Nutritional regulation of mRNA levels. J. Biol. Chem. 260: 5621-5624.

70. Hodge, D. L., and L. M. Salati. 1997. Nutritional regulation of the glucose-6phosphate dehydrogenase gene is mediated by a nuclear posttranscriptional mechanism. Arch. Biochem. Biophys. 348: 303-312.

71. Ross, J. 1995. mRNA stability in mammalian cells. Micobiol. Rev. 59: 423-450.

72. Winz, R., D. Hess, R. Aebersold, and R. W. Browney. 1994. Unique structural features and differential phosphorylation of the $280-\mathrm{kDa}$ component (isozyme) of rat liver acetyl-CoA carboxylase. J. Biol. Chem. 269: 365-371.

73. Widmer, J., K. S. Fassihi, S. C. Schlicter, K. S. Wheeler, B. E. Crute, N. King, N. Nutile-McMenemy, W. W. Noll, S. Daniel, J. Ha, K. H. Kim, and L. A. Witters. 1996. Identification of a second human acetyl-CoA carboxylase gene. Biochem J. 316: 915922.

74. Abu-Elheiga, L., D. B. Almarza-Ortega, A. Baldini, and S. J. Wakil. 1997. Human acetyl-CoA carboxylase 2. Molecular cloning, characterization, chromosomal mapping, and evidence for two isoforms. J. Biol. Chem. 272: 10669-10677. 
75. Zammit, V. A. 1996. Role of insulin in hepatic fatty acid partitioning: emerging concepts. Biochem J. 314: 1-14.

76. Salati, L. M., and S. D. Clarke. 1986. Fatty acid inhibition of hormonal induction of acetyl-coenzyme A carboxylase in hepatocyte monolayers. Arch. Biochem. Biophys. 246: $82-89$.

77. Luo, X., K. Park, F. Lopez-Casillas, and K.-H. Kim. 1989. Structural features of the acetyl-CoA carboxylase gene: mechanisms for the generation of mRNA's with 5' end heterogeneity. Proc. Natl. Acad. Sci. USA. 86: 4042-4046.

78. Ha, J., J.-K. Lee, K.-S., Kim, L. A. Witters, and K.-H. Kim. 1996. Cloning of human acetyl-CoA carboxylase-beta and its unique features. Proc. Natl. Acad. Sci. USA. 93: $11466-11470$.

79. Lopez-Casillas, F., and K.-H. Kim. 1991. In vivo regulation of the two promoters of the rat acetyl-CoA carboxylase gene. Endocrinology. 129: 1049-1058.

80. Kim, K.-H., and H.-J. Tae. 1994. Pattern and regulation of acetyl-CoA carboxylase gene expression. J. Nutr. 124: 1273S-1283S.

81. Hillgartner, F. B., T. Charron, and K. A. Chestnut. 1996. Alterations in nutritional status regulate acetyl-CoA carboxylase expression in avian liver by a transcriptional mechanism. Biochem J. 319: 263-268.

82. Hillgartner, F. B., and T. Charron. 1997. Arachidonate and medium-chain fatty acids inhibit transcription of the acetyl-CoA carboxylase gene in hepatocytes in culture. J. Lipid Res. 38: 2548-2557.

83. Lopez-Casillas, F., and K. H. Kim. 1989. Heterogeneity at the 5'-end of rat acetylcoenzyme A carboxylase mRNA. Lipogenic conditions enhance synthesis of a unique mRNA in liver. J. Biol. Chem. 264: 7176-7184.

84. Tae, H. J., X. Luo, and K. H. Kim. 1994. Roles of CCAAT/enhancer-binding protein and its binding site on repression and derepression of acetyl CoA carboxylase gene. J. Biol. Chem. 269: 10475-10484.

85. Park, K., and K. H. Kim. 1993. The site of cAMP action in the insulin induction of gene expression of acetyl-CoA carboxylase is AP-2. J. Biol. Chem. 268: 17811-17819.

86. Barber, M. C., and M. T. Travers. 1998. Elucidation of a promoter activity that directs the expression of acetyl-CoA carboxylase $\alpha$ with an alternative $\mathrm{N}$-terminus in a tissue-restricted fashion. Biochem. J. 333:17-25.

87. Kim, K.-S., S.-W. Park, and Y.-S. Kim. 1992. Regulation of ATP-citrate lyase at transcriptional and posttranscriptional levels in rat liver. Biochem. Biophys. Res. Comm. 189: $264-271$.

88. Fukuda, H, N. Iritani, A. Katsurada, and T. Noguchi. 1996. Insulin- and polyunsaturated fatty acid-responsive region(s) of rat citrate-lyase gene promoter. FEBS letters. 380: 204-207.

89. Back, D. W., M. J. Goldman, J. E. Fisch, R. S. Ochs, and A. G. Goodridge. 1986. the fatty acid synthase gene in avian liver: two mRNAs are expressed and regulated in 
parallel by feeding, primarily at the level of transcription. J. Biol. Chem. 261: 41904197.

90. Katsurada, A., N. Iritani, H. Fukuda, Y. Matsumura, N. Nishimoto, T. Noguchi, and T. Tanaka. 1990. Effects of nutrients and hormones on transcriptional and posttranscriptional regulation of fatty acid synthase in rat liver. Eur. J. Biochem. 190: 427433.

91. Semenkovich, C. F., T. Coleman, and R. Goforth. 1993. Physiologic concentrations of glucose regulate fatty acid synthase activity in HepG2 cells by mediating fatty acid synthase mRNA stability. J. Biol. Chem. 268: 6961-6970.

92. Clarke, S. D., M. K. Armstrong, and D. B. Jump. 1990. Nutritional control of rat liver fatty acid synthase and S14 mRNA abundance. J. Nutr. 120: 218-224.

93. Nepokroeff, C. M., K. Adachi, C. Yan, and J. W. Porter. 1984. Cloning of DNA complementary to rat liver fatty acid synthetase mRNA. Eur. J. Biochem. 140: 441-445.

94. Paulauskis, J. D., and H. S. Sul. 1989. Hormonal regulation of mouse fatty acid synthase gene transcription in liver. J. Biol. Chem. 264: 574-577.

95. Volpe, J. J., and J. C. Marasa. 1975. Hormonal regulation of fatty acid synthetase, acetyl-CoA carboxylase and fatty acid synthesis in mammalian adipose tissue and liver. Biochim. Biophys. Acta. 380: 454-472.

96. Volpe, J. J., and P. R. Vagelos. 1974. Regulation of mammalian fatty acid synthetase. The roles of carbohydrate and insulin. Proc. Natl. Acad. Sci. USA. 71: 889893.

97. Craig, M. C., and J. W. Porter. 1973. Synthesis of fatty acid synthetase by isolated liver cells obtained from rats in different nutritional or hormonal states. Arch. Biochem. Biophys. 159: 606-614.

98. Spence, J. T., and H. C. Pitot. 1982. Induction of lipogenic enzymes in primary cultures of rat hepatocytes: Relationship between lipogenesis and carbohydrate metabolism. Eur. J. Biochem. 128: 15-20.

99. Semenkovich, C. F., T. Coleman, and F. T. Fiedorek, Jr. 1995. Human fatty acid synthase mRNA: tissue distribution, genetic mapping, and kinetics of decay after glucose deprivation. J. Lipid Res. 36: 1507-1521.

100. Stapleton, S. R., D. A. Mitchell, L. M. Salati, and A. G. Goodridge. 1990.

Triiodothyronine stimulates transcription of the fatty acid synthase gene in chick embryo hepatocytes in culture. Insulin and insulin-like growth factor amplify that effect. J. Biol. Chem. 265: 18442-18446.

101. Wilson, S. B., D. W. Back, S. M. Morris, Jr., J. Swierczynski, and A. G. Goodridge. 1986. Hormonal regulation of lipogenic enzymes in chick embryo hepatocytes in culture. Expression of the fatty acid synthase gene is regulated at both translational and pretranslational steps. J. Biol. Chem. 261: 15179-15182.

102. Clarke, S. D., and S. Abraham. 1992. Gene expression: Nutrient control of preand posttranscriptional events. FASEB J. 6: 3146-3152. 
103. Clarke, S. D., M. K. Armstrong, and D. B. Jump. 1990. Nutritional control of rat liver fatty acid synthase and S14 mRNA abundance. J. Nutr. 120: 218-224.

104. Shih, H.-M., and H. C. Towle. 1994. Definition of the carbohydrate response element of the rat S14 gene. Context of the CACGTG motif determines the specificity of carbohydrate regulation. J. Biol. Chem. 269: 9380-9387.

105. Moustaid, N., K. Sakamoto, S. Clarke, R. S. Beyer, and H. S. Sul. 1993.

Regulation of fatty acid synthase gene transcription. Sequences that confer a positive insulin effect and differentiation-dependent expression in 3T3-L1 preadipocytes are present in the 332 bp promoter. Biochem. J. 292: 767-772.

106. Wang, D., and H. S. Sul. 1995. Upstream stimulatory factors bind to insulin response sequence of the fatty acid synthase promoter. USF1 is regulated. J. Biol. Chem. 270: $28716-28722$.

107. Foufelle, F., N. Lepetit, D. Bosc, N. Delzenne, J. Morin , M. Raymondjean, and P. Ferre. 1995. DNase I hypersensitivity sites and nuclear protein binding on the fatty acid synthase gene: Identification of an element with properties similar to known glucoseresponsive elements. Biochem J. 308: 521-527.

108. Hasegawa, J., K. Osatomi, R. Wu, and K. Uyeda. 1999. A novel factor binding to the glucose response elements of liver pyruvate kinase and fatty acid synthase genes. $J$. Biol. Chem. 274: 1100-1107.

109. Magana, M. M., S. S. Lin, K. A. Dooley, and T. F. Osborne. 1997. Two tandem binding sites for sterol regulatory element binding proteins are required for sterol regulation of fatty-acid synthase promoter. J. Lipid Res. 38: 1630-1638.

110. Goodridge, A. G., and E. G. Ball. 1966. Lipogenesis in the pigeon: In vitro studies. Am J. Physiol. 211: 803-808.

111. Katz, J., and R. Rognstad. 1966. The metabolism of tritiated glucose by rat adipose tissue. J. Biol. Chem. 241: 3600-3610.

112. Rognstad, R., and J. Katz. 1979. Effects of 2, 4-dihydroxybutyrate on lipogenesis in rat hepatocytes. J. Biol. Chem. 254: 11969-11972.

113. Dozin, B., M. A. Magnuson, and V. M. Nikodem. 1986. Thyroid hormone regulation of malic enzyme synthesis. Dual tissue-specific control. J. Biol. Chem. 261: 10290-10292.

114. Towle, H. C., C. N. Mariash, H. L. Schwartz, and J. H. Oppenheiner. 1981. Quantitation of rat liver messenger ribonucleic acid for malic enzyme during induction by thyroid hormone. Biochemistry. 20: 3486-3492.

115. Song, M.-K. H., B. Dozin, D. Grieco, J. E. Rall, and V. M. Nikodem. 1988. Transcriptional activation and stabilization of malic enzyme mRNA precursor by thyroid hormone. J. Biol. Chem. 263: 17970-17974.

116. Silpananta, P., and A. G. Goodridge. 1971. Synthesis and degradation of malic enzyme in chick liver. J. Biol. Chem. 246: 5754-5761. 
117. Tepperman, H. M., and J. Tepperman. 1964. Patterns of dietary and hormonal induction of certain NADP-linked liver enzymes. Am. J. Physiol. 206: 357-361.

118. Wise, E. M., and E. G. Ball. Malic enzyme and lipogenesis. Proc. Natl. Acad. Sci. USA. 52: 1255-1263.

119. Ma, X.-J., L. M. Salati, S. E. Ash, D. A. Mitchell, S. A. Klautky, D. A. Fantozzi, and A. G. Goodridge. 1990. Nutritional regulation and tissue-specific expression of the malic enzyme gene in chicken. Transcriptional control and chromatin structure. J. Biol. Chem. 265: 6330-6338.

120. Dozin, B., J. E. Rall, and V. M. Nikodem. 1986. Tissue-specific control of rat malic enzyme activity and messenger RNA genes by a high carbohydrate diet. Proc. Natl. Acad. Sci. USA. 83: 4705-4709.

121. Cochary, E. F., Z. Kiknis, and K. E. Paulson. 1993. Positional and temporal regulation of lipogenic gene expression in mouse liver. Gene Expression. 3: 265-278.

122. Roncero, C., and A. G. Goodridge. 1992. Hexanoate and octanoate inhibit transcription of the malic enzyme and fatty acid synthase genes in chick-embryo hepatocytes in culture. J. Biol. Chem. 267: 14918-14927.

123. Carr, F. E., C. Bingham, J. H. Oppenheimer, C. Kistner, and C. N. Mariash. 1984. Quantitative investigation of hepatic genomic response to hormonal and pathophysiological stimuli by multivariate analysis of two-dimensional mRNA activity profiles. Proc. Natl. Acad. Sci. USA. 81: 974-978.

124. Kinlaw, W. B., P. Tron, and A. S. Friedmann. 1992. Nuclear localization and hepatic zonation of rat "spot 14" protein: Immunohistochemical investigation employing anti-fusion protein antibodies. Endocrinology. 131: 3120-3122.

125. Moncur, J. T., J. P. Park, V. A Memoli, T. K. Mohandas, and W. B. Kinlaw. 1998. The "Spot 14" gene resides on the telomeric end of the 11q13 amplicon and is expressed in lipogenic breast cancers: Implications for control of tumor metabolism. Proc. Natl. Acad. Sci. USA. 95: 6989-6994.

126. Jump, D. B., and J. H. Oppenheimer. 1985. High basal expression and 3,5,3'triiodothyronine regulation of messenger ribonucleic acid S14 in lipogenic tissues. Endocrinology. 117: 2259-2266.

127. Jump, D. B., A. Bell, and V. Santiago. 1990. Thyroid hormone and dietary carbohydrate interact to regulate rat liver S14 gene transcript and chromatin structure. $J$. Biol. Chem. 265: 3474-3478.

128. Shih, H. M., and H. C. Towle. 1992. Definition of the carbohydrate response element of the rat S14 gene. Evidence for a common factor required for carbohydrate regulation of hepatic genes. J. Biol. Chem. 267: 13222-13228.

129. Jacoby, D. B., N. D. Zilz, and H. C. Towle. 1989. Sequences within the 5'flanking region of the S14 gene confer responsiveness to glucose in primary hepatocytes. J. Biol. Chem. 264: 17623-17626.

130. Sudo, Y., Y. Goto, and C. N. Mariash. 1993. Location of a glucose dependent response element in the rat S14 promoter. Endocrinology. 133: 1221-1229. 
131. Jump, D. B., A. Bell, G. Lepar, and D. Hu. 1990. Insulin rapidly induces rat liver S14 gene transcription. Mol. Endocrinol. 4: 1655-1660.

132. Kinlaw, W. B., H. L. Schwartz, H. C. Towle, and J. H. Oppenheimer. 1986.

Opposing effects of glucagon and triiodothyronine on the hepatic levels of messenger ribonucleic acid S14 and the dependence of such effects on circadian factors. J. Clin. Invest. 78: 1091-1096.

133. Walker, J. D., L. A. Burmeister, A. Mariash, J. F. M. Bosman, J. Harmon, and C. N. Mariash. 1996. Insulin increases the processing efficiency of messenger ribonucleic acid-S14 nuclear precursor. Endocrinology. 137: 2293-2299.

134. Burmeister, L. A., and C. N. Mariash. 1991. Dietary sucrose enhances processing of mRNA-S14 nuclear precursor. J. Biol. Chem. 266: 22905-22911.

135. Mariash, C. N., S. Seeling, H. C. Schwartz, and J. H. Oppenheimer. 1986. Rapid synergistic interaction between thyroid hormone and carbohydrate on mRNA S14 induction. J. Biol. Chem. 261: 9583-9586.

136. Liu, H.-C., and H. C. Towle. 1994. Functional synergism between multiple thyroid hormone response elements regulates hepatic expression of the rat S14 gene. Mol.

Endocrinology. 8: 1021-1037.

137. Bernlohr, D. A., C. W. Angus, M. D. Lane, M. A. Bolanowski, and T. J. Kelly, Jr. 1984. Expression of specific mRNA's during adipose differentiation: identification of an mRNA encoding a homologue of myelin P2 protein. Proc. Natl. Acad. Sci. USA. 81: 5468-5472.

138. Ntambi, J. M., S. A. Buhrow, K. H. Kaestner, R. J. Christy, E. Sibley, T. J. Kelly, Jr., and M. D. Lane. 1988. Differentiation-induced gene expression in 3T3-L1 preadipocytes. Characterization of a differentially expressed gene encoding stearoyl-CoA desaturase. J. Biol. Chem. 263: 17291-17300.

139. Kaestner, K. H., J. M. Ntambi, J. T. Kelly, Jr., and M. D. Lane. 1989. Differentiation-induced gene expression in 3T3-L1 preadipocytes. A second differentially expressed gene encoding stearoyl-CoA desaturase. J. Biol. Chem. 264: $14755-14761$.

140. Ntambi, J. M. 1992. Dietary regulation of stearoyl-CoA desaturase 1 gene expression in mouse liver. J. Biol. Chem. 267: 10925-10930.

141. Li, J., S.-F. Ding, N. A. Habib, B. F. Fermor, C. B. Wood, and R. S. Gilmour. 1994. Partial characterization of a cDNA for human stearoyl-CoA desaturase and changes in its mRNA expression in some normal and malignant tissues. Int. J. Cancer. 57: 348-352.

142. Theide, M. A., and P. Strittmatter. 1985. The induction and characterization of rat liver stearoyl-CoA desaturase mRNA. J. Biol. Chem. 260: 14459-14463.

143. Kasturi, R., V. C. Joshi, and S. J. Wakil. 1984. Colchicine induction and insulin induction of stearoyl-CoA desaturase and fatty acid synthetase in cultured avian liver explants. Arch. Biochem. Biophys. 233: 530-539. 
144. Jeffcoat, R., P. A. Roberts, J. Ormesha, and A. T. James. 1979. Stearoyl-CoA desaturase: A control enzyme in hepatic lipogenesis. Eur. J. Biochem. 101: 439-445.

145. Prasad, M. R., and V. C. Joshi. 1979. Regulation of rat hepatic stearoyl coenzyme A desaturase. The roles of insulin and carbohydrate. J. Biol. Chem. 254: 997-999.

146. Joshi, V. C., and L. P. Aranda. 1979. Hormonal regulation of the terminal enzyme of microsomal stearoyl coenzyme A desaturase in cultured avian liver explants. Role of insulin. J. Biol. Chem. 254: 11779-11782.

147. Waters, K. M., C. W. Miller, and J. M. Ntambi. 1997. Localization of a negative thyroid hormone-response region in hepatic stearoyl-CoA desaturase gene 1. Biochem. Biophys. Res. Comm. 233: 838-843.

148. Waters, K. M., and J. M. Ntambi. 1996. Polyunsaturated fatty acids inhibit hepatic stearoyl-CoA desaturase 1 gene in diabetic mice. Lipids. 31: 533-536.

149. Landshultz, K. T., Jump, D. B., MacDougald, O. A., and Lane, M. D. 1994. Transcriptional control of the stearoyl-CoA desaturase I gene by polyunsaturated fatty acids. Biochem. Biophys. Res. Comm.. 200: 763-768.

150. Jones, B. H., M. A. Maher, W. J. Banz, M. B. Zemel, J. Wheten, P. J. Smith, and N. Moustaid. 1996. Adipose tissue stearoyl-CoA desaturase mRNA is increased by obesity and decreased by polyunsaturated fatty acids. Am. J. Physiol. 271: E44-E49.

151. Sessler, A. M., N. Kaur, J. P. Palta, and J. M. Ntambi. 1996. Regulation of stearoyl-CoA desaturase mRNA stability by polyunsaturated fatty acids in 3T3-L1 adipocytes. J. Biol. Chem. 271: 29854-29858.

152. Noguchi, T., K. Yamada, H. Inoue, T. Matsuda, and T. Tanaka. 1987. The L- and R-type isozymes of rat pyruvate kinase are produced from a single gene by use of different promoters. J. Biol. Chem. 262: 14366-14371.

153. Kanno, H., H. Fujii, and S. Miwa. 1992. Structural analysis of human pyruvate kinase L-gene and identification of the promoter activity in erythroid cell. Biochem. Biophys. Res. Com. 188: 516-523.

154. Tanaka, T., Y. Harano, F. Sue, and H. Morimura. 1967. Crystallization, characterization and metabolic regulation of 2 types of pyruvate kinase isolated from rat tissue. J. Biochem. (Tokyo) 62: 71-91.

155. Noguchi, T., H. Inoue, H. L. Chen, K. Matsubara, and T. Tanaka. 1983. Molecular cloning of DNA complementary to rat L-type pyruvate kinase mRNA. Nutritional and hormonal regulation of L-type pyruvate kinase mRNA content. J. Biol. Chem. 258: $15220-15223$.

156. Noguchi, T, H. Inoue, and T. Tanaka. 1982. Regulation of rat liver L-type pyruvate kinase mRNA by insulin and fructose. Eur. J. Biochem. 128: 583-588.

157. Noguchi, T., H. Inoue, and T. Tanaka. 1985. Transcriptional and posttranscriptional regulation of L-type pyruvate kinase in diabetic rat liver by insulin and dietary fructose. J. Biol. Chem. 260: 14393-14397. 
158. Decaux, J-. F., B. Antoine, and A. Kahn. 1989. Regulation of the expression of the L-type pyruvate kinase gene in adult rat hepatocytes in primary culture. J. Biol. Chem.

264: $11584-11590$.

159. El-Maghrabi, M. R., W. S. Haston, D. A. Flockhart, T. H. Claus, and S. J. Pilkis. 1980. Studies on the phosphorylation and dephosphorylation of L-type pyruvate kinase by the catalytic subunit of cAMP-dependent protein kinase. J. Biol. Chem. 255: 668-675.

160. Assimacopoulas, J. F., and B. Jeanrenaud. 1990. Insulin activates 6phosphofructo-2-kinase and pyruvate kinase in the liver. Indirect evidence for an action via a phosphatase. J. Biol. Chem. 265: 7202-7206.

161. Munnich, A., S. Lyonnet, D. Chauvet, E. Van Schaftingen, and A. Kahn. 1987. Differential effects of glucose and fructose on liver L-type pyruvate kinase gene expression. J. Biol. Chem. 262: 17065-17071.

162. Iritani, N., H. Fukuda, K. Tada, A. Itoh, and T. Noguchi. 1995. Diet differentially regulates glucokinase and L-type pyruvate kinase gene expression in rat liver. J. Nutr. 125: 2945-2952.

163. Yamada, K., T. Noguchi, T. Matsuda, M. Takenaka, P. Monaci, A. Nicosia, and T. Tanaka. 1990. Identification and characterization of hepatocyte-specific regulatory regions of the rat pyruvate kinase $\mathrm{L}$ gene. The synergistic effects of multiple elements. $J$. Biol. Chem. 265: 19885-19891.

164. Vaulont, S., N. Puzenat, F. Levrat, M. Cognet, A. Kahn, and M. Raymondjean. 1989. Proteins binding to the liver-specific pyruvate kinase gene promoter. A unique combination of known factors. J. Mol. Biol. 209: 205-219.

165. Liu, Z., K. S. Thompson, and H. C. Towle. 1993. Carbohydrate regulation of the rat L-type pyruvate kinase gene requires two nuclear factors: LF-A1 and a member of the c-myc family. J. Biol. Chem. 268: 12787-12795.

166. Bergot, M. O., M. J. Diaz-Guerra, N. Puzenat, M. Raymondjean, and A. Kahn. 1992. Cis-regulation of the L-type pyruvate kinase gene promoter by glucose, insulin and cyclic AMP. Nuc. Acid. Res. 20: 1871-1878.

167. Lefrancois-Martinez, A,-M., A. Matrinez, B. Antoine, M. Raymondjean, and A. Kahn. 1995. Upstream stimulatory factor proteins are major components of the glucose response complex of the L-type pyruvate kinase gene promoter. J. Biol. Chem. 270: 2640-2643.

168. Kaytor, E. N., H.-M. Shih, and H. C. Towle. 1997. Carbohydrate regulation of hepatic gene expression. Evidence against a role for the upstream stimulatory factor. $J$. Biol. Chem. 272: 7525-7531.

169. Nakshatri, H., and P. Bhat-Nakshatri. 1998. Multiple parameters determine the specificity of transcriptional response by nuclear receptors HNF-4, ARP-1, PPAR, RAR and RXR through common response elements. Nuc. Acid Res. 26: 2491-2499.

170. Yamada, K., and T. Noguchi. 1999. Nutrient and hormonal regulation of pyruvate kinase gene expression. Biochem J. 337: 1-11. 
171. Hertz, R., J. Magneheim, I. Berman, and J. Bar-Tana. 1998. Fatty acyl-CoA thioesters are ligands of hepatic nuclear factor-4 alpha. Nature. 392: 512-516.

172. Ohno, M., N. Kataoka, and Y. Shimura. 1990. A nuclear cap binding protein from HeLa cells. Nuc. Acids Res. 18: 6989-6995.

173. Izaurralde, E., J. Lewis, C. McGuigan, M. Jankowska, E. Darzynciewicz, and I. W. Mattaj. 1994. A nuclear cap binding complex involved in pre-mRNA splicing. Cell. 78: $657-668$.

174. Muhlrad, D., C. J. Decker, and R. Parker. 1994. Deadenylation of the unstable mRNA encoded by the yeast MFA2 gene leads to decapping followed by 5 ' to 3 ' digestion of the transcript. Genes Dev. 8: 855-866.

175. Muhlrad, D., C. J. Decker, and R. Parker. 1995. Turnover mechanisms of the stable yeast PGK1 mRNA. Mol. Cell. Biol. 15: 2145-2156.

176. Beelman, C. A., A. Stevens, G. Caponigro, T. E. LaGrandeur, L. Hatfield, D. M. Fortner, and R. Parker. 1996. An essential component of the decapping enzyme required for normal rates of mRNA turnover. Nature. 382: 642-646.

177. Larimer, F. W., C. L. Hsu, M. K. Maupin, and A. Stevens. 1990. Disruption of the gene XRN1, coding for a 5'-3' exoribonuclease, restricts yeast cell growth. Gene. 95: $85-90$

178. Hsu, C. L., and A. Stevens. 1993. Yeast cells lacking a 5' to 3' exoribonuclease 1 contain mRNA species that are poly(A) deficient and partially lack the 5' cap structure. Mol. Cell. Biol. 13: 4826-4835.

179. Coutts, M., A. Krowczynska and G. Brawerman. 1993. A 5' exoribonuclease from cytoplasmic extracts of mouse sarcoma 180 ascites cells. Biochim. Biophys. Acta. 1173: $57-62$.

180. Gallie, D. R., and R. Tanguay. 1994. Poly(A) binds to initiation factors and increases cap-dependent translation in vitro. J. Biol. Chem. 269: 17166-17173.

181. Jiang, Z. H., and J. Y. Wu. 1999. Alternative splicing and programmed cell death. Proc. Soc. Exp. Biol. Med. 220: 64-72.

182. Grabowski, P. J. 1998. Splicing regulation in neurons: Tinkering with cellspecific control. Cell. 92: 709-712.

183. Hodges, D., and S. I. Bernstein. 1994. Genetic and biochemical analysis of alternative splicing. Adv. Genet. 31: 207-281.

184. Steinmann-Zwicky, M., H. Amrein, and R. Nothiger. 1990. Genetic control of sex determination in Drosophila. Adv. Genet. 27: 189-237.

185. Bell, L. R., E. M. Maine, P. Schedl, and T. W. Cline. 1988. Sex-lethal and Drosophila sex determination switch gene exhibits sex-specific RNA splicing and sequence similarity to RNA binding proteins. Cell. 55: 1037-1046. 
186. Bell, L. R., J. I. Horabin, P. Schedl, and T. W. Cline. 1991. Positive autoregulation of Sex-lethal by alternative splicing maintains the female determined state in Drosophila. Cell. 65: 229-239.

187. Wang, J., and L. R. Bell. 1994. The sex-lethal amino terminus mediates cooperative interactions in RNA binding and is essential for splicing regulation. Genes Dev. 3: 1206-1216.

188. Boggs, R. T., P. Gregor, S. Idriss, J. M. Belote, and M. McKeown. 1987. Regulation of sexual differentiation in D. melanogaster via alternative splicing of RNA from the transformer gene. Cell. 50: 739-747.

189. Burtis, K. C., and B. S. Baker. 1989. Drosophila doublesex gene controls somatic sexual differentiation by producing alternatively spliced mRNAs encoding related sexspecific polypeptides. Cell. 56: 997-1010.

190. Clement, J. Q., L. Qian, N. Kaplinsky, and M. F. Wilkinson. 1999. The stability and fate of a spliced intron from vertebrate cells. RNA. 5: 206-220.

191. Decker, C. J., and R. Parker. 1994. Mechanism of mRNA degradation in eukaryotes. Trends Biochem. Sci. 19: 336-340.

192. Wickens, M. 1990. In the beginning is the end: Regulation of poly(A) addition and removal during early development. Trends Biochem. Sci. 15: 322-324.

193. Bernstein, P., and J. Ross. 1989. Poly (A), poly (A)-binding protein and the regulation of mRNA stability. Trends Biochem. Sci. 14: 373-377.

194. Shyu, A.-B., J. G. Belasco, and M. E. Greenberg. 1991. Two distinct destabilizing elements in the c-fos messenger trigger deadenylation as a first step in rapid mRNA decay. Genes and Dev. 5: 221-234.

195. Beelman, C. A., and R. Parker. 1995. Degradation of mRNA in eukaryotes. Cell. 81: $179-183$.

196. Edwalds-Gilbert, G., K. L. Veraldi, and C. Milcarek. 1997. Alternative poly(A) site selection in complex transcription units: Means to an end? Nuc. Acids Res. 25: 2547-2561.

197. Frayne, E. G., E. J. Leys, G. F. Crouse, A. G. Hook, and R. E. Kellems. 1984. Transcription of the mouse dihydrofolate reductase gene proceeds unabated through seven polyadenylation sites and terminates near a region of repeated DNA. Mol. Cell. Biol. 4: 2921-2924.

198. Kaufman, R. J., and P. A. Sharp. 1983. Growth-dependent expression of dihydrofolate reductase mRNA from modular cDNA reductase sequences. Mol. Cell. Biol. 3: 1598-1608.

199. Chandler, L. A., C. P. Ehretsmann, and S. Bourgeois. 1994. A novel mechanism of Ha-ras oncogene action: regulation of fibronectin mRNA levels by a nuclear posttranscriptional event. Mol. Cell. Biol. 14: 3085-3093. 
200. Ehretsmann, C. P., L. A. Chandler, and S. Bougeois. 1995. A nuclear posttranscriptional mechanism mediates the induction of fibronectin by glucocorticoids. Mol. Cell. Endo. 110: 185-194.

201. Meskini, R. E., F. Boudouresque, and L'H. Ouafik. 1997. Estrogen regulation of peptidylglycine $\alpha$-amidating monooxygenase messenger ribonucleic acid levels by a nuclear posttranscriptional event. Endocrinology. 138: 5256-5265.

202. Berezney, R., and D. S. Coffey. 1974. Identification of a nuclear protein matrix. Biochem. Biophys. Res. Comm. 60: 1410-1417.

203. Blencowe, B. J., J. A. Nickerson, R. Issner, S. Penman, and P. A. Sharp. 1994. Association of nuclear matrix antigens with exon-containing splicing complexes. J. Cell. Biol. 127: 593-607.

204. Huang, S., and D. L. Spector. 1996. Dynamic organization of pre-mRNA splicing factors. J. Cell. Biochem. 62: 191-197.

205. Mortillaro, M. J., B. J. Blencowe, X. Y. Wei, H. Nakayasu, L. Du, S. L. Warren, P. A. Sharp, and R. Berezney. 1996. A hyperphosphorylated form of the large subunit of RNA polymerase II is associated with splicing complexes and the nuclear matrix. Proc. Natl. Acad. Sci. USA. 93: 8253-8257.

206. Zhou, H., S. S. Manji, D. M. Findlay, T. J. Martin, J. K. Heath, and K. W. Ng. 1994. Novel action of retinoic acid. Stabilization of newly synthesized alkaline phosphatase transcripts. J. Biol. Chem. 269: 22433-22439.

207. Kiledjian, M., and T. Kadesh. 1991. Post-transcriptional regulation of the human liver/bone/kidney alkaline phosphatase gene. J. Biol. Chem. 266: 4207-4213.

208. Manji, S. S., K. W. Ng, T. J. Martin, and H. Zhou. 1998. Transcriptional and posttranscriptional regulation of osteopontin gene expression in preosteoblasts by retanoic acid. J.Cell. Phys. 176: 1-9.

209. Czaplinski, K., Y. M. Weng, and S. W. Peltz. 1995. Purification and characterization of the Upf1p: A factor involved in translation and mRNA turnover. RNA. 1: 610-623.

210. Cui, Y., K. W. Hagan, S. Zhang, and S. W. Peltz. 1995. Identification and characterization of genes that are required for the accelerated degradation of mRNAs containing a premature translational termination codon. Genes Dev. 9: 423-436.

211. Zhang, S., M. J. Ruiz-Echevarria, Y. Quan, and S. W. Peltz. 1995. Identification and characterization of a sequence motif involved in nonsense-mediated mRNA decay. Mol. Cell. Biol. 15: 2231-2244.

212. Maquat, L. E. 1995. When cells stop making sense: Effects of nonsense codons on RNA metabolism in vertebrate cells. RNA. 1: 453-465.

213. Barker, G. F., and K. Beemon. 1991. Nonsense codons within the rous sarcoma virus gag gene decrease the stability of unspliced viral mRNA. Mol. Cell. Biol. 11: 2760-2768. 
214. Barker, G. F. and K. Beeman. 1994. Rous sarcoma virus RNA stability requires an open reading frame in the gag gene and sequences downstream of the gag-pol junction. Mol. Cell. Biol. 14: 1986-1996.

215. Daar, I. O., and L. E. Maquat. 1988. Premature translation termination mediates triosephosphate isomerase mRNA degradation. Mol. Cell. Biol. 8: 802-813.

216. Cheng, J., M. Fogel-Petrovic, and L. E. Maquat. 1990. Translation to near the distal end of the penultimate exon is required for normal levels of spliced triosphosphate isomerase mRNA. Mol. Cell. Biol. 10: 5215-5225.

217. Cheng, J., and L. E. Maquat. 1993. Nonsense codons can reduce the abundance of nuclear mRNA without affecting the abundance of pre-mRNA or the half-life of cytoplasmic mRNA. Mol. Cell. Biol. 13: 1892-1902.

218. Zhang, J., X. Sun, Y. Qian, J. P. LaDuca, and L. E. Maquat. 1998. At least one intron is required for the nonsense-mediated decay of triosphosphate isomerase mRNA: A possible link between nuclear splicing and cytoplasmic translation. Mol. Cell. Biol. 18: $5272-5283$.

219. Nagy, E., and L. E. Maquat. 1998. A rule for termination-codon position within intron containing genes: When nonsense affects RNA abundance. TIBS. 23: 198-199.

220. Caceres, J. F., G. R. Scredaton, and A. R. Krainer. 1998. A specific subset of SR proteins shuttle continuously between the nucleus and the cytoplasm. Genes Dev. 12: $55-66$.

221. Pinol-Roma, S., and G. Dreyfuss. 1992. Shuttling of pre-mRNA binding proteins between nucleus and cytoplasm. Nature. 355: 730-732.

222. McKusik, V. A. (with the assistance of C. A. Francomano, S. E. Antonarakis, and P. L. Pearson). 1994. Mendelian inheritance in man: A catalog of human genes and genetic disorders. John Hopkins University Press, Baltimore, MD. (Web site http:/www.ncbi.nlm.nih.gov/Omim/).

223. Lew, J. E., S. Enomoto, and J. Berman. 1998. Telomere length regulation and telomeric chromatin require the nonsense-mediated mRNA decay pathway. Mol. Cell. Biol. 18: 6121-6130.

224. Aziz, N., and H. N. Munro. 1987. Iron regulates ferritin mRNA translation through a segment of its 5' untranslated region. Proc. Natl. Acad. Sci. USA. 84: 8478-8482.

225. Casey, J. L., M. W. Hentze, D. M. Koeller, S. W. Caughman, T. A. Rouault, R. D. Klausner, and J. B. Harford. 1988. Iron-responsive elements: Regulatory RNA sequences that control mRNA levels and translation. Science. 240: 924-928.

226. Leibold, E. A., and H. N. Munro. 1988. Cytoplasmic protein binds in vitro to a highly conserved sequence in the 5' untranslated region of ferritin heavy-and lightsubunit mRNAs. Proc. Natl. Acad. Sci. USA. 85: 2171-2175.

227. Constable, A., S. Quick, N. K. Gray, and M. W. Hentze. 1992. Modulation of the RNA-binding activity of a regulator protein by iron in vitro: switching between enzymatic and genetic function. Proc. Natl. Acad. Sci. USA. 89: 4554-4558. 
228. Haile, D. J., M. W. Hentze, T. A. Roualt, J. B. Harford, and R. D. Klausner. 1989. Regulation of interaction of the iron-responsive element binding protein with ironresponsive elements. Mol. Cell. Biol. 9: 5055-5061.

229. Hentze, M. W., T. A. Roualt, J. B. Harford, and R. D. Klausner. 1989. Oxidationreduction and the molecular mechanism of a regulatory RNA-protein interaction.

Science. 244: 357-359.

230. Binder, R., J. A. Horowitz, J. P. Basilion, D. M. Koeller, R. D. Klausner, and J. B. Harford. 1994. Evidence that the pathway of transferrin receptor mRNA degradation involves an endonucleolytic cleavage within the 3'-UTR and does not involve poly(A)tail shortening. EMBO J. 13: 1969-1980.

231. Berstein, P. L., D. J. Herrick, R. D. Prokipcak, and J. Ross. 1992. Control of c-myc mRNA half-life in vitro by a protein capable of binding to a coding region stability determinant. Genes \& Dev. 6: 642-654.

232. Dompenciel, R. E., V. R. Garnepudi, and D. R. Schoenberg. 1995. Purification and characterization of an estrogen-regulated Xenopus liver polysomal nuclease involved in selective destabilization of albumin mRNA. J. Biol. Chem. 270: 6108-6118.

233. Kabnick, K. S., and D. E. Housman. 1988. Determinants that contribute to cytoplasmic stability of human c-fos and $\beta$-globin mRNAs are located at several sites in each mRNA. Mol. Cell. Biol. 8: 3244-3250.

234. Bonnieu, A., P. Roux, L. Marty, P. Jeanteur, and M. Piechaczyk. 1990. AUUUA motifs are dispensable for rapid degradation of the mouse c-myc mRNA. Oncogene. 5: $1585-1588$.

235. Shyu, A.-B., M. E. Greenberg, and J. G. Belasco. 1989. The c-fos transcript is targeted for rapid decay by two distinct mRNA degradation pathways. Genes Dev. 3: $60-72$.

236. Chen, C.-Y. A., Y. You, and A.-B. Shyu. 1992. Two cellular proteins bind specifically to a purine-rich sequence necessary for the destabilization function of a c-fos protein-coding region determinant of mRNA instability. Mol.Cell. Biol. 12: 5748-5757.

237. Wisdom, R., and W. Lee. 1991. The protein-coding region of c-myc mRNA contains a sequence that specifies rapid mRNA turnover and induction by protein synthesis inhibitors. Genes Dev. 5: 232-243.

238. Prokipcak, R. D., D. J. Herrick, and J. Ross. 1994. Purification and properties of a protein that binds to the $\mathrm{C}$-terminal coding region of human c-myc mRNA. J. Biol.

Chem. 269: 9261-9269.

239. Chen, C.-Y. A., and A.-B. Shyu. 1994. Selective degradation of early-response gene mRNAs: Functional analyses of sequence features of the AU-rich elements. Mol. Cell. Biol. 14: 8471-8482.

240. Chen, C.-Y. A., T.-M. Chen, and A.-B. Shyu. 1994. Interplay of two functionally and structurally distinct domains of the c-fos AU-rich element specifies its mRNAdestabilizing function. Mol. Cell. Biol. 14: 416-426. 
241. Lee, W. M. F., C. Lin, and T. Curran. 1988. Activation of the transforming potential of the human fos proto-oncogene requires message stabilization and results in increased amounts of partially modified fos protein. Mol. Cell. Biol. 8: 5521-5527.

242. Wilson, G. M., and G. Brewer. 1999. The search for trans-acting factors controlling messenger RNA decay. Prog. Nucleic Acid Res. Mol. Biol. 62: 257-291.

243. Shaw, G., and R. Kamen. 1986. A conserved AU sequence from the 3' untranslated region of GM-CSF mRNA mediates selective mRNA degradation. Cell. 46: $659-667$.

244. Laird-Offringa, I. A. 1992. What determines the instability of c-myc protooncogene mRNA? Bioessays. 14: 119-124.

245. Peppel, K., J. M. Vinci, and C. Baglioni. 1991. The AU-rich sequences in the 3' untranslated region mediate the increased turnover of interferon mRNA induced by glucocorticoids. J. Exp. Med. 173: 349-355.

246. Chen, C.-Y., and A.-B. Shyu. 1995. AU-rich elements: characterization and importance in mRNA degradation. Trends Biochem. Sci. 20: 465-470. 
CHAPTER 2. POLYUNSATURATED FATTY ACIDS INHIBIT THE EXPRESSION OF THE GLUCOSE-6-PHOSPHATE DEHYDROGENASE GENE IN PRIMARY RAT HEPATOCYTES BY A NUCLEAR POSTTRANSCRIPTIONAL MECHANISM

*This chapter has been reproduced with permission from the Journal of Lipid Research. Stabile, L. P., S. A. Klautky, S. M. Minor, and L. M. Salati. 1998. J. Lipid Res. 39: 1951-1963.

(Fig. 3A was done entirely by S. Klautky)

\section{Introduction}

Glucose-6-phosphate dehydrogenase (G6PD, EC 1.1.1.49) is the rate-determining enzyme of the pentose phosphate pathway, which provides a source of NADPH for many biosynthetic reductive reactions and ribose-5-phosphate for nucleic acid synthesis. The reaction catalyzed by G6PD provides $50-75 \%$ of NADPH needed for fatty acid biosynthesis in rat liver (1). All cell types contain G6PD activity; however, regulation of the enzyme only occurs in liver and adipose tissue (2,3). G6PD activity in the regulated tissues correlates with the rate of fatty acid biosynthesis and thus it is a member of the lipogenic family of enzymes. Like other lipogenic enzymes, G6PD is regulated by both nutritional and hormonal stimuli. For example, when rodents are fed a highcarbohydrate, low-fat diet after a period of starvation, G6PD activity increases 10- to 16fold $(3,4)$. Conversely, G6PD activity decreases $80 \%$ in mice and rats consuming a highfat diet versus those fed a low-fat diet $(5,6)$. Hormonal aspects of G6PD regulation include a decrease in G6PD activity in diabetic and adrenalectomized rats that is restored by hormone replacement (7). In addition, in primary rat hepatocytes, insulin increases G6PD activity in a dose-dependent manner (8). Curiously, treatment of rat hepatocytes with dexamethasone does not change G6PD activity (8), suggesting that the effect of adrenalectomy is indirect.

Regulation of G6PD by nutritional factors occurs at a nuclear posttranscriptional step. In this regard, the $80 \%$ decrease in G6PD mRNA amount is accompanied by an $80 \%$ decrease in nuclear precursor mRNA (pre-mRNA) for G6PD in the nucleus.

Similarly, the increase in G6PD mRNA due to refeeding starved mice is accompanied by comparable increases in the amount of G6PD pre-mRNA (9). Nevertheless, the rate of transcription of the G6PD gene is not altered despite large changes in the abundance of pre-mRNA (5). Further characterization of the regulation of the G6PD gene indicates that transport of the mRNA from the nucleus to the cytoplasm and splicing of the primary 
transcript are not regulated steps in its expression. Thus, regulation of the amount of G6PD pre-mRNA is probably occurring very soon after transcription of the primary transcript.

The nuclear posttranscriptional regulation of G6PD contrasts with the large changes in transcriptional activity observed with other lipogenic enzymes, such as fatty acid synthase and stearoyl-CoA desaturase I $(10,11)$. Yet, changes in pre-mRNA stability may be a common mechanism for all these genes. In this regard, S14, a protein of unknown function that is thought to be involved in lipogenesis, undergoes large transcriptional changes in response to dietary carbohydrate and polyunsaturated fatty acids (10). In addition to these transcriptional changes, dietary carbohydrate enhances the accumulation of processing intermediates of S14 pre-mRNA $(12,13)$ suggesting that enhanced expression of the S14 gene involves increased efficiency of the processing of its pre-mRNA.

The goal of these studies is to further analyze the mechanism by which polyunsaturated fat inhibits G6PD expression. Studies in the intact animal are hampered by an inability to distinguish a direct effect of fatty acids on expression of a gene from an indirect effect due to changes in the hormonal environment of the animal. Cell culture models provide a mechanism to control the hormonal environment while examining the action of fatty acids. Incubation of primary rat hepatocytes with polyunsaturated fatty acids mimics the effect of dietary fat on the transcription of S14 and pyruvate kinase $(14,15)$. The ability of this cell model to mimic posttranscriptional actions of polyunsaturated fatty acids has not been described. In this paper we demonstrate that the action of polyunsaturated fatty acids on G6PD pre-mRNA accumulation in rat hepatocytes mimics the action of dietary fat in the intact animal both qualitatively and quantitatively.

\section{Materials and methods}

Materials. Williams' medium E (Gibco-BRL), newborn calf serum (GibcoBRL), fatty acids (Nu-Chek Prep), collagenase H (EC 3.4.99.5, Boehringer Mannheim), insulin (Eli Lilly Research Laboratories), Matrigel (Collaborative Biomedical Research), Percoll (Sigma), pBluescriptKS+ (Stratagene), RNase-free DNase I (Gibco-BRL), and RPA II kit (Ambion) were obtained from the indicated sources. Bovine serum albumin fraction V (fatty acid-free), $\alpha-\left[{ }^{32} \mathrm{P}\right] \mathrm{UTP}, 3000 \mathrm{Ci} / \mathrm{mmol}$ and $\alpha-\left[{ }^{32} \mathrm{P}\right] \mathrm{dCTP}, 3000 \mathrm{Ci} / \mathrm{mmol}$ were from ICN Biochemicals. Other chemicals were from Fisher Biotech or of the highest purity commercially available. Rats were purchased from Harlan Laboratories 
(Indianapolis, IN). Standard chow diet was Harlan Teklad and the fat-free, high-glucose diet was from Purina Mills. Rat genomic DNA was obtained from Clontech.

Animal care and cell culture. Male Sprague-Dawley rats (approximately $200 \mathrm{~g}$ ) fed on a standard chow diet were used for all experiments. Rats used for dietary experiments were starved for $24 \mathrm{~h}$ or starved for $24 \mathrm{~h}$ and then refed a high-glucose, fatfree diet (5) for $15 \mathrm{~h}$ prior to sacrifice. Rats were starved for $48 \mathrm{~h}$ prior to use as hepatocyte donors.

Hepatocytes were isolated by a modification of the technique of Seglen (16). The livers were perfused with $350 \mathrm{ml}$ of calcium-free buffer $(0.14 \mathrm{M} \mathrm{NaCl}, 6.7 \mathrm{mM} \mathrm{KCl}, 0.02$ M HEPES, pH 7.4, $25 \mathrm{mM}$ glucose, $250 \mu \mathrm{M}$ EGTA) at $40 \mathrm{ml} / \mathrm{min}$ followed by $100 \mathrm{ml}$ of a buffer containing collagenase $(67 \mathrm{mM} \mathrm{NaCl}, 6.7 \mathrm{mM} \mathrm{KCl}, 0.1 \mathrm{M}$ HEPES, $\mathrm{pH}$ 7.4, 6 $\mathrm{mM} \mathrm{CaCl} 2 \cdot 2 \mathrm{H}_{2} \mathrm{O}, 25 \mathrm{mM}$ glucose, $1 \mathrm{mg} / \mathrm{ml}$ collagenase $\mathrm{H}, 0.05 \mathrm{mg} / \mathrm{ml}$ trypsin inhibitor). The hepatocytes were then teased from the capsid of the liver and washed into cold, welloxygenated Williams' medium E supplemented with 23 mM HEPES, pH 7.4, 26 mM sodium bicarbonate, penicillin $(100 \mathrm{U} / \mathrm{ml})$, streptomycin $(100 \mu \mathrm{g} / \mathrm{ml})$, and gentamicin $(50$ $\mu \mathrm{g} / \mathrm{ml})$. Glucose was added to a final concentration of $27 \mathrm{mM}$. The cells were spun through a Percoll gradient for $10 \mathrm{~min}$ at $50 \mathrm{X} \mathrm{g}$ to remove non-parenchymal cells (17). Hepatocytes $\left(4 \times 10^{6}\right)$ were placed in $60 \mathrm{~mm}$ Primaria dishes preincubated $\left(37^{\circ} \mathrm{C}, 5 \%\right.$ $\mathrm{CO}_{2}$ ) with medium containing $5 \%$ newborn calf serum. Cell viability in all experiments was $90 \%$ or greater as estimated by Trypan Blue $(0.4 \%)$ exclusion. After $4 \mathrm{~h}$, the medium was replaced with serum-free medium. After an additional $16 \mathrm{~h}$ of incubation, the medium was replaced with medium containing the treatments indicated in the figure legends and a Matrigel overlay $(0.3 \mathrm{mg} / \mathrm{ml})$ (18). Subsequently, the medium was changed every 12 to $24 \mathrm{~h}$ to one of the same composition but without Matrigel. The hepatocytes were maintained in a humidified chamber at $37 \cdot \mathrm{C}$ in $5 \% \mathrm{CO}_{2} / 95 \%$ air. Fatty acids were bound to bovine serum albumin (19). The fatty acid (4 mM)-albumin (1 mM) stocks contained butylated hydroxytoluene $(0.01 \%)$ and Williams' medium E contains $\alpha$ tocopherol phosphate, disodium $(10 \mu \mathrm{g} / \mathrm{L})$ to minimize oxidation of fatty acids.

Thiobarbituric acid (TBA) assay. The TBA assay was performed as described by Hostmark and Lystad (20) with minor modifications. Phenol red typically found in cell culture medium interfered with this assay, thus for these experiments Williams' medium E without phenol red was used. To measure TBA reactive material in the cell culture medium, $4.5 \mathrm{ml}$ of a $0.4 \%$ TBA solution in water was mixed with $0.4 \mathrm{ml}$ of medium from hepatocytes incubated with various fatty acids. Glacial acetic acid (100 $\mu 1)$ containing $0.5 \%$ butylated hydroxytoluene was added, the mixture was vortexed vigorously, and heated to $100 \bullet \mathrm{C}$ for $20 \mathrm{~min}$. Insoluble material was removed by 
extraction with $3 \mathrm{ml}$ of chloroform/methanol $(5: 1, \mathrm{v} / \mathrm{v})$. The absorbance at $532 \mathrm{~nm}$ of the aqueous phase was determined. The amount of TBA reactive material was calculated using the molar extinction coefficient $\left(156,000 \mathrm{M}^{-1} \mathrm{~cm}^{-1}\right)$.

Measurement of G6PD activity. Hepatocytes were prepared as described above and incubated $72 \mathrm{~h}$ with the treatments indicated in the figure legends. Cells were washed one time with phosphate-buffered saline, and lysed by three cycles of freezing

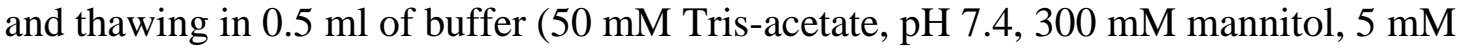
dithiothreitol) per $60 \mathrm{~mm}$ Primaria plate. The lysates were centrifuged for $10 \mathrm{~min}$ at $11,000 \times \mathrm{g}$. Supernatants were used for measurement of G6PD enzyme activity (8) and total protein concentration (21). G6PD activity is reported as $\mathrm{mU} / \mathrm{mg}$ protein in the cell supernatant; $1 \mathrm{mU}$ equals $1 \mathrm{nmol}$ of NADPH produced per minute. Statistical analysis was with ANOVA and t-test.

Isolation of total RNA and Northern analysis. Total RNA from 2-3 plates per treatment was isolated by the method of Chomczynski and Sacchi (22). The denatured cell mix was forced through an 18 gauge syringe two to three times to sheer genomic DNA. Quantitation of RNA using Northern analysis was done as previously described (5).

Isolation of nuclear RNA. Nuclei from hepatocytes were isolated by a modification of the method of Leppard and Shenk (23). Hepatocytes and medium from 15-20 plates per treatment were collected into $50 \mathrm{ml}$ centrifuge tubes and the cells pelleted in a Beckman JS 4.2 rotor at $490 \mathrm{rpm}(50 \mathrm{X} \mathrm{g})$ for $5 \mathrm{~min}$. The cell pellet was washed two times with ice-cold phosphate-buffered saline, then homogenized in $3 \mathrm{ml}$ of isotonic buffer (10 mM Tris, $\mathrm{pH} 7.5,150 \mathrm{mM} \mathrm{NaCl}, 1.5 \mathrm{mM} \mathrm{MgCl}_{2}, 175 \mu \mathrm{g}$ phenylmethylsulfonyl fluoride/ml, $0.6 \%$ nonidet NP-40) by 12 strokes in a Dounce homogenizer using a tight-fitting pestle. The homogenate was incubated on ice for $5 \mathrm{~min}$. Nuclei were pelleted in a Beckman JS 4.2 rotor at $2000 \mathrm{rpm}(800 \mathrm{X} \mathrm{g})$ for $5 \mathrm{~min}$ at 4 • C and washed one time with $2 \mathrm{ml}$ of isotonic buffer without nonidet NP-40. RNA was purified from the final nuclear pellet by the method of Chomczynski and Sacchi (22); 3 $\mathrm{ml}$ of denaturing solution were used per nuclear pellet. The denatured nuclear RNA mix was forced through an 18 gauge syringe five times to sheer genomic DNA. In experiments using intact rat liver (Fig. 2), nuclei were purified through a $2 \mathrm{M}$ sucrose cushion as previously described (5) prior to isolation of nuclear RNA.

Nuclear run-on assays and DNA probes. Nuclei were isolated from hepatocytes using the method of Leppard and Shenk (23) as described above. In one experiment, nuclei were isolated by the method of Milsted (24). The same results were obtained in the run-on assays regardless of the method of nuclei preparation. The final nuclear pellet 
was resuspended and washed into nuclei storage buffer (50 mM HEPES, $\mathrm{pH}$ 7.4, $75 \mathrm{mM}$ $\mathrm{NaCl}, 0.1 \mathrm{mM}$ EDTA, $5 \mathrm{mM}$ dithiothreitol, $0.12 \mathrm{mM}$ phenylmethlysulfonyl fluoride, and $50 \%$ glycerol). Nuclei were purified from intact rat liver by centrifugation through a $2 \mathrm{M}$ sucrose cushion as previously described (5). The nuclei were stored at $-70 \bullet \mathrm{C}$ in $100 \mu \mathrm{l}$ of storage buffer prior to use in a nuclear run-on assay.

The nuclear run-on assay was performed on both hepatocyte and liver nuclei as previously described $(25,5)$. DNA used as probes were obtained as follows: mouse G6PD cDNA (pMZ3) from M. Zollo (26), rat phosphoenolpyruvate carboxykinase (pPCK10) cDNA from R. Hanson (27), mouse albumin cDNA (pmalb-2) from S. Tilghman (28), rat glyceraldehyde-3-phosphate dehydrogenase (GAPDH) cDNA (pRGAPDH1) from F. Rottman (29), mouse stearoyl-CoA desaturase I cDNA (pC3) from J. Ntambi (30), rat fatty acid synthase cDNA (pFAS-17) from S. Clarke (31). The G6PD cDNA probe is the BamHI (exon 2) to XbaI (exon 13) fragment of pMZ3 which was subcloned into pBluescriptKS+ thereby eliminating exon 1 which is GC-rich, and most of exon 13 which is dissimilar between rats and mice.

Probe design for ribonuclease protection assay (RPA). Two probes were designed for use in the ribonuclease protection assay (Fig. 1). The first probe, intron 3exon 4, was derived from PCR amplification of rat genomic DNA using primer 1, 5' GGGGTACCGGTAATATCTCTACACTACCCCCCAATC-3' and primer 2, 5' GGAATTCGCTCACTCTGTTTGCGGATGTC-3’. Primer 1 contained a KpnI restriction site at its 5' end (underline) for subcloning of the PCR amplified product into pBluescriptKS+ and the remaining sequence is from intron 3. Primer 2 contained an EcoRI site at its 5' end (underline) and the G6PD sequence begins $11 \mathrm{nt}$ from the end of exon 4. The second probe, exon 9-intron 9, was derived from PCR amplification of rat genomic DNA using primer 3, 5'-GGGGTACCCAGAGGTGGAAACTGACAAC GTG3' and primer 4, 5'-GGAATTCTAGCCCTCCTTCTCCAGCATTC-3'. The same restriction sites are present as for the previous probe. Primer 3 contained exon 9-specific sequences beginning $22 \mathrm{nt} 3$ ' from the start of exon 9. Primer 4 contained intron 9specific sequences.

The DNA fragments, following PCR amplification, were subcloned into pBluescriptKS+ and the authenticity of these sequences was verified by sequencing. The subclones were linearized with HindIII and used in an in vitro transcription reaction. The transcripts produced with $\mathrm{T} 7$ polymerase were designed to be larger than the protected fragments so that incompletely digested probe could be differentiated from the target signal in the ribonuclease protection assay. As a control for strand-specific hybridization, 


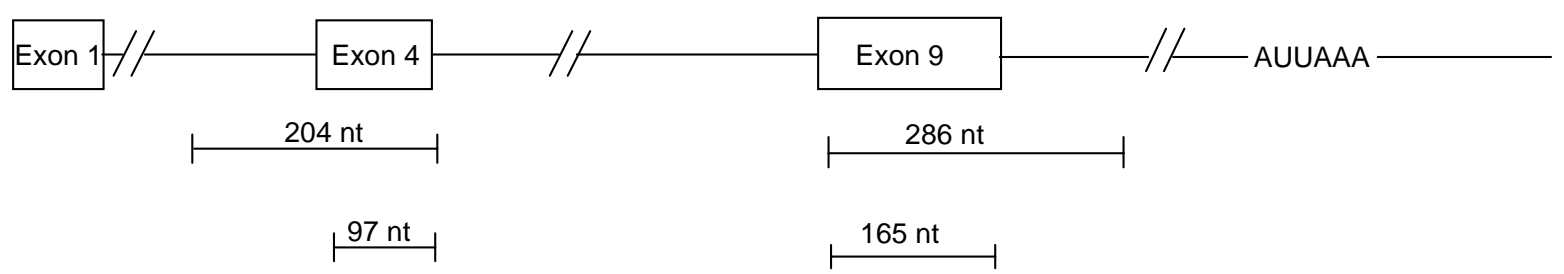

Figure 1. Probes and predicted fragments for the ribonuclease protection assay. The top line represents a simplified diagram of the G6PD primary transcript showing 3 of the genes 13 exons. The lower lines represent G6PD specific mRNA fragments that are detected in the ribonuclease protection assays by specific G6PD probes. Two probes were designed to hybridize across intron-exon boundaries of target mRNA such that premRNA with and without introns could be detected in the assay. The first probe (intron 3exon 4) was designed to cross the intron 3 - exon 4 boundary and protects a $204 \mathrm{nt}$ fragment of pre-mRNA containing intron 3 . In addition this probe recognizes processed transcripts ( $97 \mathrm{nt}$ fragment) that have undergone splicing of intron 3 . The second probe (exon 9 - intron 9) spans the exon 9- intron 9 boundary. It protects a $286 \mathrm{nt}$ fragment of the transcript containing intron 9, and nuclear mRNA without intron 9 (165 nt fragment). 
RNA probes were also generated from the $\mathrm{T} 3$ promoter in $\mathrm{pBluescriptKS}+$ which resulted in a probe whose sequence was identical to G6PD mRNA (sense probe) and thus should not hybridize to cellular RNAs. No bands were detected in a ribonuclease protection assay using these probes (data not shown) therefore only T7-generated probes could hybridize to G6PD mRNA.

Ribonuclease protection assay. Antisense RNA probes were synthesized in an in vitro transcription reaction. Template DNA $(0.5 \mu \mathrm{g})$ was added to a reaction mixture containing $40 \mathrm{mM}$ Tris- $\mathrm{HCl}$, pH 7.5, $6 \mathrm{mM} \mathrm{MgCl} 2,2 \mathrm{mM}$ spermidine, $10 \mathrm{mM} \mathrm{NaCl}, 10$ $\mathrm{mM}$ dithiothreitol, $14 \mathrm{U}$ RNasin, $400 \mu \mathrm{M}$ each ATP, CTP, and GTP, $20 \mu \mathrm{M}$ cold UTP, $20 \mathrm{U}$ T7 RNA polymerase and $50 \mu \mathrm{Ci} \alpha-\left[{ }^{32} \mathrm{P}\right] \mathrm{UTP}$ (sp. act. $3000 \mathrm{Ci} / \mathrm{mmol}$ ) and incubated at $37 \cdot \mathrm{C}$ for $1 \mathrm{~h}$. RNase-free DNase I (100 U) was added and the reaction was incubated for $15 \mathrm{~min}$ at $37 \cdot \mathrm{C}$. The probes were purified in a $5 \%$ denaturing polyacrylamide gel and eluted overnight at $37 \cdot \mathrm{C}$ in $0.5 \mathrm{M}$ ammonium acetate, $1 \mathrm{mM}$ EDTA, and $0.2 \%$ SDS.

Ribonuclease protection assays were performed using the RPA II kit. Nuclear or total RNA ( 25 or $30 \mu \mathrm{g}$ ) was hybridized to $2 \times 10^{4} \mathrm{cpm}$ of ${ }^{32} \mathrm{P}$-labeled RNA in $20 \mu \mathrm{l}$ of hybridization solution ( $80 \%$ deionized formamide, $100 \mathrm{mM}$ sodium citrate, $\mathrm{pH}$ 6.4, 300 $\mathrm{mM}$ sodium acetate, $\mathrm{pH}$ 6.4, $1 \mathrm{mM}$ EDTA) at 45• C for $16 \mathrm{~h}$. Following hybridization, the solution was treated with a mixture of $0.5 \mathrm{U}$ RNase $\mathrm{A}$ and $20 \mathrm{U}$ RNase $\mathrm{T}_{1}$ for $30 \mathrm{~min}$ at $37 \cdot \mathrm{C}$. The resulting hybridization products protected from RNase digestion were separated in a 5\% denaturing polyacrylamide gel. The gel was dried and placed in a storage phosphor cassette for 1 to $3 \mathrm{~d}$. Images were quantified using ImageQuaNT software by Molecular Dynamics.

\section{Results}

Effect of starvation and refeeding on transcriptional activity of G6PD in rat.

Refeeding starved mice results in a 15-fold or more increase in G6PD mRNA, while the addition of polyunsaturated fat to a high-carbohydrate diet results in an $80 \%$ decrease in G6PD mRNA (5). In mice, dietary-induced changes in G6PD mRNA accumulation are caused by changes in the amount of pre-mRNA for G6PD via a posttranscriptional regulatory mechanism in the nucleus (9). Mouse hepatocytes in primary culture do not provide a hormonally-responsive system to study the molecular basis for this regulation (32; S. A. Klautky and L. M. Salati, unpublished). In contrast, G6PD activity is regulated by both insulin and fatty acids in rat hepatocytes in primary culture (8). Prior to choosing rat hepatocytes as a model to further define the molecular basis of G6PD regulation, we verified that regulation of G6PD expression by diet 
occurred by a posttranscriptional regulatory mechanism as observed in mice. No difference in G6PD transcription was observed in rats that were starved versus starved and then refed a high-carbohydrate diet (Fig. 2A). In contrast, refeeding increased the transcription of the stearoyl-CoA desaturase I (pC3) and fatty acid synthase (FAS) genes, by 85 - and 77-fold, respectively, and transcription of the phosphoenolpyruvate carboxykinase gene was inhibited by $93 \%$. Thus, the expected transcriptional changes were observed for genes regulated at the level of transcription while regulation of G6PD expression is occurring primarily at a posttranscriptional step in rats as in mice.

We next measured nuclear pre-mRNA for the G6PD gene using a ribonuclease protection assay and probes that hybridized across two different intron/exon boundaries in the G6PD primary transcript (Fig. 1). Because the G6PD gene contains 13 exons and the primary transcript is $18 \mathrm{~kb}$ in length it cannot be examined in total. The probes represent discrete locations within the primary transcript and permit quantitative analysis of the amount of pre-mRNA. The intron 3-exon 4 probe hybridized across a 3'-splice site and the exon 9-intron 9 probe hybridized across a 5'-splice site. RNase digestion of each hybrid of probe and target RNA resulted in two protected fragments. These included RNA containing the intron and RNA from which the intron had been spliced. The 204 and $286 \mathrm{nt}$ bands represented pre-mRNAs that contained introns 3 and 9, respectively (Fig. 2B). The 97 and 165 nt bands represented pre-mRNAs from which introns 3 and 9, respectively, had been spliced. Protected fragments representing only intron 9 (121 nt) and the exon 4 and intron 3 lariat $(33 ; 133 n t)$ also appeared to be detected. The relative intensity of these fragments was much less than the bands containing exon sequences. This may reflect that introns, once spliced, were rapidly degraded in the nucleus. In some experiments (Fig. 2B and 6A) a doublet in the intron 3-exon 4 band was observed. The sequence at one end of the intron 3-exon 4 probe is AU-rich which may allow local denaturation of the hybrid making it susceptible to ribonuclease digestion. This doublet disappeared when the RNase digestion conditions were altered to use either $50 \%$ less RNase A and RNase T1 or only RNase T1 (data not shown) confirming that the doublet was due to "breathing" at the ends of the hybrid.

To determine if the abundance of G6PD pre-mRNA was regulated in the rat, RNA was isolated from the nuclei of the same rats as were used for transcriptional measurements (Fig. 2B). In the livers of rats that had been starved for $24 \mathrm{~h}$, G6PD premRNA was barely detectable. G6PD pre-mRNA was 18.9- and 19.5-fold higher as detected by the exon 9-intron 9 and intron 3-exon 4 protected fragments, respectively, in the livers of rats that had been refed a high-carbohydrate, low-fat diet relative to the rats 
B

A

Figure 2. Effect of starvation and refeeding on expression of G6PD in the rat. (A) Nuclei were isolated from the pooled livers of 2 rats that had been starved for $15 \mathrm{~h}$ or from the livers of 2 rats that had been starved for $24 \mathrm{~h}$ followed by refeeding a highglucose, low-fat diet for $15 \mathrm{~h}$. Nuclear run-on assays were performed as described in "Materials and Methods." Hybridization to the probes was quantified using ImageQuaNT. Quantitation of the hybridization signals for G6PD, vector (pBluescriptKS+), and B-actin are listed below each strip. The values are the integration units (x 10-2) from ImageQuaNT. cDNA clones for fatty acid synthase (FAS) and stearoyl-CoA desaturase I (pC3) were used as positive controls to show transcriptional activation due to refeeding a high-carbohydrate diet. A PEPCK cDNA probe was used as a negative control to show transcriptional inhibition by refeeding. $\beta$-actin, glyceraldehyde-3-phosphate-dehydrogenase (GAPDH), albumin, and phosphoenolpyruvate carboxykinase (PEPCK) cDNA probes were used as controls for selectivity of the response. The assay was done in duplicate with identical results. (B) Nuclear RNA was isolated from the same batch of nuclei as described above. G6PD nuclear RNA (25 $\mu \mathrm{g})$ was analyzed using a ribonuclease protection assay and 2 G6PD specific probes. $M=$ RNA Century marker (Ambion), $U=$ Undigested probe (hybridization of probes to $25 \mu \mathrm{g}$ yeast RNA without subsequent RNase digestion), $\mathrm{D}=$ Digested probe (hybridization to $25 \mu \mathrm{g}$ yeast RNA followed by RNase digestion), $\mathrm{S}=$ nuclear RNA isolated from livers of starved rats, $\mathrm{R}=$ nuclear RNA isolated from livers of refed rats, open arrow $=$ exon 4 and intron 3 lariat protected fragment, closed arrow= intron 9 protected fragment. (C) Quantitation of the signals was done using ImageQuaNT. The values shown in the table are the integration units (x 10-2) and the calculated fold-increase due to refeeding. 
that had been starved. Pre-mRNAs in which introns 9 and 3 had been spliced, were increased 17.3- and 18.9-fold, respectively. The changes in amount of exon-only protected fragments were similar to the full-length protected fragments, suggesting that splicing was not a regulated step. Thus, refeeding starved rats increased the abundance of pre-mRNAs for G6PD in the nucleus in the absence of an observable change in transcriptional activity of the gene. Thus, the regulated step mediating the effects of starvation and refeeding on G6PD expression in the rat appears to be the same as that in the mouse. Rat hepatocytes should provide a useful model system for further characterizing the molecular mechanisms involved in regulation of G6PD expression.

Regulation of enzyme activity and mRNA accumulation by glucose, insulin, and fatty acids in rat hepatocytes in primary culture.

G6PD activity has been shown to be maximally increased by insulin, and this increase is attenuated by arachidonic acid in rat hepatocytes (8). To determine whether fatty acids regulated G6PD at a pretranslational step, mRNA accumulation and enzyme activity were measured in rat hepatocytes incubated with insulin or insulin and arachidonic acid. Incubation with insulin $(0.1 \mu \mathrm{M}$ or $1 \mu \mathrm{M})$ for $72 \mathrm{~h}$ resulted in a 5.7- to 5.9-fold increase in G6PD activity (Fig. 3A). Coincubation with arachidonic acid significantly inhibited $(P<0.05)$ the insulin dependent increase in G6PD activity by 56\% and $51 \%$, for $0.1 \mu \mathrm{M}$ and $1 \mu \mathrm{M}$ insulin, respectively. These results are consistent with a previous report (8). G6PD mRNA accumulation was examined using Northern analysis. The increase in G6PD activity in hepatocytes incubated with insulin was accompanied by a 4.2-fold increase in mRNA for G6PD (Figs. 3B \& 3C). This increase in G6PD expression was not exclusively due to the addition of insulin. In this regard, incubation with $27 \mathrm{mM}$ glucose in the medium for $48 \mathrm{~h}$ resulted in a $2.9 \pm 0.5$-fold increase in G6PD mRNA $(n=6)$; the addition of insulin $(0.1 \mu \mathrm{M})$ resulted in a further increase in G6PD mRNA of $1.6 \pm 0.06$-fold ( $\mathrm{n}=6$; Fig. 3B). Incubation with $250 \mu \mathrm{M}$ arachidonic acid or eicosapentaenoic acid decreased the amount of G6PD mRNA by approximately $50 \%$ relative to hepatocytes incubated with glucose and insulin (Fig. 3C). The concentration of arachidonic acid used in these experiments has previously been shown to maximally inhibit G6PD expression (8). Arachidonic acid or eicosapentaenoic acid did not inhibit the increase in G6PD mRNA caused by $27 \mathrm{mM}$ glucose alone (data not shown) suggesting that inhibition of G6PD expression by fatty acids may be caused by an inhibition of the action of insulin. Thus, changes in G6PD enzyme activity due to long chain polyunsaturated fatty acids were accompanied by comparable changes in the amount of mRNA for G6PD indicating that regulation was pretranslational. 


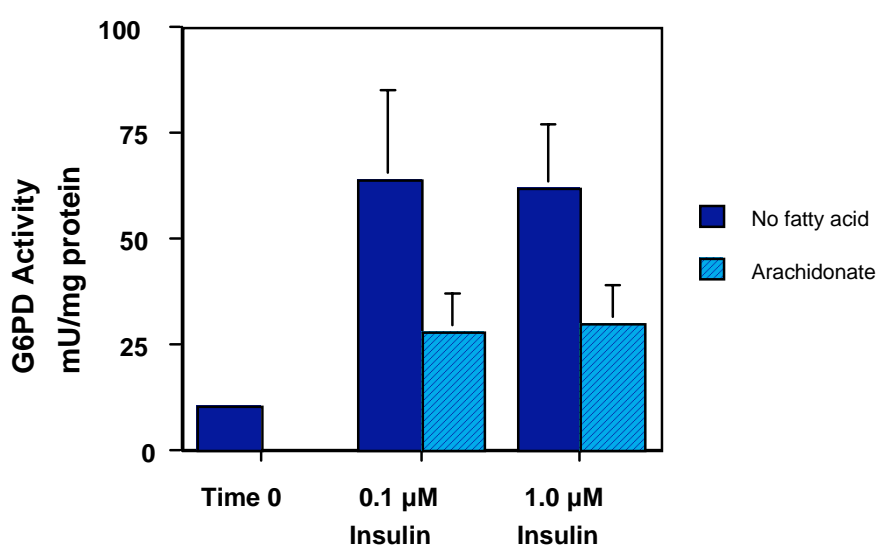

B

\begin{tabular}{|c|c|c|c|c|c|}
\hline - & + & + & + & + & Glucos \\
\hline - & - & + & + & + & Insulin \\
\hline$=$ & $=$ & - & + & - & $20: 4$ \\
\hline . & - & - & $=$ & + & $20: 5$ \\
\hline
\end{tabular}
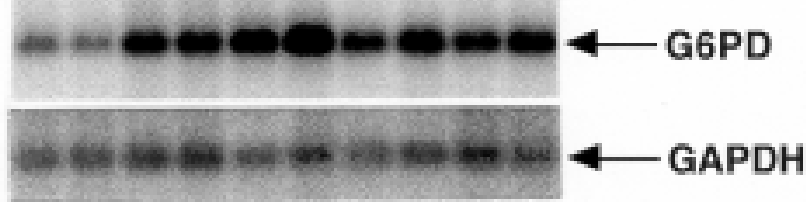

C

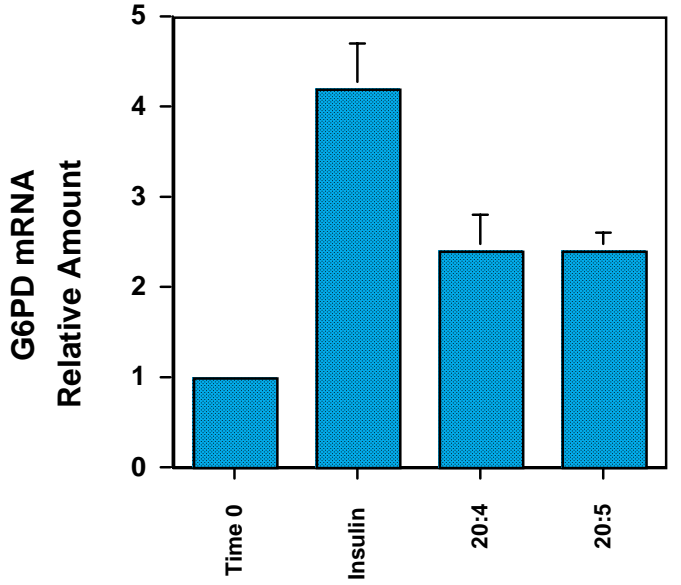


Figure 3. Effect of insulin, glucose, and arachidonic acid on G6PD enzyme activity and mRNA accumulation in cultured rat hepatocytes. (A) Rat hepatocytes were cultured in serum-free Waymouth's 752/1 medium (27 mM glucose). 24 hours after the cells were plated the medium was changed to one containing various concentrations of insulin and arachidonic acid ( $250 \mu \mathrm{M}$, premixed, at a 4:1 ratio with BSA) or a control-BSA solution (BSA prepared without fatty acid). Matrigel $(0.3 \mathrm{mg} / \mathrm{ml})$ was added at the same time. Subsequently, the media was replaced every $24 \mathrm{~h}$ with one of the same composition but without Matrigel. After $72 \mathrm{~h}$ of incubation, the cells were harvested, lysed by freezethaw, and G6PD enzyme activity was measured in the soluble protein extracts. The results are presented as $\mathrm{mU} / \mathrm{mg}$ soluble protein and are the mean $\pm \mathrm{SD}$ of $\mathrm{n}=2$ independent experiments each of which had 2 plates per culture treatment. Time 0 represents the activity in hepatocytes prior to the addition of insulin and fatty acids $(24 \mathrm{~h}$ after plating the hepatocytes). (B) Rat hepatocytes were isolated and cultured in Williams' medium E (11 mM glucose) as described in Materials and Methods. Twenty four hours after plating, the medium was replaced with one containing $0.1 \mu \mathrm{M}$ insulin, 27 $\mathrm{mM}$ glucose or $250 \mu \mathrm{M}$ fatty acids as indicated. After 48 hours in culture with the indicated treatments, total RNA was isolated from the hepatocytes. The amount of G6PD and GAPDH mRNA in total RNA was analyzed by Northern analysis. The first two lanes without treatments represents RNA isolated from hepatocytes after $24 \mathrm{~h}$ of incubation, prior to the addition of the treatments (time 0). The signal for GAPDH was enhanced 1.5-fold over the signal for G6PD using ImageQuaNT. The size of the mRNAs for G6PD and GAPDH are 2.3 and $1.8 \mathrm{~kb}$, respectively. Part B is a representative Northern and Part $\mathrm{C}$ is the mean \pm the $\mathrm{SE}$ of $n=8$ experiments for the time 0 , insulin $(0.1 \mu \mathrm{M}$ insulin and 27 $\mathrm{mM}$ glucose), and arachidonic acid $(20: 4 ; 250 \mu \mathrm{M})$ treatments and $\mathrm{n}=3$ experiments for the eicosapentaenoic acid $(20: 5 ; 250 \mu \mathrm{M}))$ treatment. Quantitation was done using ImageQuaNT analysis and the results are expressed in relative amounts where the amount of RNA at time 0 was set to one. 
To determine whether the effect of glucose, insulin and arachidonic acid on G6PD expression was specific, we also measured the amount of GAPDH and $\beta$-actin mRNA with these treatments. Expression of GAPDH mRNA was consistently increased 2-fold by insulin and glucose, but the amount of GAPDH mRNA was not changed by incubation with polyunsaturated fatty acids indicating that the effect of fatty acids was specific (Fig. $3 B)$. Further, the amount of $\beta$-actin mRNA did not change with any of the treatments (data not shown) indicating that insulin, glucose and long chain polyunsaturated fatty acids do not have generalized positive or negative effects within the hepatocytes.

\section{Time course of the effect of arachidonic acid on G6PD mRNA accumulation.}

In the intact mouse, inhibition of G6PD mRNA amount by dietary fat is very rapid; a $20 \%$ decrease is observed within $4.5 \mathrm{~h}$ after providing a high-fat diet compared to mice consuming a low-fat diet (5). To test whether inhibition by fatty acids in culture was as rapid as the inhibition by dietary fat, hepatocytes were incubated in the presence of glucose and insulin for $48 \mathrm{~h}$ to induce the amount of G6PD expression prior to the addition of arachidonic acid (Fig. 4A). Incubation of hepatocytes for $48 \mathrm{~h}$ with $27 \mathrm{mM}$ glucose in the medium increased the expression of G6PD mRNA 4.1-fold, compared to time 0. Insulin further enhanced this accumulation 1.5-fold relative to glucose-treated cells. Within $2 \mathrm{~h}$ after the addition of arachidonic acid, the amount of G6PD mRNA was decreased $13.8 \%$ (average of 2 experiments). The maximum decrease of $50 \%$ in G6PD mRNA abundance was observed by $8 \mathrm{~h}$. This decrease in mRNA was similar to the $60 \%$ decrease observed in hepatocytes incubated with arachidonic acid coincidentally with glucose and insulin for the entire $48 \mathrm{~h}$ period (Fig. 4A, $48 \mathrm{~h}$ lane). The expression of GAPDH and $\beta$-actin were not affected by arachidonic acid in these cells (Fig. 4A). The inhibition of G6PD mRNA accumulation was also rapid when arachidonic acid was added coincidently with glucose and insulin (Fig. 4B). The amount of G6PD mRNA was decreased $52 \%$ within $12 \mathrm{~h}$ of treatment in the absence of changes in the expression of GAPDH and $\beta$-actin (Fig. 4B). Thus, polyunsaturated fatty acids inhibit the insulin stimulation of G6PD mRNA accumulation when added coincidentally with insulin and glucose, or when added to cells that were previously incubated with insulin and glucose for $48 \mathrm{~h}$. Further, the kinetics of inhibition by polyunsaturated fatty acids in hepatocytes in culture was similar to the kinetics of inhibition by dietary polyunsaturated fat in the intact mouse. 
A
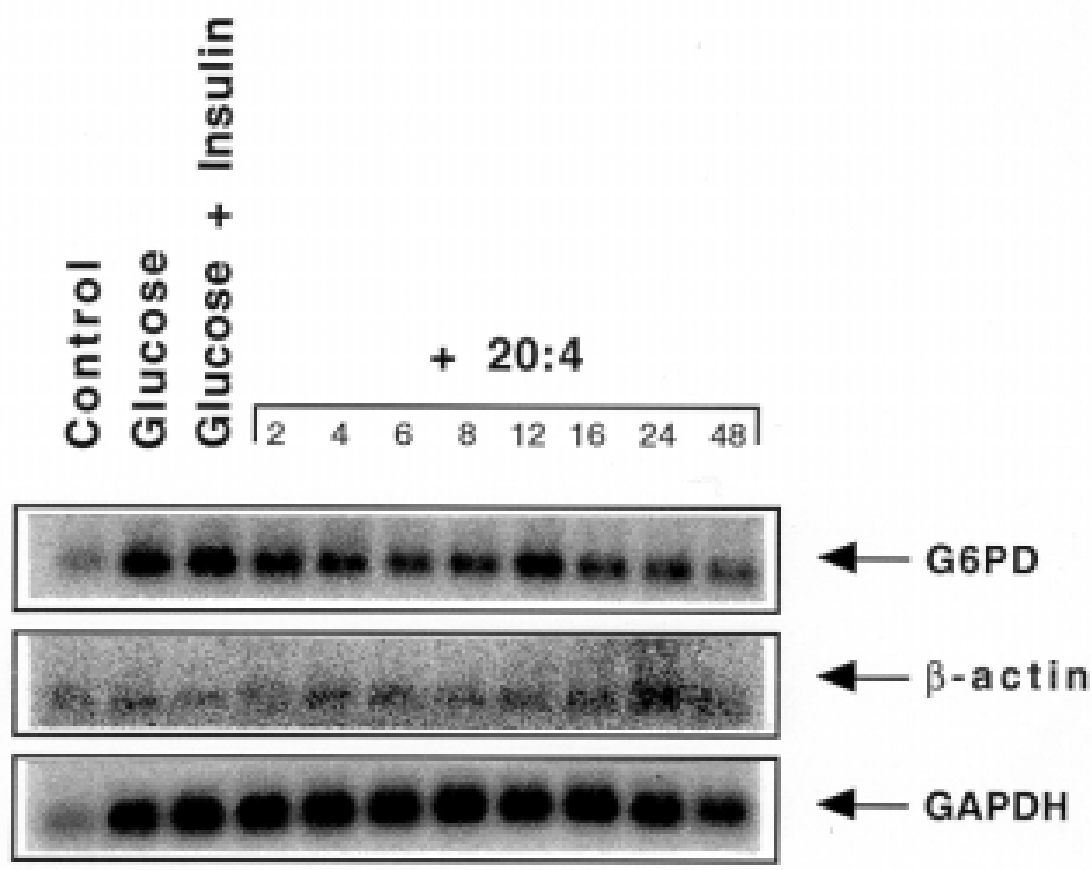

B

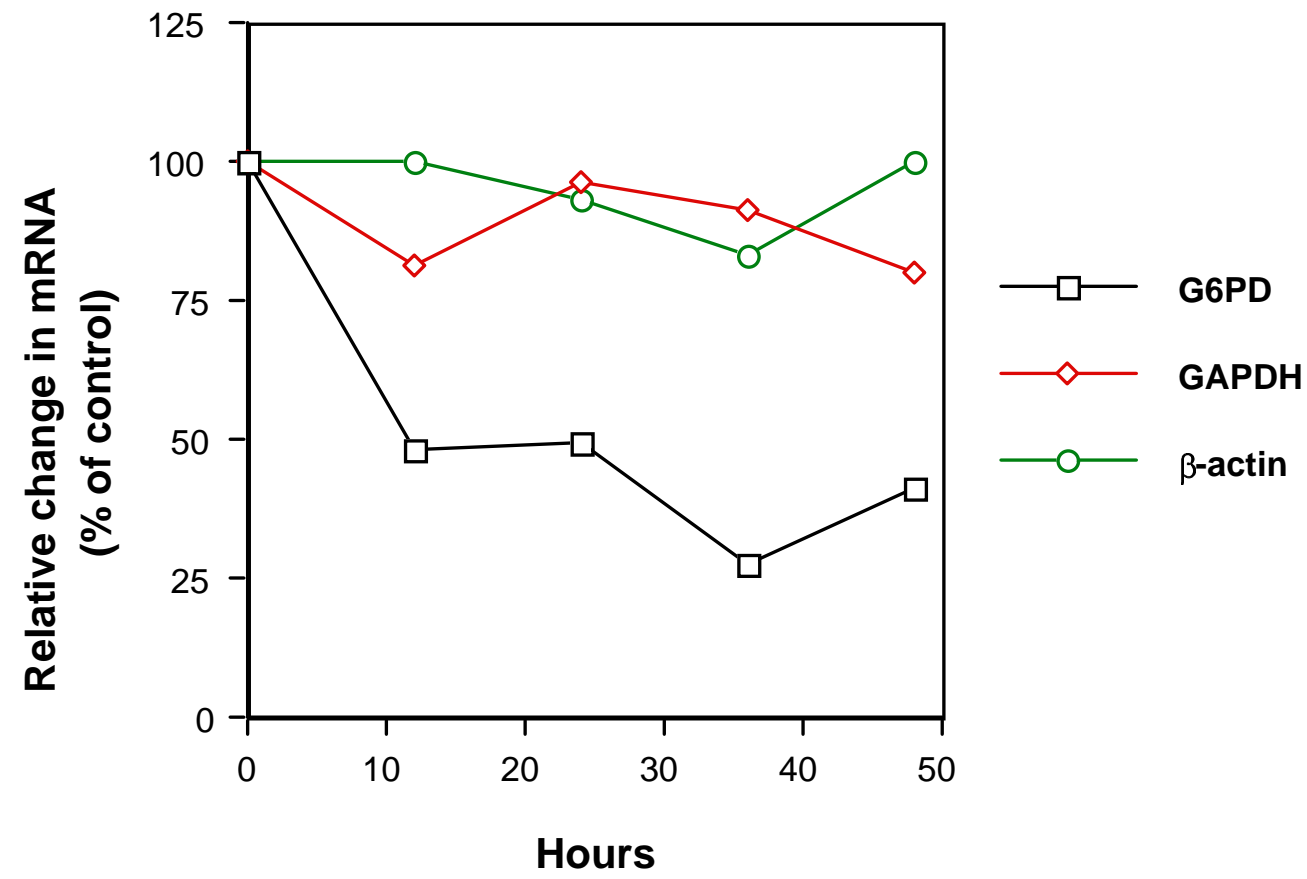


Figure 4. Time course of the inhibition of G6PD mRNA accumulation by arachidonic acid. Rat hepatocytes were isolated and cultured as described. (A) Twenty four hours later, the medium was replaced with one containing $0.1 \mu \mathrm{M}$ insulin, $27 \mathrm{mM}$ glucose and Matrigel $(0.3 \mathrm{mg} / \mathrm{ml})$. The medium was replaced every $24 \mathrm{~h}$ to one of the same composition but without Matrigel. Arachidonic acid $(250 \mu \mathrm{M})$ was added after $48 \mathrm{~h}$ of incubation with hormones. RNA was isolated at the indicated times (2-24 h) after the addition of fatty acid. The $48 \mathrm{~h}$ lane represents RNA isolated from hepatocytes in which arachidonic acid was added with glucose and insulin after $24 \mathrm{~h}$ in culture. In addition, cells prior to treatment (control), cells incubated with glucose alone for $48 \mathrm{~h}$, and cells incubated with glucose plus insulin for $48 \mathrm{~h}$ were harvested and total RNA was isolated. Northern analysis was performed as described and results were quantified using ImageQuaNT. The signal for $\beta$-actin was enhanced 4 times over the signals for G6PD and GAPDH. Similar results were obtained in two independent experiments. (B) Twenty four hours after hepatocyte isolation, the medium was replaced with one containing $0.1 \mu \mathrm{M}$ insulin, $27 \mathrm{mM}$ glucose, $250 \mu \mathrm{M}$ arachidonic acid, and Matrigel (0.3 $\mathrm{mg} / \mathrm{ml}$ ) . The medium was replaced every $12 \mathrm{~h}$ to one of the same composition but without Matrigel. At the indicated times, RNA was isolated and G6PD mRNA was measured by RNase protection assay as described. GAPDH and $\beta$-actin were measured by Northern analysis. Quantitation was done using ImageQuaNT and the results are expressed in relative amounts where the amount of the specific mRNA in cells incubated without fatty acid was set to $100(0 \mathrm{~h})$. The data are representative of two separate experiments with similar results. 
G6PD is regulated at a posttranscriptional step in the nucleus of rat hepatocytes

We next tested if fatty acids regulated G6PD expression by a posttranscriptional mechanism. Nuclei were isolated from hepatocytes and transcriptional activity of the G6PD gene was measured using nuclear run-on assays. Transcriptional activity of the G6PD gene was low in rat hepatocytes and little or no change was observed due to either glucose and insulin or arachidonic acid (Fig. 5A). The apparent increase in G6PD transcription due to glucose and insulin shown in Fig. 5A was only observed in this experiment. In multiple experiments, transcriptional activity of the G6PD gene was not significantly increased by glucose and insulin (Fig. 5B). In the same preparation of cells, the abundance of G6PD mRNA was increased 5-fold by glucose and insulin, whereas arachidonic acid attenuated this increase by $47 \%$ (Fig. 5B). Expression of the $\beta$-actin gene was not regulated by any of the treatments (Figs. 5A \& 5B), thus, the transcriptional activity of the other genes was expressed relative to transcription of the $\beta$-actin gene. Transcriptional activity of the GAPDH gene was increased 3-fold by glucose and insulin, consistent with the change in accumulation of GAPDH mRNA. Although PEPCK transcriptional activity was low in the absence of transcriptional activators such as cAMP, PEPCK transcription was still decreased 31 to $94 \%$ in hepatocytes incubated with glucose and insulin. Arachidonic acid did not change the transcriptional activity of the PEPCK gene and had only a minor effect on transcription of the GAPDH gene which was not reflected by a change in its mRNA. In one experiment (shown), glucose and insulin caused a two-fold increase in G6PD transcription, this was not consistently observed. Thus, we conclude that transcription of the G6PD gene is not regulated by polyunsaturated fatty acids.

Posttranscriptional regulation of G6PD by diet in the intact mouse and rat involves changes in pre-mRNA accumulation in the nucleus. We tested if arachidonic acid inhibited G6PD expression in rat hepatocytes by changing the amount of pre-mRNA for G6PD in the nucleus or by changing the amount of mRNA for G6PD in the cytoplasm. Nuclear RNA was purified from hepatocytes treated with glucose and insulin with or without arachidonic acid. G6PD pre-mRNA was measured using the ribonuclease protection assay as previously described. Hybridization of each probe in the assay with nuclear RNA resulted in two protected fragments corresponding to the fulllength protected fragment and the exon-only protected fragment (Fig. 6A). Incubation of the hepatocytes with glucose and insulin for $48 \mathrm{~h}$ resulted in a 3- to 4-fold increase in premRNA for G6PD. This increase was observed with both the exon 9-intron 9 and intron 3 -exon 4 probes. Inhibition of G6PD pre-mRNA accumulation by arachidonic acid was approximately $60 \%$ as quantified with each of the protected fragments (Fig. 6B). The 
A

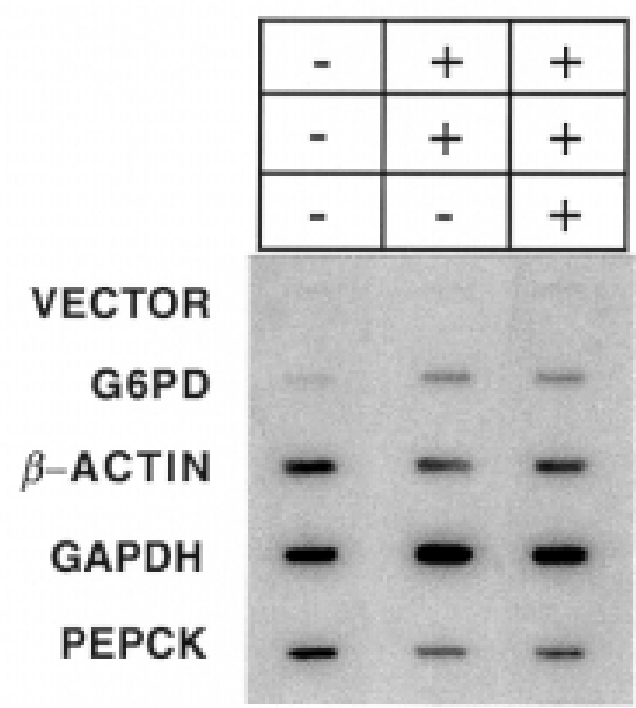

Glucose

Insulin

20:4

B

\begin{tabular}{|c|c|c|c|}
\hline & \multicolumn{3}{|c|}{ Transcription } \\
\hline & No Addition & Glucose+Insulin & Glucose+Insulin $+20: 4$ \\
\hline G6PD & $0.35 \pm 0.2$ & $0.55 \pm 0.1$ & $0.51 \pm 0.2$ \\
\hline GAPDH & $1.74 \pm 0.5$ & $5.65 \pm 0.6$ & $3.23 \pm 0.1$ \\
\hline \multirow[t]{3}{*}{ PEPCK } & $0.91 \pm 0.2$ & $0.33 \pm 0.1$ & $0.45 \pm 0.1$ \\
\hline & \multicolumn{3}{|c|}{$\underline{\mathrm{mRNA}}$} \\
\hline & & Fold increase & $\%$ Decrease \\
\hline G6PD & & $5.0 \pm 1.0$ & $47.0 \pm 1.0$ \\
\hline GAPDH & & $2.5 \pm 0.07$ & $9.0 \pm 3.2$ \\
\hline$\beta$-Actin & & $1.1 \pm 0.08$ & $4.0 \pm 0.05$ \\
\hline
\end{tabular}


Figure 5. G6PD is regulated at a posttranscriptional step in rat hepatocytes. (A) Hepatocytes were isolated and maintained in culture as described in the legend to Fig. 3B. Nuclei were isolated from 16 plates per treatment and nuclear run-on assays were performed as described in Materials and Methods. Lane 1 represents nuclei isolated from hepatocytes at $24 \mathrm{~h}$ after isolation of the cells. Lanes 2 and 3 represent the results from nuclei isolated after $48 \mathrm{~h}$ of incubation with $27 \mathrm{mM}$ glucose and $0.1 \mu \mathrm{M}$ insulin (lane 2), or $27 \mathrm{mM}$ glucose, $0.1 \mu \mathrm{M}$ insulin and $250 \mu \mathrm{M}$ arachidonic acid (lane 3). The amount of hybridization of the transcripts to the DNA probes was quantified using ImageQuaNT. Part A is a representative blot. (B) Quantitative results of 3 independent experiments comparing transcriptional activity with mRNA abundance $(n=2$ plates per treatment per experiment) within the same hepatocyte population. Transcriptional activity of the G6PD, GAPDH and PEPCK genes are expressed relative to the transcriptional activity of the $\beta$-actin gene, which was not regulated by these treatments. Fold increase is the amount of mRNA in hepatocytes treated with glucose and insulin divided by the amount of mRNA in hepatocytes prior to these treatments. The \% decrease is the amount of mRNA in hepatocytes treated with arachidonic acid divided by the amount of mRNA in hepatocytes that were not incubated with arachidonic acid X 100. 
increase in signal intensity observed in protected fragments representing pre-mRNA without the intron versus pre-mRNA with the intron may reflect either the detection of cytoplasmic RNA co-purifying with the nuclei. Using more highly purified nuclei, the difference in these signals decreased (data not shown). Both pre-mRNA and mature mRNAwas decreased by arachidonic acid to a similar extent suggesting that regulation occurs early in the nuclear processing pathway, perhaps, prior to splicing.

To determine whether changes in the pre-mRNA pool could account for the changes in mRNA for G6PD, total RNA was prepared from the same hepatocytes and the amount of G6PD mRNA measured using the ribonuclease protection assay (Fig. 6A). Total RNA is primarily cytoplasmic RNA (9). The amount of mature G6PD mRNA was increased 3- to 4-fold by incubation with glucose and insulin, and the inhibition of G6PD mRNA amount was $50 \%$ or more (Fig. 6B). Thus changes in the amount of pre-mRNA for G6PD due to insulin, glucose or arachidonic acid can account for all of the change in G6PD mature mRNA.

\section{Effect of monounsaturated versus polyunsaturated fatty acids on G6PD expression}

Two characteristics of the inhibition of gene expression by fatty acids are that 1 ) only polyunsaturated fatty acids of the n- 6 and n-3 families of fatty acids are inhibitors, and 2) the inhibition is not a consequence of toxic actions such as an increase in peroxide formation. We tested whether the inhibition of G6PD expression by fatty acids fulfilled these two criteria. Hepatocytes were incubated with glucose and insulin or glucose, insulin and various fatty acids for $48 \mathrm{~h}$. RNA was isolated from nuclei and cells and the amount of pre-mRNA for G6PD was measured using the ribonuclease protection assay (Fig. 7A). Arachidonate (n-6) and eicosapentaenoate (n-3) inhibited G6PD pre-mRNA amount by $88 \%$ and $57 \%$, respectively. In contrast oleate (n-9 and one double bond) had little or no effect. A $45 \%$ inhibition was observed with $\alpha$-linolenate and $\gamma$-linolenate, the metabolic precursors of arachidonate and eicosapentaenoate, respectively. The lower potency of these 18 carbon fatty acids as inhibitors was not unexpected. Previous work has shown that conversion of $\alpha$-linoleate to arachidonate is attenuated in primary hepatocyte cultures (34). Thus, inhibition of G6PD expression at a nuclear posttranscriptional step is specific for long chain polyunsaturated fatty acids of the n-3 and n-6 classes.

Long chain polyunsaturated fatty acids can be subject to oxidation within cells releasing toxic peroxides into the medium (35). Thus we determined if the inhibition of G6PD expression was due to a specific action of long chain polyunsaturated fatty acids or a more generalized effect due to toxicity of these fatty acids. Toxicity was assessed by 
A

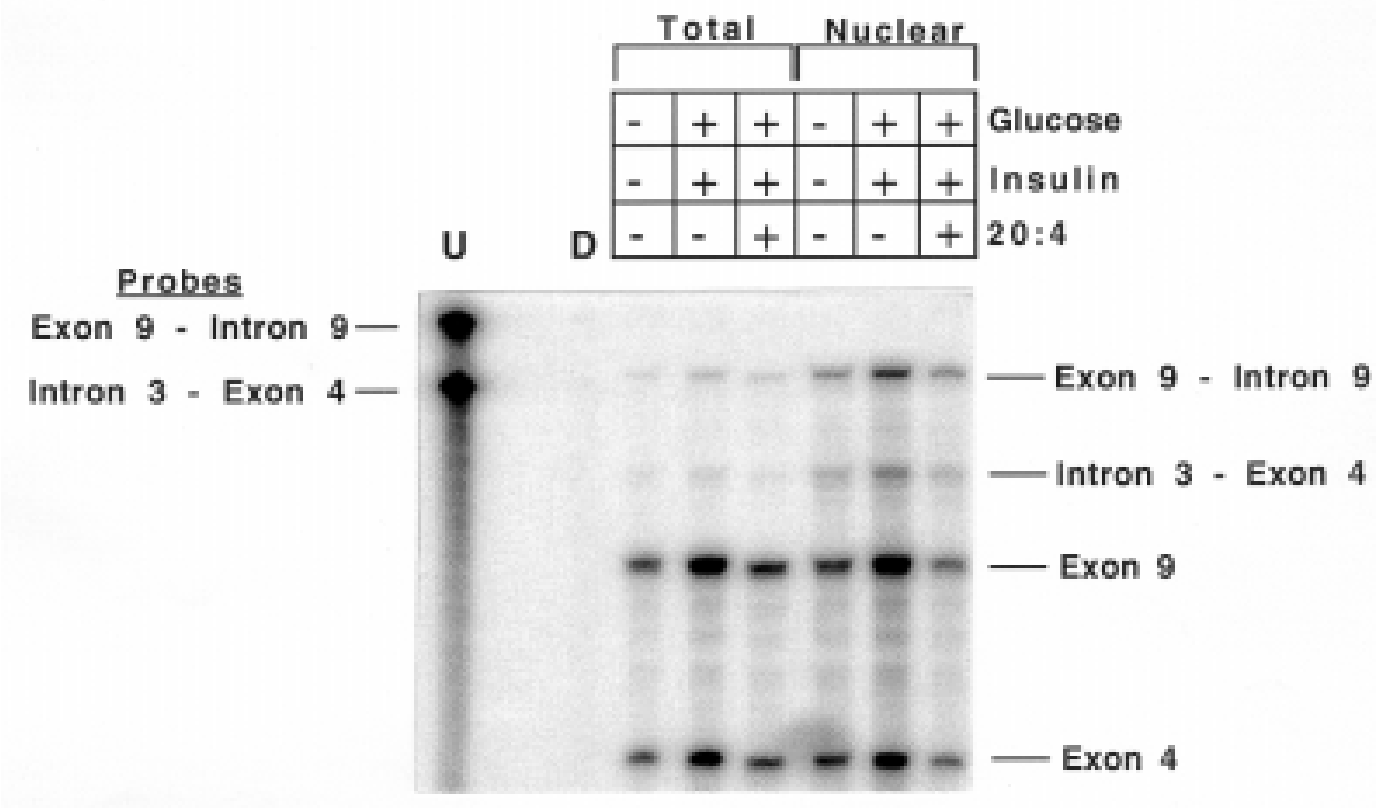

B

Nuclear RNA

\begin{tabular}{lcc}
\hline \multicolumn{1}{c}{ Protected Fragment } & $\begin{array}{c}\text { Fold-increase due to } \\
\text { glucose and insulin }\end{array}$ & \% inhibition due to 20:4 \\
\hline Intron 3- Exon 4 & $3.5 \pm 0.3$ & $58 \pm 5.7$ \\
Exon 4 & $3.2 \pm 0.6$ & $57 \pm 6.8$ \\
Exon 9- Intron 9 & $5.6 \pm 1.5$ & $62 \pm 6.4$ \\
Exon 9 & $3.7 \pm 0.8$ & $60 \pm 7.3$ \\
\hline
\end{tabular}

Total RNA

\begin{tabular}{lcc}
\hline Protected Fragment & $\begin{array}{c}\text { Fold-increase due to } \\
\text { glucose and insulin }\end{array}$ & $\begin{array}{c}\text { \% inhibition due } \\
\text { to 20:4 }\end{array}$ \\
\hline Exon 4 & $3.1 \pm 0.2$ & $51 \pm 2.5$ \\
Exon 9 & $3.6 \pm 0.3$ & $52 \pm 2.8$ \\
\hline
\end{tabular}


Figure 6. Posttranscriptional regulation of G6PD by arachidonic acid occurs in the nucleus. Hepatocytes were isolated and incubated with $27 \mathrm{mM}$ glucose, $0.1 \mu \mathrm{M}$ insulin with or without $250 \mu \mathrm{M}$ arachidonic acid (20:4) as described in Fig. 5. The lane indicating the absence of these additions represents RNA from cells prior to the addition of these treatments (time $0 ; 24 \mathrm{~h}$ after hepatocyte isolation). After $48 \mathrm{~h}$ of treatment, nuclear RNA was isolated from 17 plates per treatment as described in Materials and Methods. Total RNA was isolated from 2 plates per treatment within the same experiment. G6PD mRNA in nuclear and total RNA was analyzed using a ribonuclease protection assay. (A) Representative experiment. $U=$ Undigested probe, $D=R$ Nase digested probe. (B) Quantitative results of 4 independent experiments (mean $\pm \mathrm{SE}$ ). Hybridization to the G6PD probes was quantified using ImageQuaNT analysis. Fold increase is the amount of mRNA in hepatocytes treated with glucose and insulin divided by the amount of mRNA in hepatocytes prior to these treatments. The \% decrease is the amount of mRNA in hepatocytes treated with arachidonic acid divided by the amount of mRNA in hepatocytes that were not incubated with arachidonic acid X 100. 
measurement of TBA-reactive substances in the medium of the hepatocytes. TBAreactive materials provide an estimate of malondialdehyde levels in the culture medium, a primary product of peroxidation of polyunsaturated fatty acids. The amount of TBA reactive material was $1.44 \mathrm{nmol}$ and $2.1 \mathrm{nmol} /$ plate after 24 and $48 \mathrm{~h}$ of incubation in the absence of fatty acids. Regardless of the presence or the degree of unsaturation of the fatty acid, little or no change in the amount of TBA reactive substances was observed in the medium of the hepatocytes (range of 1.24-1.75 nmol/plate at $24 \mathrm{~h}$ and 1.09-1.87 $\mathrm{nmol} / \mathrm{plate}$ at $48 \mathrm{~h}$ ). These results coupled with the lack of change in the expression of GAPDH and $\beta$-actin (Fig. 7B) indicate that the effects of long chain polyunsaturated fatty acids on G6PD expression are not due to a generalized toxicity within the cells.

\section{Discussion}

G6PD activity and mRNA accumulation undergo large changes with starvation/refeeding and during consumption of a high fat diet versus a low fat diet in rats and mice $(5,36)$. Transcription rate of the gene does not change under these conditions (5; Fig. 2A) and thus, regulation is posttranscriptional. Further, this regulation occurs in the nucleus at an early step, perhaps prior to processing events (9; Fig. 2B). In the present report we present several lines of evidence that fatty acids directly mediate the effect ofdietay fat on the expression of G6PD. First, long chain polyunsaturated fatty acids inhibit the expression of G6PD in primary hepatocyte cultures at the same posttranscriptional step observed with dietary fat in the intact animal. In this regard, G6PD expression was inhibited by arachidonic acid by decreases in the amount of premRNA for G6PD in the nucleus in the absence of transcriptional regulation of the G6PD gene. Second, the inhibition of G6PD expression by arachidonic acid in hepatocyte cultures occurs rapidly. A decrease in G6PD mRNA was detected as early as $2 \mathrm{~h}$ after the addition of fatty acid and the decrease was maximal by $8 \mathrm{~h}$, identical to the time course of the decrease of G6PD mRNA observed with the intact animal (5). Last, the specificity of the effect of fatty acids on G6PD expression is the same as that observed in the intact animal. For example, polyunsaturated fatty acids but not monounsaturated fatty acids inhibit G6PD in intact animals and in primary rat hepatocyte cultures $(6,8$; Fig. 7).

Our observations with respect to posttranscriptional regulation by fatty acids are very similar to the observations with respect to transcriptional regulation by fatty acids. Transcriptional activities of the genes for fatty acid synthase, S14, and pyruvate kinase are inhibited by polyunsaturated fatty acids in intact animals or in hepatocytes in 
A

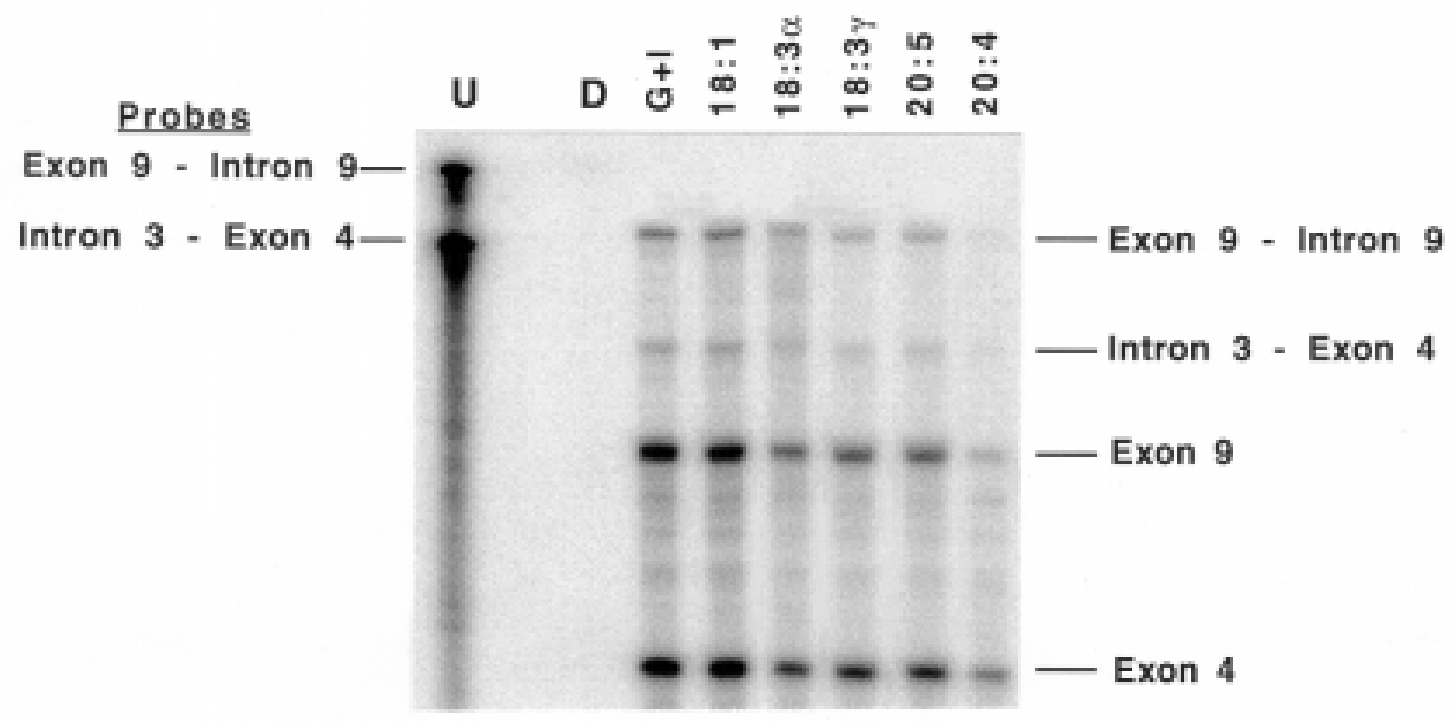

B

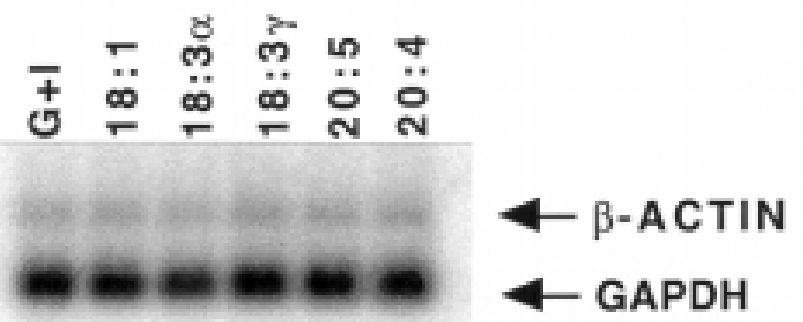


Figure 7. Effects of polyunsaturated fatty acids and monounsaturated fatty acids on inhibition of G6PD pre-mRNA accumulation. (A) Hepatocytes were isolated and incubated in Williams' Medium E as described in Materials and Methods. Twenty four hours after plates the hepatocytes, the medium was replaced with one containing $0.1 \mu \mathrm{M}$ insulin and $27 \mathrm{mM}$ glucose with or without $250 \mu \mathrm{M}$ fatty acids as indicated in the figure. After $48 \mathrm{~h}$ in culture with the indicated treatments, nuclear RNA was isolated from 12 plates/treatment. G6PD RNA in nuclear RNA was analyzed using the ribonuclease protection assay. $\mathrm{U}=$ Undigested probe; $\mathrm{D}=\mathrm{RNase}$ digested probe. (B) Hepatocytes were isolated and maintained as described in part (A). Messenger RNA for GAPDH and $\beta$ actin was measured by Northern analysis. 
primary culture $(10,14,15)$. The differential effect of polyunsaturated fatty acids versus monounsaturated fatty acids is observed for these genes. These similarities between the transcriptional and posttranscriptional regulation by polyunsaturated fatty acids suggests that a common fatty acid metabolite is involved in both modes of regulation.

Glucose and insulin increase G6PD expression 5- to 7-fold in the hepatocytes. This change is similar to the increase in G6PD mRNA and pre-mRNA abundance that is observed in mice during their typical feeding cycle (9). In mice consuming a highcarbohydrate, low-fat diet ad libitum, the amounts of G6PD mRNA and pre-mRNA increase 7-fold from a low level prior to the onset of the dark or feeding cycle, to the highest level observed $8 \mathrm{~h}$ into the dark cycle (9). Thus, factors needed for the positive regulation of G6PD expression appear to be present in the hepatocyte system. Arachidonic acid inhibited G6PD enzyme activity and mRNA accumulation by 50-60\% due to arachidonic acid. These changes are somewhat smaller than the $80 \%$ decreases observed in the intact animal. The attenuated effect of fatty acids may reflect that the effect of dietary fat is not exclusively due to the fatty acids in the diet but may also involve hormonal regulation. Alternatively, this may reflect an absence of some of the regulatory factors in primary hepatocyte cultures needed to observe the maximal effect.

The inhibition of G6PD expression by arachidonic acid was only observed in cells treated with both glucose and insulin. Arachidonic acid does not decrease the amount of G6PD mRNA in hepatocytes treated only with glucose. The simplest interpretation of these observations is that polyunsaturated fatty acids inhibit signal transduction by insulin. As insulin is also thought to stimulate glucose metabolism in hepatocytes and generation of the glucose-signal (37), the step in signal transduction inhibited by arachidonic acid must be downstream of the step involved in glucose utilization. Alternatively, separate signalling pathways may be involved in insulin stimulation of glucose metabolism and insulin stimulation of G6PD expression. Formal proof of this hypothesis will require the identification of the specific signals involved in regulation by insulin and fatty acids. It is not clear if all genes inhibited by arachidonic acid will share a similar signal transduction pathway. In this regard, the activity of fatty acid synthase is inhibited by polyunsaturated fat in diabetic rats (38) suggesting a mechanism independent of insulin. Inhibition of fatty acid synthase by fatty acids with and without insulin has not been tested in primary hepatocyte cultures.

Examples of nutrient regulation at posttranscriptional steps indicate that cytoplasmic mRNA stability is the primary process involved. For example, excess cellular iron leads to a decrease in stability of the transferrin receptor mRNA which is mediated by the binding of an iron regulatory protein to the iron response element in the 
3'-UTR of the transferrin receptor mRNA $(39,40)$. Glucose increases the stability of the fatty acid synthase mRNA. Incubating HepG2 cells with increasing concentrations of glucose stimulates a 5-fold increase in fatty acid synthase mRNA in the absence of transcriptional regulation (41). The mechanism for this stability appears to involve a differential partitioning of the cytoplasmic mRNA between a translated pool protected from degradation and a decay compartment (42). Fatty acids also act posttranscripitionally by decreasing the stability of glut-4 (43) and stearoyl-CoA desaturase I (44) mRNAs in the cytoplasm of 3T3-L1 adipocytes. In contrast, the posttranscriptional mechanism involved in the regulation of G6PD by nutrients is quite different in that it occurs in the nucleus and involves the pre-mRNA (Fig. 6B).

Regulation of pre-mRNA in the nucleus could result from a change in the rate of processing of the pre-mRNA, stability of pre-mRNA in the nucleus or a block in transport of mRNA from the nucleus to the cytoplasm. Posttranscriptional regulation in the nucleus has been reported for several genes. The putative lipogenic protein, S14, is regulated partly by a nuclear posttranscriptional mechanism which involves enhanced splicing of S14 pre-mRNA during consumption of a high-carbohydrate diet or after insulin administration $(12,13)$. Fibronectin and liver/kidney/bone alkaline phosphatase genes are both regulated by accumulation of the pre-mRNA for these genes in the nucleus. The fibronectin gene is regulated by dexamethasone (45) or by transformation of TE-85 cells with Ha-ras (46), whereas alkaline phosphatase is regulated in a tissuespecific manner (47). Changes in expression of fibronectin and the alkaline phosphatase genes are not mediated by changes in transcription, splicing or polyadenylation. In both of these cases, nuclear stability of the pre-mRNA is the postulated mechanism, although this has not been tested experimentally.

Regulation of G6PD pre-mRNA accumulation is most likely occurring early after transcription of the gene, perhaps prior to processing. Accumulation of G6PD mRNA in the cytoplasm due to consumption of a high-carbohydrate diet occurs shortly after an increase in pre-mRNA is observed in the nucleus thereby ruling out nuclear-cytoplasmic transport as a potential regulatory mechanism (9). Whether regulated by diet or nutrients in cultured hepatocytes, the similarity in the rate of change of pre-mRNAs both with and without introns suggests that the efficiency of splicing is also not a regulated step. Regulation could, however, involve any of the other processing reactions occurring within the nucleus such as capping or polyadenylation. Deadenylation and decapping of pre-mRNA can function as regulatory mechanism in the nucleus (48) but are most often associated with the presence of nonsense codons (49). In previous work (9) we detected a 
selective disappearance of the 3'-most portion of G6PD pre-mRNA as a result of dietary manipulation.

We hypothesize that nuclear posttranscriptional regulation of G6PD occurs early after transcription by differential partitioning of the pre-mRNA into various compartments in the nucleus. This idea is not without precedent. For example, processing of pre-RNAs is thought to occur in close association with the nuclear matrix (50-52). Further, this type of compartmentalization has been suggested for the regulation of the alkaline phosphatase gene by retinoic acid (53). Stabilization of the nascent alkaline phosphatase mRNA by retinoic acid is hypothesized to occur by enhanced processing of the pre-mRNA in the nuclear matrix compartment thereby facilitating movement through the nucleus to the cytoplasm. Preliminary evidence from our laboratory suggests that this is also the case for G6PD (Amir-Ahmady and Salati, unpublished results). The amount of G6PD pre-mRNA on the nuclear matrix is increased in livers of fed mice relative to livers of mice that have been starved. Perhaps a protein is induced during high-carbohydrate feeding which facilitates the movement of the premRNA through the nuclear processing reactions, thus protecting it from degradation. In the starved animal or animal fed a high-fat diet, the activity or amount of this protein may be decreased and thus association with the nuclear matrix would not occur. Pre-mRNA not associated with the nuclear matrix would be more susceptible to degradation by RNases in the nucleus.

In summary, regulation of G6PD by polyunsaturated fatty acids in primary rat hepatocytes is mediated by a nuclear posttranscriptional mechanism. This mechanism of regulation by fatty acids has not previously been described for other genes. However, nuclear posttranscriptional regulation may be a common mechanism for all lipogenic genes. The data with carbohydrate regulation of S14 (12) suggests that such a regulatory mechanism occurs in a gene that also undergoes transcriptional changes to the same stimulus. G6PD provides an ideal model to examine this form of regulation because of the absence of transcriptional changes which would confound the interpretation of nuclear events. Experiments are currently in progress aimed at determining the cis-acting elements within the G6PD pre-mRNA sequence involved in regulation by polyunsaturated fat using this cell culture system.

\section{References}

1. Rognstad, R., and J. Katz. 1979. Effects of 2,4-dihydroxybutyrate on lipogenesis in rat hepatocytes. J. Biol. Chem. 254: 11969-11972. 
2. Glock, G. E., and P. McLean. 1954. Levels of enzymes of the direct oxidative pathway of carbohydrate metabolism in mammalian tissues and tumours. Biochem. $J$. 56: $171-175$.

3. Tepperman, J., and H. M. Tepperman. 1958. Effects of antecedent food intake pattern on hepatic lipogenesis. Am. J. Physiol. 193: 55-64.

4. Kletzien, R. F., C. R. Prostko, D. J. Stumpo, J. K. McClung, and K. L. Dreher. 1985. Molecular cloning of DNA sequences complementary to rat liver glucose-6-phosphate dehydrogenase mRNA. Nutritional regulation of mRNA levels. J. Biol. Chem. 260: 5621-5624.

5. Stabile, L. P., D. L. Hodge, S. A. Klautky, and L. M. Salati. 1996. Posttranscriptional regulation of glucose-6-phosphate dehydrogenase by dietary polyunsaturated fat. Arch. Biochem. Biophys. 332: 269-279.

6. Clarke, S. D., D. R. Romsos, and G. A. Leveille. 1977. Differential effects of dietary methyl esters of long-chain saturated and polyunsaturated fatty acids on rat liver and adipose tissue lipogenesis. J Nutr. 107: 1170-1181.

7. Berdanier, C. D., and D. Shubeck. 1979. Interaction of glucocorticoid and insulin in the responses of rats to starvation-refeeding. J. Nutr. 109: 1766-1771.

8. Salati, L. M., B. Adkins-Finke, and S. D. Clarke. 1988. Free fatty acid inhibition of the insulin induction of glucose-6-phosphate dehydrogenase in rat hepatocyte monolayers. Lipids. 23: 36-41.

9. Hodge, D. L., and L. M. Salati. 1997. Nutritional regulation of the glucose-6phosphate dehydrogenase gene is mediated by a nuclear posttranscriptional mechanism. Arch. Biochem. Biophys. 348: 303-312.

10. Blake, W. L., and S. D. Clarke. 1990. Suppression of rat hepatic fatty acid synthase and S14 gene transcription by dietary polyunsaturated fat. J. Nutr. 120: 1727-1729.

11. Ntambi, J. M. 1992. Dietary regulation of stearoyl-CoA desaturase I gene expression in mouse liver. J. Biol. Chem. 267: 10925-10930.

12. Burmeister, L. A., and C. N. Mariash. 1991. Dietary sucrose enhances processing of mRNA-S14 nuclear precursor. J. Biol. Chem. 266: 22905-22911.

13. Walker, J. D., L. A. Burmeister, A. Mariash, J. F. M. Bosman, J. Harmon, and C. N. Mariash. 1996. Insulin increases the processing efficiency of messenger ribonucleic acid-S14 nuclear precursor. Endocrinology. 137: 2293-2299.

14. Liimatta, M., H. C. Towle, S. Clarke, and D. B. Jump. 1994. Dietary polyunsaturated fatty acids interfere with the insulin/glucose activation of L-type pyruvate kinase gene transcription. Mol. Endocrinol. 8: 1147-1153.

15. Jump, D. B., S. D. Clarke, O. MacDougald, and A. Thelen. 1993. Polyunsaturated fatty acids inhibit S14 gene transcription in rat liver and cultured hepatocytes. Proc. Natl. Acad. Sci. USA. 90: 8454-8458.

16. Seglen, P. O. 1973. Preparation of rat liver cells. III. Enzymatic requirements for tissue dispersion. Exp. Cell Res. 82: 391-398. 
17. Kreamer, B. L., J. L. Staecker, N. Sawada, G. L. Sattler, M. T. Stephen Hsia, and H. C. Pitot. 1986. Use of a low-speed, iso-density percoll centrifugation method to increase the viability of isolated rat hepatocyte preparations. In Vitro Cell. and Dev. Biol. 22: 201-210.

18. Shih, H. M. and H. C. Towle. 1995. Matrigel ${ }^{\circledR}$ treatment of primary hepatocytes following DNA transfection enhances responsiveness to extracellular stimuli.

Biotechniques. 18: 813-816.

19. Mooney, R. A., and M. D. Lane. 1981. Formation and turnover of triglyceride-rich vesicles in the chick liver cell. J. Biol. Chem. 256: 11724-11733.

20. Hostmark, A. T., and E. Lystad. 1992. Growth inhibition of human hepatoma cells (HepG2) by polyunsaturated fatty acids. Protection by albumin and vitamin E. Acta Physiol. Scand. 144: 83-88.

21. Bradford, M. M. 1976. A rapid and sensitive method for the quantitation of microgram quantities of protein utilizing the principle of protein dye binding. Anal. Biochem. 72: 248-254.

22. Chomczynski, P., and N. Sacchi. 1987. Single-step method of RNA isolation by acid guanidinium thiocyanate-phenol-chloroform extraction. Anal. Biochem. 162: 156-159.

23. Leppard, K. N., and T. Shenk. 1989. The adenovirus E1B $55 \mathrm{kd}$ protein influences mRNA transport via an intranuclear effect on RNA metabolism. EMBO J . 8: 23292336.

24. Milsted, A., R. P. Cox, and J. H. Nilson. 1987. Cyclic AMP regulates transcription of the genes encoding human chorionic gonadotropin with different kinetics. DNA. 6: 213-219.

25. Salati, L. M., X.-J. Ma, C. C. McCormick, S. R. Stapleton, and A. G. Goodridge. 1991. Triiodothyronine stimulates and cyclic AMP inhibits transcription of the gene for malic enzyme in chick embryo hepatocytes in culture. J. Biol. Chem. 266: 4010-4016.

26. Zollo, M., M. D’Urso, D. Schlessinger, and E. Y. Chen. 1993. Sequence of mouse glucose-6-phosphate dehydrogenase cDNA. J. DNA Sequencing and Mapping. 3: 319322 .

27. Yoo-Warren, H., J. Monahan, H. Short, A. Short, A. Bruzel, A. Wynshaw-Boris, H. Meisner, D. Samols, and R. W. Hanson. 1983. Isolation and characterization of the gene coding for cytosolic phosphoenolpyruvate carboxykinase (GTP) from the rat. Proc. Natl. Acad. Sci. USA. 80: 3636-3660.

28. Kioussis, D., F. Eiferman, P. van de Rijn, M. B. Gorin, R. S. Ingram, and S. M.

Tilghman. 1981. The evolution of $\alpha$-fetoprotein and albumin. II. The structures of the $\alpha$-fetoprotein and albumin genes in the mouse. J. Biol. Chem. 256: 1960-1967.

29. Piechaczyk, M., J. M. Blanchard, L. Marty, Ch. Dani, F. Panabieres, S. E. Sabouty, $\mathrm{Ph}$. Fort, and $\mathrm{Ph}$. Jeanteur. 1984. Posttranscriptional regulation of glyceraldehyde-3phosphate dehydrogenase gene expression in rat tissues. Nucleic Acids Res. 12: 69516963. 
30. Ntambi, J. M., S. A. Buhrow, K. H. Laestner, R. J. Christy, E. Sibley, T. J. Kelly, and M. D. Lane. 1988. Differentiation-induced gene expression in 3T3-L1 preadipocytes. J. Biol. Chem. 263: 17291-17300.

31. Neprokroeff, C. M., K. Adachi, C. Yan, and J. W. Porter. 1984. Cloning of DNA complementary to rat liver fatty acid synthase mRNA. Eur. J. Biochem. 140: 441-445.

32. Hillyard, L. A., C. Y. Lin, and S. Abraham. 1988. Lipogenic enzyme activities in primary cultures of adult mouse hepatocytes. Lipids. 23: 242-247.

33. Green, M. R. 1991. Biochemical mechanisms of constitutive and regulated premRNA splicing. Annu. Rev. Cell. Biol. 7: 559-599.

34. Strum-Odin, R., B. Adkins-Finke, W. L. Blake, S. D. Phinney, and S. D. Clarke. 1987. Modification of fatty acid composition of membrane phospholipid in hepatocyte monolayer with $n-3, n-6$ and $n-9$ fatty acids and its relationship to triacylglycerol production. Biochim. Biophys. Acta. 921: 378-391.

35. Kosugi, H., T. Kojima, and K. Kikugawa. 1989. Thiobarbituric acid-reactive substances from peroxidized lipids. Lipids. 24: 873-881.

36. Tomlinson, J. E., R. Nakayama, and D. Holten. 1988. Repression of pentose phosphate pathway dehydrogenase synthesis and mRNA by dietary fats in rats. J. Nutr. 118: $408-415$.

37. Shih, H. M., and H. C. Towle. 1992. Definition of the carbohydrate response element of the rat S14 gene. Evidence for a common factor required for carbohydrate regulation of hepatic genes. J. Biol. Chem. 267: 13222-13228.

38. Volpe, J. J., and P. R. Vagelos. 1974. Regulation of mammalian fatty-acid synthetase. The roles of carbohydrate and insulin. Proc. Natl. Acad. Sci. USA. 71: 889893.

39. Casey, J. L., D. M. Koeller, V. C. Ramin, R. D. Klausner, and J. B. Harford. 1989. Iron regulation of transferrin receptor mRNA levels requires iron-responsive elements and a rapid turnover determinant in the 3' untranslated region of the mRNA. EMBO J. 8: $3693-3699$.

40. Haile, D. J., M. W. Hentze, T. A. Rouault, J. B. Harford, and R. D. Klausner. 1989. Regulation of interaction of the iron-responsive element binding protein with ironresponsive RNA elements. Mol. Cell. Biol. 9: 5055-5061.

41. Semenkovich, C. F., T. Coleman, and R. Goforth. 1993. Physiologic concentrations of glucose regulate fatty acid synthase activity in HepG2 cells by mediating fatty acid synthase mRNA stability. J. Biol. Chem. 268: 6961-6970.

42. Semenkovich, C. F., T. Coleman, and F. T. Fiedorek, Jr. 1995. Human fatty acid synthase mRNA: tissue distribution, genetic mapping, and kinetics of decay after glucose deprivation. J. Lipid Res. 36: 1507-1521.

43. Tebbey, P. W., K. M. McGowan, J. M. Stevens, T. M. Buttke, and P. H. Pekala. 1994. Arachidonic acid down-regulates the insulin-dependent glucose transporter gene (GLUT4) in 3T3-L1 adipocytes by inhibiting transcription and enhancing mRNA turnover. J. Biol. Chem. 269: 639-644. 
44. Sessler, A. M., N. Kaur, J. P. Palta, and J. M. Ntambi. 1996. Regulation of stearoylCoA desaturase I mRNA stability by polyunsaturated fatty acids in 3T3-L1 adipocytes. $J$. Biol. Chem. 271: 29854-29858.

45. Ehretsmann, C. P., L. A. Chandler, and S. Bourgeois. 1995. A nuclear posttranscripitional mechanism mediates the induction of fibronectin by glucocorticoids. Mol. Cell. Endocrinol. 110: 185-194.

46. Chandler, L. A., C. P. Ehretsmann, and S. Bourgeois. 1994. A novel mechanism of Ha-ras oncogene action: regulation of fibronectin mRNA levels by a nuclear posttranscriptional event. Mol. Cell. Biol. 14: 416-426.

47. Kiledjian, M., and T. Kadesh. 1991. Postranscriptional regulation of the human liver/bone/kidney alkaline phosphatase gene. J. Biol. Chem. 266: 4207-4213.

48. Murphy, D., K. Pardy, V. Seah, and D. Carter. 1992. Posttranscriptional regulation of rat growth hormone gene expression: increased message stability and nuclear polyadenylation accompany thyroid hormone depletion. Mol. Cell. Biol. 12: 2624-2632.

49. Cheng, J., and L. E. Maquat. 1993. Nonsense codons can reduce the abundance of nuclear mRNA without affecting the abundance of pre-mRNA or the half-life of cytoplasmic mRNA. Mol. Cell. Biol. 13: 1892-1902.

50. Verheijen, R., W. Van Venrooij, and F. Ramaekers. 1988. The nuclear matrix: structure and composition. J. Cell Sci. 90: 11-36.

51. Blencowe, B. J., J. A. Nickerson, R. Issner, S. Penman, and P. A. Sharp. 1994. Association of nuclear matrix antigens with exon-containing splicing complexes. J. Cell Biol. 127: 593-607.

52. Mortillaro, M. J., B. J. Blencowe, X. Wei, H. Nakayasu, L. Du, S. L. Warren, P. A. Sharp, and R. Berezney. 1996. A hyperphosphorylated form of the large subunit of RNA polymerase II is associated with splicing complexes and the nuclear matrix. Proc. Natl. Acad. Sci. USA. 93: 8253-8257.

53. Zhou, H., S.S. Manji, D. M. Findlay, T. J. Martin, J. K. Heath, and K. W. Ng. 1994. Novel action of retinoic acid. Stabilization of newly synthesized alkaline phosphatase transcripts. J. Biol. Chem. 269: 22433-22439. 


\section{CHAPTER 3. LOCALIZATION OF A FATTY ACID RESPONSE ELEMENT WITHIN THE G6PD MATURE SEQUENCE}

\section{Introduction}

Dietary polyunsaturated fatty acids (PUFA) have been shown to decrease the expression of a number of genes involved in lipid and carbohydrate metabolism such as fatty acid synthase (FAS) (1), liver-type pyruvate kinase (L-PK) (2), spot 14 (S14) (1), stearoyl-CoA desaturase I (SCD1) (3) and glucose-6-phosphate dehydrogenase (G6PD) $(4,5)$. G6PD is regulated very differently by PUFA compared to the other lipogenic enzymes. Addition of PUFA to a high-carbohydrate diet results in a decrease in the amount of G6PD precursor mRNA (pre-mRNA) in the nucleus, in the absence of changes in the rate of transcription of the gene (6,7). In addition, the changes in the amount of G6PD pre-mRNA in the nucleus parallel the changes in the amount of mature G6PD mRNA in the cytoplasm, which suggests that the nucleus is the primary site of regulation. The amount of G6PD pre-mRNA is regulated early in the processing pathway, without apparent regulation of splicing, nucleocytoplasmic transport, or changes in stability of the pre-mRNA (6). In contrast, other PUFA-regulated enzymes undergo large transcriptional changes in response to diet or hormones with only small components of posttranscriptional regulation in some genes (8-10). G6PD provides an ideal model to study the posttranscriptional regulation because of the absence of transcriptional regulation which would otherwise confound the interpretation of intranuclear events. One possibility for the exclusive posttranscriptional regulation of G6PD is that G6PD plays multiple roles in the cell in addition to its role in lipogenesis. Posttranscriptional regulation would allow increased expression of G6PD in liver when the needs for lipogenesis are great but uniform expression in all cells for other roles such as cellular detoxification and nucleotide biosynthesis. On the other hand, fat biosynthesis is the main function of many of the other lipogenic genes.

Nuclear posttranscriptional regulation can occur by many mechanisms including capping, polyadenylation, splicing, nonsense-mediated decay, nuclear pre-mRNA stability or regulated processing. The role of the nuclear matrix in regulated processing is becoming increasingly evident. For example, the nuclear matrix has been hypothesized to function as an anchor for actively transcribed chromatin and to direct newly synthesized RNA into the processing pathway for processing and transport to the cytoplasm (11-14). Thus, the nuclear matrix can potentially be the site of posttranscriptional regulation of G6PD. Preliminary data from our laboratory suggest that posttranscriptional regulation of G6PD gene expression by diet occurs by changes in the amount of precursor mRNA that 
enters the processing pathway (Amir-Ahmady and Salati, unpublished results). Our hypothesis is that this regulation involves the binding of trans-acting regulatory proteins in the nucleus to cis-acting elements within the G6PD pre-mRNA to mediate either stability or degradation of the mRNA. The nature of the RNA element in G6PD premRNA involved in this regulation is of interest to this laboratory.

Only a few cis-acting RNA elements involved in nuclear RNA stability have been identified. One such element is the premature termination codon which targets the RNA for degradation either prior to or coincident with its export from the nucleus (15). These elements arise by mutation (16). One could envision a mechanism whereby a slowlyspliced intron could result in an apparent premature termination codon but this has not been demonstrated experimentally. RNA elements have also been identified within the coding region of pre-mRNA which enhance splicing (14). A direct relationship between these elements and nuclear RNA stability has not been studied.

The goal of these studies is to localize a PUFA response element in the G6PD premRNA. Since all of the regulation of G6PD by PUFA is occurring in the nucleus, any region of the primary transcript can be subject to regulation. The G6PD primary transcript is $18 \mathrm{~kb}$ necessitating the use of reporter constructs containing subsets of these sequences. Chimeric constructs containing portions of the $18 \mathrm{~kb}$ G6PD gene, either exonic sequences or 3'-UTR sequences, were transiently transfected into primary rat hepatocytes. Arachidonic acid inhibits G6PD expression both quantitatively and qualitatively in primary hepatocyte cultures at the same intracellular step as dietary polyunsaturated fat in the intact animal (17). Thus, the primary rat hepatocytes provide an ideal model system in which to identify a PUFA response element for G6PD.

\section{Materials and methods}

Materials. Arachidonic acid (Nu-Chek Prep), collagenase H (EC 3.4.99.5, Boehringer Mannheim), insulin (Eli Lilly Research Laboratories), Matrigel (Collaborative Biomedical Research), Percoll (Sigma), pBluescriptKS+ (Stratagene), pGL3-Basic (Promega), pCMV $\beta$ (Clontech), RNasin (5 Prime-3 Prime, Inc.), EndoFree Plasmid Purification kit (Qiagen) and Galacto-Light kit ${ }^{\mathrm{TM}}$ (Tropix) were obtained from the indicated sources. Williams' medium E, newborn calf serum, Klenow, RNase-free DNase I and lipofectin were from Gibco-BRL. RPA II kit and CAT Direct kit were purchased from Ambion. Bovine serum albumin fraction $V$ (fatty acid-free) and $\alpha-$ $\left[{ }^{32} \mathrm{P}\right] \mathrm{UTP}, 3000 \mathrm{Ci} / \mathrm{mmol}$ were from ICN Biochemicals. Other chemicals were from Fisher Biotech or of the highest purity commercially available. Rats were purchased from 
Harlan Laboratories (Indianapolis, IN). Standard chow diet was Harlan Teklad. Rat genomic DNA was obtained from Clontech.

Animal care and cell culture. Male Sprague-Dawley rats (approximately $200 \mathrm{~g}$ ) fed on a standard chow diet were used for all experiments. Rats were starved for $48 \mathrm{~h}$ prior to use as hepatocyte donors. The cell culture procedure is as described (17, Chapter 2).

Plasmid construction. The pcDNA construct was made using pGL3-Basic (Promega) as the parent plasmid and the 3'-UTR constructs were made using pCMV $\beta$ (Clontech) as the parent plasmid. Fig. 1A shows the parent vectors and 1B shows the test constructs and lists the features of each one. The structure of all the constructs described below was verified by restriction digestion and sequencing across splice junctions.

pcDNA construct: pGEM-4Z was obtained from M. Zollo (18) and contains the mouse G6PD cDNA, lacking $11 \mathrm{nt}$ 3' of the transcription start site, inserted into the EcoRI site of the pGEM vector. For subcloning purposes, the orientation of the cDNA to the plasmid vector was reversed so that the multiple cloning site was now located 5' of the G6PD sequences. This was done by digestion with EcoRI to remove the G6PD cDNA sequence followed by religation into the plasmid. The correct orientation of insert to plasmid was determined by restriction enzyme digestion. Next, an additional $25 \mathrm{nt} 5$, of the G6PD cDNA was added from plasmid p123 so as to include the transcription start site which was missing in pGEM-4Z. This plasmid, p123, contains 132 nt of G6PD 5'flanking sequences and G6PD exons 1, 2 and 3 cloned into pBluescriptKS+ (19). There is a unique BstEII restriction site in exon 3 and a HindIII restriction site in the G6PD 5'flanking region $25 \mathrm{nt}$ upstream of the transcription start site. Plasmid p123 was digested with HindIII and BstEII. A $201 \mathrm{bp}$ fragment was isolated from this digest. pGEM-4Z with G6PD in the new orientation was also cut with HindIII and BstEII. A $2.3 \mathrm{~kb}$ band was isolated and directional cloning was done resulting in a plasmid containing $25 \mathrm{nt}$ of 5'-flanking DNA, the entire mouse G6PD cDNA and the pGEM backbone.

Next all of the G6PD sequences were subcloned into an expression vector, pGL3Basic. The pGL3-Basic vector contains a high copy number prokaryotic origin of replication for maintenance in $E$. coli, an ampicillan resistance gene for selection, a filamentous phage origin of replication for single stranded DNA production, the SV40 late poly(A) signal, a synthetic poly(A) and transcriptional pause site for background reduction, and the firefly luciferase cDNA (Fig. 1A). In addition, pGL3-Basic lacks eukaryotic promoter and enhancer sequences allowing maximum flexibility in cloning putative regulatory sequences. The luciferase gene and SV40 polyadenylation sequence 


\section{A}
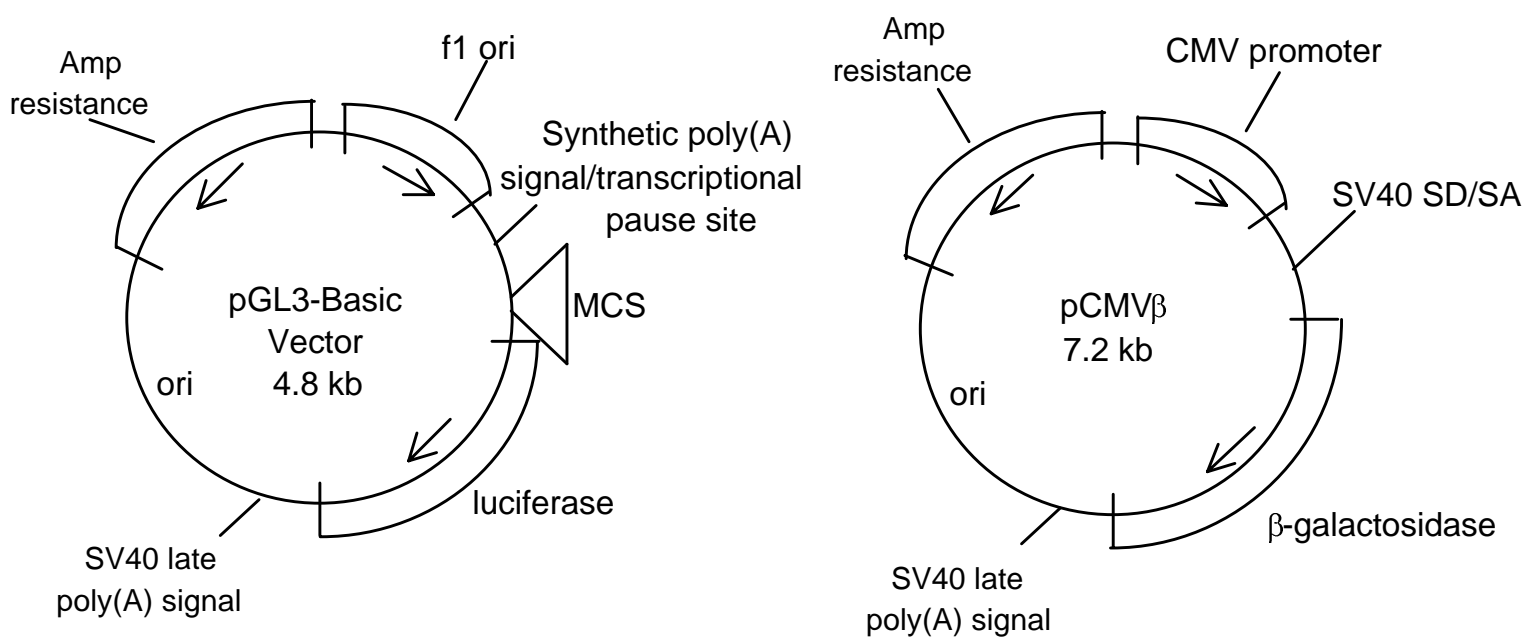

B

NAME

MAP

pGL3 based:

pcDNA

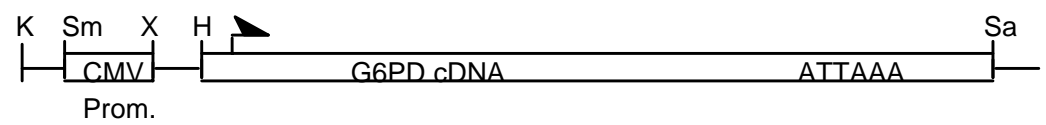

pCMV $\beta$ based:

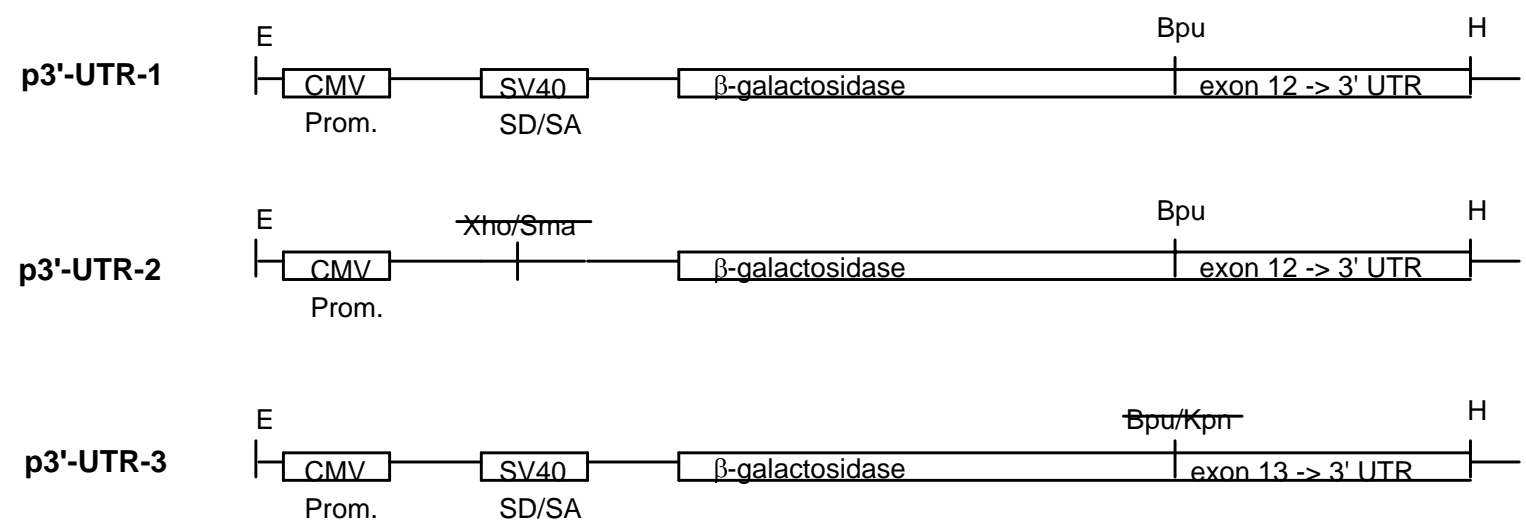


Figure 1. A) Parent vectors for designing chimeric constructs, pGL3-Basic and pCMV $\beta$. $\mathrm{MSC}=$ multiple cloning site. SD/SA= splice donor/splice acceptor. B) cDNA and 3'UTR constructs. The pcDNA construct contains the CMV promoter inserted in the polylinker of the pGL3-Basic vector and the full-length G6PD cDNA inserted in place of luciferase. The SV40 late polyadenylation signal has been deleted since the G6PD DNA contains the native polyadenylation signal. Three different constructs were designed to detect cis-acting elements in the 3'-UTR, designated 3'-UTR-1, 3'-UTR-2 and 3'-UTR-3. G6PD sequences were added within the context of the $\beta$-galactosidase gene of the pCMV $\beta$ vector. $\mathrm{K}=\mathrm{KpnI}, \mathrm{Sm}=\mathrm{SmaI}, \mathrm{X}=\mathrm{XhoI}, \mathrm{H}=\mathrm{HindIII}, \mathrm{B}=\mathrm{BamHI}, \mathrm{E}=\mathrm{EcoRI}$, $\mathrm{Bpu}=\mathrm{Bpu}$ 1102I. A line through the names of restriction enzymes indicates those sites that were destroyed during the cloning. 
were removed from the pGL3-Basic plasmid using HindIII and BamHI restriction enzymes and replaced with a HindIII-EcoRI fragment of G6PD cDNA plus the additional 25 nt of 5'-flanking sequences from the pGEM-4Z to make pcDNA (Fig. 1B). The BamHI and EcoRI sites were filled in with Klenow to create blunt-ends. Thus, these sites have been destroyed in the cloning process. The G6PD DNA contains the native polyadenylation signal in exon 13 , thus the SV40 late polyadenylation signal was deleted to prevent inclusion of vector sequences in the RNA due to utilization of the vector polyadenylation signal.

Finally, the cytomegalovirus (CMV) promoter was added to the pcDNA construct. The $639 \mathrm{bp}$ band of the CMV promoter was excised from pCMV $\beta$ (Fig. 1A) using XhoI and EcoRI. The EcoRI site was filled in with Klenow to create a blunt end. This fragment was subcloned into the $5.5 \mathrm{~kb}$ pcDNA construct which was cut with XhoI and SmaI (blunt). The final pcDNA construct contains $12 \mathrm{nt}$ of untranscribed, the entire $66 \mathrm{nt}$ of 5'-UTR and 622 nt of 3'-UTR sequences for the G6PD gene and mRNA. The approximate size of this construct is $6 \mathrm{~kb}$.

pCMV-GL3-Gal: This is a control plasmid to ensure that the vector and promoter sequences of the pcDNA construct (made using pGL3-Basic as the parent plasmid) are not regulated by the experimental treatments. It contains the pGL3-Basic vector backbone, the CMV promoter, and the $\beta$-galactosidase gene in place of G6PD. Luciferase was removed from pGL3-Basic by restriction digestion with NarI and SalI. The DNA from a 2929 bp band was purified. Next, the CMV promoter and $\beta$ galactosidase sequence was removed from the $\mathrm{pCMV} \beta$ parent vector by restriction digestion with NarI and SalI. The DNA from a $4671 \mathrm{bp}$ band was purified from this digest. The 2929 bp band and 4671 bp band were ligated together to make pCMV-GL3Gal.

3'-UTR constructs: Three different constructs were used to detect cis-acting elements in the 3'-UTR (Fig. 1B). G6PD sequences were added within the context of the $\beta$-galactosidase gene of $\mathrm{pCMV} \beta$. $\mathrm{pCMV} \beta$ is the control plasmid to ensure that the vector and promoter sequences of these 3'-UTR constructs are not regulated by experimental treatments.

3'-UTR-1 construct: 3'-UTR-1 was constructed by PCR amplification of mouse genomic DNA. The amplified sequence included exon 12 (starting at position 1454 in the mouse cDNA sequence), intron 12, exon 13, and 3'-flanking DNA $160 \mathrm{bp}$ from the polyadenylation signal using primer 1, 5'-GCGCGGCTGAGAGCTGCTGCACAAG ATTGATCGAG-3' and primer 2, 5'-GCGCAAAGCTTTGGACTG TAGCTTC-3'. The single underlined sequence is a Bpu1102I restriction site for subcloning purposes 
followed by G6PD exon 12 specific sequences. The double underlined sequence is a HindIII restriction site for subcloning purposes followed by G6PD exon 13 specific sequences. The 3'-UTR of $\beta$-galactosidase was excised from pCMV $\beta$ (Fig. 1A) by digestion with HindIII and Bpu1102I. This was replaced with the $1091 \mathrm{bp}$ PCR amplified G6PD sequence containing the same restriction sites which resulted in a $7.7 \mathrm{~kb}$ plasmid.

3'-UTR-2 construct: The SV40 intron is known to enhance expression of transgenes (20). However, the presence of these sequences may interfere with the mode of regulation of G6PD. Therefore, the SV40 intron and splice donor/splice acceptor site were removed from 3'UTR-1 by restriction digestion with SmaI and XhoI followed by Klenow treatment and religation to make 3'-UTR-2. This construct retains all the G6PD sequences of 3'-UTR-1.

3'-UTR-3 construct: G6PD exon 12 and intron 12 were removed from 3'-UTR-1 by restriction digestion with $\mathrm{Bpu} 1102 \mathrm{I}$ and $\mathrm{KpnI}$ followed by Klenow treatment and religation to make 3'-UTR-3. Thus, this construct contains G6PD exon 13, 3'-flanking DNA and the SV40 intron.

Transient transfection of primary hepatocytes. Plasmid DNA for all transfections was purified using the Qiagen EndoFree plasmid purification kit. Endotoxins have been shown to influence DNA transfection efficiency in cultured cells (21). In our hands, endotoxin free purified DNA results in higher transfection efficiency than standard purification procedures (data not shown). Transfection of primary hepatocytes was performed using liposome-mediated uptake (22). All plasticware that came in contact with the transfection reagents was made of polystyrene. The formation of liposome/DNA complexes was carried out by mixing $5 \mu \mathrm{g}$ of test plasmid DNA and $1 \mu \mathrm{g}$ of control pRSV-CAT in $1 \mathrm{ml}$ media/60 mm plate (Solution A) and $40 \mu \mathrm{g}$ of Lipofectin reagent in $1 \mathrm{ml}$ media/60 mm plate (Solution B). This resulted in a 1:6.7 ratio of DNA to liposomes. Solution B was incubated at room temperature for 30-45 min. Solution A was added to Solution B and mixed by gentle inversion and this incubation continued for 10-15 min at room temperature. The DNA/liposome complex was added directly to the hepatocytes directly after the $4 \mathrm{~h}$ attachment period. The cells were incubated for $14 \mathrm{~h}$ in the presence of the DNA/liposome complexes. At that time, the medium containing liposome/DNA complex was removed and replaced with media containing the experimental treatments and Matrigel overlay as previously described (23). Cells were incubated with these treatments for the times indicated in the figure legends.

Ribonuclease protection assay. Four G6PD specific probes were designed for use in the ribonuclease protection assay (Fig. 2A). The rat G6PD exon 13 probe was 


\section{Probe Design for Ribonuclease Protection Assays}

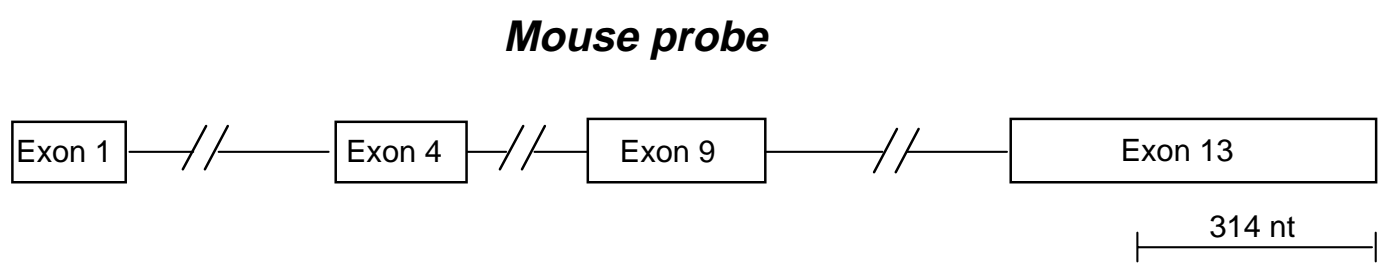

Rat probes

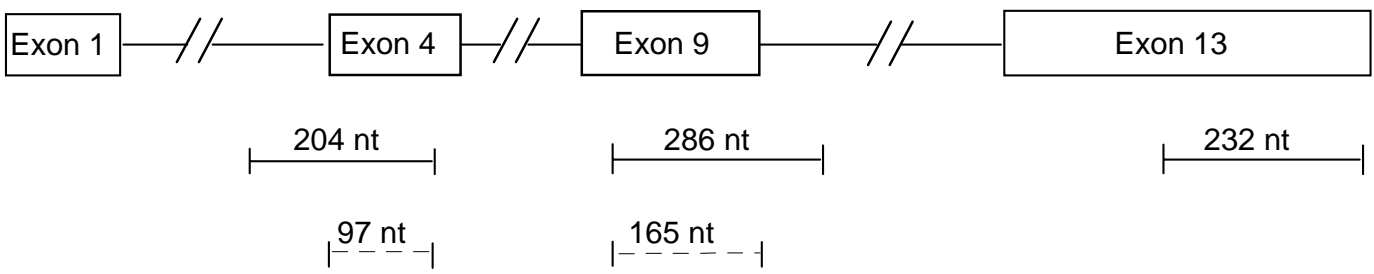

B $\rightarrow$ 3' end of rat versus mouse G6PD cDNA

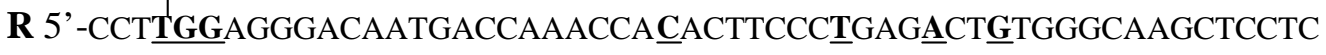

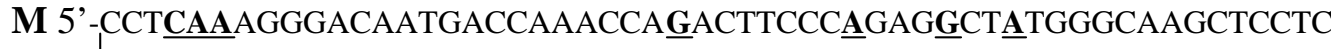
$\Rightarrow$

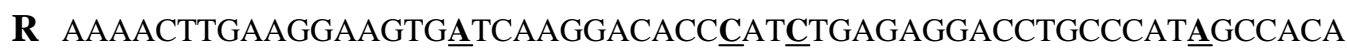

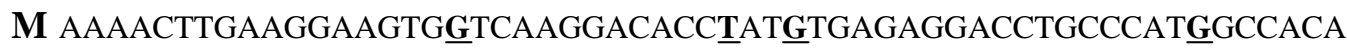

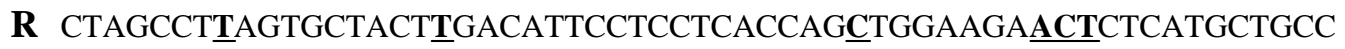

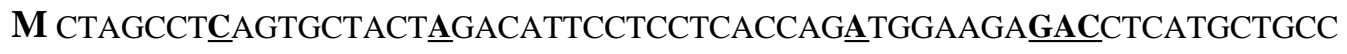

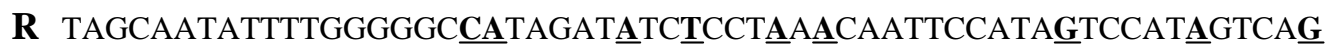

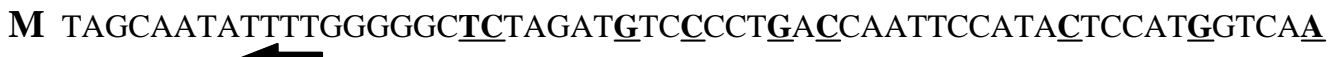

R CCTCATCCAACCDATGGGCAGCCTCCTTACCAAAGGAAGGTAAGAGCAGCAGCTAGA

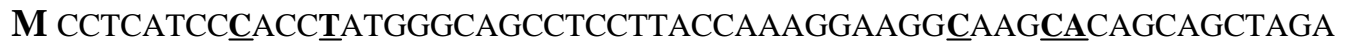

R ATTTTCCTACCCCAACCCTGCCATTAAATC-3'

M ATTTTCCTATCCCAACCCTGCCATTAAATC-3'<smiles>[CH]1C=C1</smiles> 
Figure 2. Probe design for ribonuclease protection assay. A) Mouse and rat probes. The diagram schematically depicts the G6PD precursor mRNA. For simplicity only 4 of the 13 exons of the G6PD gene are shown. A probe for exon 13 of mouse mRNA hybridizes to a $314 \mathrm{nt}$ fragment that is located $13 \mathrm{nt} 5^{\prime}$ ' of the poly(A) tail. Three probes were designed for the rat mRNA. The intron 3-exon 4 protects a $204 \mathrm{nt}$ fragment of premRNA containing intron 3. In addition, this probe recognizes $97 \mathrm{nt}$ of processed transcripts (dashed line) that have undergone splicing of intron 3. The exon 9-intron 9 probe protects a $286 \mathrm{nt}$ fragment of the transcript containing intron 9 and nuclear mRNA without intron 9 (165 nt fragment, dashed line). The rat exon 13 probe hybridizes to a $232 \mathrm{nt}$ fragment that is located $89 \mathrm{nt} 5$ ' of the poly (A) tail. B) The 3'-end of exon 13 is different in mice and rats. $\mathrm{R}=\mathrm{Rat}$ G6PD exon 13 sequence. $\mathrm{M}=$ Mouse G6PD exon 13 sequence. Solid arrows represent starting bases for forward and reverse primers used for amplifying the sequence of the rat exon 13 probe. Open arrows represent starting bases for forward and reverse primers used for amplifying the sequence of the mouse exon 13 probe. Bases which are in bold and underlined are those that are different in the rat versus mouse sequence. 
derived from PCR amplification of genomic rat DNA using primer 3, 5'-CGGAATTCT GGAGGGACAATGACCAAACC-3' and primer 4, 5' -CGCGGATCCGGTTGGAT GAGGCTGACTATGGAC-3'. The 5'-end of primer 3 contained an EcoRI restriction site (underlined sequence) for subcloning purposes followed by sequence specific for rat G6PD exon 13. The 5'-end of primer 4 contained a BamHI restriction site (double underlined) for subcloning purposes followed by sequence specific for rat G6PD exon 13 . The PCR amplified product was subcloned into the EcoRI and BamHI sites of pBluescriptKS+ and linearized with HindIII for use in in vitro transcription. This probe protects a $232 \mathrm{nt}$ fragment when hybridized to rat RNA in ribonuclease protection assays.

The mouse exon 13 probe was described by Hodge and Salati (6). The rat intron 3-exon 4 probe and exon 9-intron 9 probe were described in Chapter 2 (17). Two other probes were used in the ribonuclease protection assay, chloramphenicol acetyl transferase (CAT) and $\beta$-galactosidase. These antisense probe templates were part of the CATDirect kit purchased from Ambion. The CAT probe protects a $152 \mathrm{nt}$ fragment and the $\beta$ galactosidase probe protects a $300 \mathrm{nt}$ fragment when hybridized to total RNA in ribonuclease protection assays. Synthesis of antisense RNA probes and ribonuclease protection assays were performed exactly as described in Chapter 2 (17).

Preparation of cell extracts and $\boldsymbol{\beta}$-galactosidase assay. This protocol is specific for the $\beta$-galactosidase activity experiments in Fig. 5A. In these experiments, it was not necessary to use $60 \mathrm{~mm}$ plates since we could obtain sufficient protein from 35 $\mathrm{mm}$ plates for this assay. Transfected cells from $35 \mathrm{~mm}$ plates were rinsed two times in 1X phosphate buffered saline (PBS, $137 \mathrm{mM} \mathrm{NaCl}, 2.7 \mathrm{mM} \mathrm{KCl}, 4.3 \mathrm{mM}$ $\left.\mathrm{Na}_{2} \mathrm{HPO}_{4} \bullet 7 \mathrm{H}_{2} 0,1.4 \mathrm{mM} \mathrm{KH} \mathrm{PO}_{4}, \mathrm{pH} 7.4\right)$. Lysis solution $(500 \mu \mathrm{l} ; 100 \mathrm{mM}$ potassium phosphate, $\mathrm{pH} 7.8,0.2 \%$ Triton X-100, 1 mM DTT) was added per $35 \mathrm{~mm}$ plate and scraped into a microfuge tube. The cells were disrupted by sonication for $15 \mathrm{sec}$ at $4{ }^{\circ} \mathrm{C}$. The cell mixture was centrifuged for $2 \mathrm{~min}$ in a microfuge to pellet cell debris. The supernatant was stored at $-70^{\circ} \mathrm{C}$.

Total protein content was determined by the method of Bradford (24). $\beta$ galactosidase activity was measured using the Galacto-light ${ }^{\mathrm{TM}}$ kit and a Berthold LB953

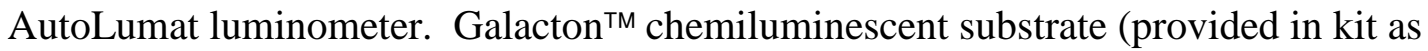
100X concentrate) was diluted 100-fold with Galacto-Light ${ }^{\mathrm{TM}}$ Reaction Buffer Diluent (100 mM sodium phosphate $\mathrm{pH} 8.0,1 \mathrm{mM}$ magnesium chloride) to make the working Reaction Buffer. Cell extracts (5-15 $\mu$ g protein) were aliquoted into luminometer sample cuvettes and Reaction Buffer ( $200 \mu \mathrm{l}$ at room temperature) was added to the luminometer cuvette. The reactions were incubated at room temperature for $60 \mathrm{~min}$. Accelerator (300 $\mu \mathrm{l})$ containing a ready-to-use luminescence accelerator reagent was added, the reaction 
was mixed by the force of the addition and the luminescence was counted for $5 \mathrm{sec}$. Galacton $^{\mathrm{TM}}$ substrate present in the reaction buffer is cleaved by the $\beta$-galactosidase enzyme. A light emission accelerator was added in the same consistent time frame as the Reaction Buffer was added. Data are reported as relative light units (RLU) per $\mu \mathrm{g}$ of protein.

Cellular fractionation. Hepatocytes were isolated as described above. The subcellular fractions were isolated after $24 \mathrm{~h}$ of treatment with glucose and insulin by a modification of the method of Leppard and Shenk (25). The fractionation scheme is shown in Fig. 3. Cells were scraped from $65-90$ plates $(60 \mathrm{~mm})$ into $50 \mathrm{ml}$ centrifuge tubes and centrifuged at $490 \mathrm{rpm}(50 \mathrm{X} \mathrm{g})$ in a JS 4.2 rotor for $5 \mathrm{~min}$. The pellet was washed two times in $1 \mathrm{X}$ PBS. The resulting pellet was resuspended in $3 \mathrm{ml}$ isotonic buffer [10 mM Tris, pH 7.5, $150 \mathrm{mM} \mathrm{NaCl}, 1.5 \mathrm{mM} \mathrm{MgCl}_{2}, 175 \mathrm{~g} / \mathrm{ml}$ phenylmethylsulphonyl fluoride (PMSF)]. The final volume was $4 \mathrm{ml}$. Nonidet NP-40 ( $200 \mu \mathrm{l}$ of $10 \%$ solution; $0.5 \%$ final concentration) was added and the mixture was homogenized with 12 strokes of a loose dounce pestle followed by 12 strokes with a tight pestle. The homogenate was incubated on ice for $5 \mathrm{~min}$ and then centrifuged at $2000 \mathrm{rpm}$ $(800 \mathrm{X} g$ ) in a JS 4.2 rotor for $5 \mathrm{~min}$. The supernatant (cytoplasmic fraction) was transferred to a fresh tube. The nuclear pellet was resuspended in $2 \mathrm{ml}$ of isotonic buffer and centrifuged as before. This supernatant was added to the previous cytoplasmic fraction supernatant. The pellet was resuspended in $2 \mathrm{ml}$ isotonic buffer. Nonidet NP-40 (100 $\mu \mathrm{l}$ of $10 \%$ solution; $0.5 \%$ final concentration) and $50 \mu \mathrm{l}$ of $10 \%$ sodium deoxycholate $(0.25 \%$ final concentration) was added, vortexed and incubated on ice for 5 min and then pelleted as before. The supernatant (nuclear membrane) was transferred to a fresh tube. The pellet was resuspended in $2 \mathrm{ml}$ reticulocyte suspension buffer, RSB, (10 $\mathrm{mM} \mathrm{NaCl}, 10 \mathrm{mM}$ Tris, $\mathrm{pH}$ 7.5, $3 \mathrm{mM} \mathrm{MgCl}_{2}, 175 \mathrm{~g} / \mathrm{ml} \mathrm{PMSF}$ ) and centrifuged as before. The supernatant was transferred to the previous nuclear membrane fraction. This pellet was resuspended in $0.5 \mathrm{ml}$ RSB. DNase I (approximately 1000 Units in $5 \mu \mathrm{l}$ ) and RNasin $(5 \mu \mathrm{l} ; 30 \mathrm{U} / \mu \mathrm{l})$ was added and the mix was incubated at room temperature for 30 min, followed by centrifugation for $10 \mathrm{~min}$ at $2500 \mathrm{rpm}(1000 \mathrm{X} g)$ in a JS 4.2 rotor. The supernatant (DNase soluble fraction) was transferred to a fresh tube. The pellet was resuspended in $1 \mathrm{ml} \mathrm{RSB}, 250 \mu \mathrm{l}$ of $5 \mathrm{M} \mathrm{NaCl}$ (1.25 M final concentration) was added and incubated at room temperature for $5 \mathrm{~min}$. This mixture was centrifuged as before. The supernatant (salt soluble fraction) was transferred to a fresh tube. The final pellet contains the nuclear matrix. RNA was isolated from this final pellet by the method of Chomczynski and Sacchi (26). 


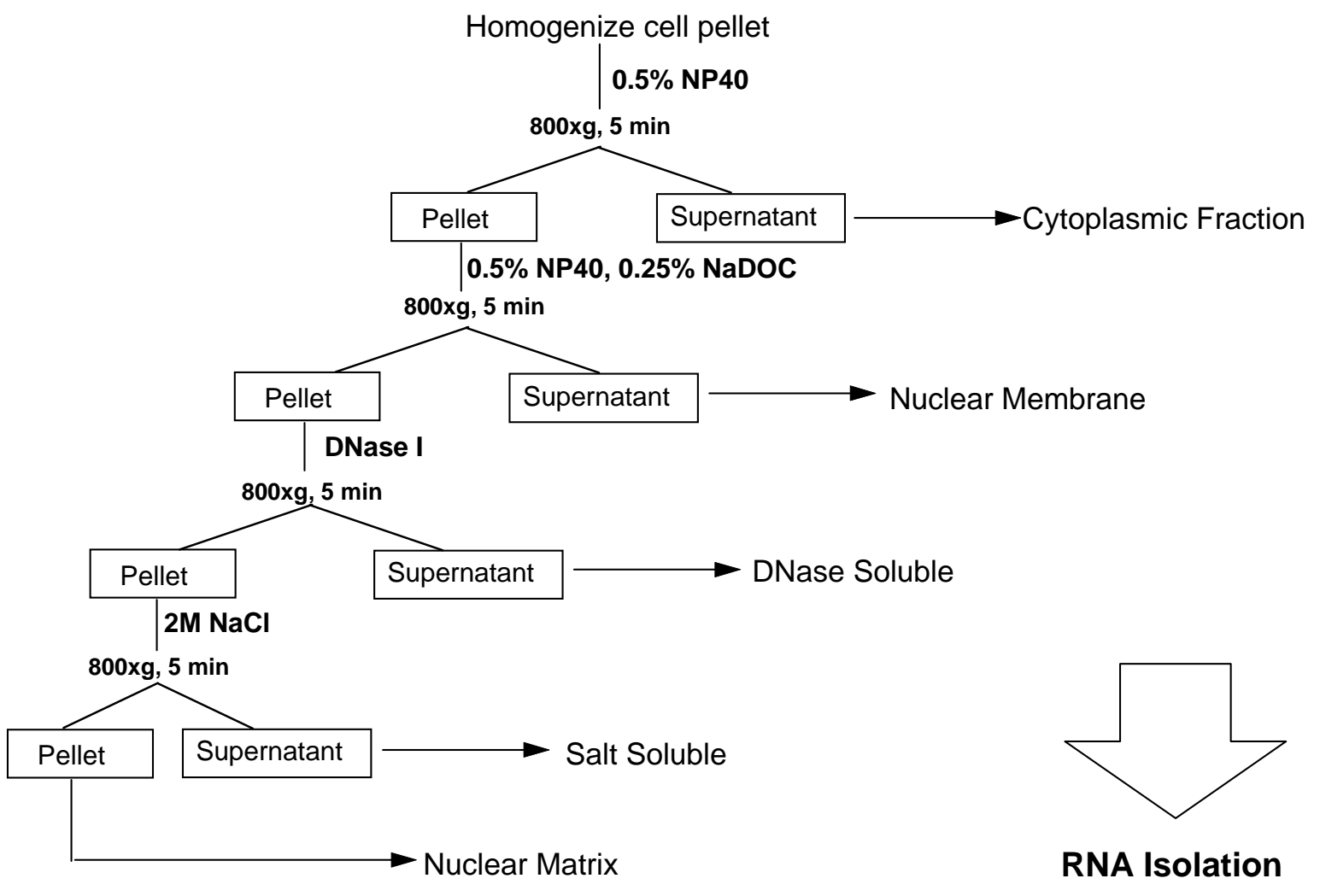

Figure 3. Cellular fractionation scheme. Five cellular fractions were isolated:

cytoplasmic, nuclear membrane, DNase soluble, salt soluble, and nuclear matrix.

Total RNA was isolated from each cellular fraction as described in Materials and Methods. NP40 = Nonidet NP40; $\mathrm{NaDOC}=$ sodium deoxycholate. 
To isolate RNA from all other fractions (27), an equal volume of denaturing solution (8 M urea, $350 \mathrm{mM} \mathrm{NaCl}, 10 \mathrm{mM}$ EDTA, 1\% SDS, $10 \mathrm{mM}$ Tris, pH 7.4) was added. Sodium acetate (1/10 volume of a $2 \mathrm{M}$ solution at $\mathrm{pH} 4.0)$ was added and the mixture was vortexed. Protein was extracted by addition of an equal volume of phenol (water saturated) and chloroform/isoamyl alcohol $(24: 1 ; 50 / 50)$ and thoroughly mixed. The mixture was incubated on ice for $15 \mathrm{~min}$ followed by centrifugation at $4000 \mathrm{rpm}(4500 \mathrm{X}$ $g$ ) for $20 \mathrm{~min}$ in a JS 4.2 rotor. The aqueous phase was transferred to a fresh tube and the RNA was precipitated with an equal volume of isopropanol $\left(-20^{\circ} \mathrm{C}\right.$ overnight $)$. The RNA was pelleted at $4000 \mathrm{rpm}(4500 \mathrm{X} \mathrm{g})$ in a JS 4.2 rotor for $30 \mathrm{~min}$ and the pellet was washed in $75 \%$ ethanol, dissolved in DEPC-treated water and quantitated spectrophotometrically. The RNA was stored at $-70^{\circ} \mathrm{C}$ prior to use. Recovery of RNA from each fraction starting with 65 plates $(60 \mathrm{~mm}$ ) was 300-500 $\mu \mathrm{g}$ (cytoplasmic), 20-25 $\mu \mathrm{g}$ (nuclear membrane), 25-35 $\mu \mathrm{g}$ (DNase soluble), 30-100 $\mu \mathrm{g}$ (salt soluble) and 70-90 $\mu \mathrm{g}$ (nuclear matrix).

Isolation of total RNA and Northern analysis. Total RNA from 1-3 plates per treatment was isolated by the method of Chomczynski and Sacchi (26). The denatured cell mix [3 $\mathrm{ml}$ solution D/1-3 plates $(60 \mathrm{~mm})$ ] was forced through an 18 gauge syringe two to three times to sheer genomic DNA. Quantitation of RNA using Northern analysis was done as previously described (7).

Lithium chloride treatment of RNA. One problem when isolating RNA from transiently transfected cells is that the transfected plasmid can be copurified with the RNA. This could lead to potential problems when using the ribonuclease protection assay because the RNA probes will hybridize to both RNA and DNA in this assay. Plasmid DNA contamination can be eliminated by either $\mathrm{LiCl}$ precipitation which selectively precipitates the RNA (28) or DNase I digestion (29). In the absence of either of these treatments, we observed a significant amount of DNA contamination. RNA was dissolved in 0.1 X SET (10\% SDS, $100 \mathrm{mM}$ Tris-HCl, pH 7.5, $50 \mathrm{mM}$ EDTA). LiCl was added to a final concentration of $2 \mathrm{M}$. The RNA was precipitated overnight at $4{ }^{\circ} \mathrm{C}$ and centrifuged at $3000 \mathrm{rpm}$ for $15 \mathrm{~min}$. The pellet was washed one time with $2 \mathrm{M} \mathrm{LiCl}$ and resuspended in DEPC-treated water. The RNA was quantitated spectrophotometrically.

DNase I treatment of RNA. The desired amounts of RNA samples isolated from transiently transfected cells were aliquoted into microfuge tubes and brought up to an equal volume in all samples with 1X NEBuffer $2(10 \mathrm{mM}$ Tris- $\mathrm{HCl}, 10 \mathrm{mM} \mathrm{MgCl} 2,50$ $\mathrm{mM} \mathrm{NaCl}, 1 \mathrm{mM}$ DTT, pH 7.9 at $25^{\circ} \mathrm{C}$; New England Biolabs) in DEPC-treated water. This was incubated with $2 \mathrm{U}$ of RNase-free DNase I per $5 \mu \mathrm{g}$ RNA for $15 \mathrm{~min}$ at $37^{\circ} \mathrm{C}$ immediately before use in a ribonuclease protection assay. After the 15 min incubation, 
the riboprobes were added and both the RNA and probe were co-precipitated with ethanol. Extraction of the sample RNA from DNase I is not required since all subsequent steps involving RNA-RNA interactions are unaffected by DNase I. Subsequent hybridization and RNase digestions were done as described in the Ribonuclease Protection Assay section in Chapter 2 (17).

\section{Results}

Assays to measure transgene and endogenous gene expression

In order to test the functional activity of the G6PD test constructs, we had to design an assay that would allow us to distinguish between the transgene (mouse G6PD sequences) and the endogenous G6PD gene in the rat hepatocytes. G6PD exon 13 is significantly different between mouse and rat (Fig. 2B) and provides the basis of an assay to distinguish between the endogenous rat gene and the transfected pcDNA transgene. Using ribonuclease protection assays, our laboratory has shown that even a single basepair difference in the ribonuclease protection assay probe versus the RNA sequence to which it should hybridize results in a cleavage by RNases $\mathrm{A} / \mathrm{T}_{1}$ and thus the appearance of an extra band in these assays. Differences between rat and mouse are enough to allow the RNases $\mathrm{A} / \mathrm{T}_{1}$ mixture to digest the rat RNA/mouse probe hybrid or mouse RNA/rat probe hybrid into smaller fragments. To ensure the validity of this assay, total mouse liver RNA or rat hepatocyte RNA was hybridized with the two different G6PD exon 13 probes, rat and mouse. The rat exon 13 probe contains 27 differences from the mouse sequence, 17 transitions and 10 transversions (see the underlined bases in Fig. 2B). This probe detects the endogenous rat gene and protects a fragment of $232 \mathrm{nt}$; it does not protect a fragment of this size in mouse RNA (Fig. 4). The mouse probe contains 32 differences from the rat sequence, 21 transitions and 11 transversions (see the underlined bases in Fig. 2B). This probe protects a $314 \mathrm{nt}$ fragment of the 3'-end of mouse exon 13 in mouse RNA, but not in rat RNA (Fig. 4). The second band (211 nt) in the mouse RNA lane is due to a single nucleotide mismatch in the mouse probe. The mismatch occurred due to a transcription error during PCR. This probe was corrected for all future experiments. Further, the difference in size between these two probes permits their use simultaneously with a single aliquot of RNA.

Additionally, in the cDNA transfection assays, expression of pRSV-CAT was measured using the probe designed by Ambion. This probe protected a $152 \mathrm{nt}$ fragment of CAT mRNA. Thus, all three probes were used with a single aliquot of RNA and the 




Figure 4. Assay to distinguish between the transgene and endogenous G6PD mRNA. Two probes were designed as described in Materials and Methods, exon 13-mouse and exon 13-rat. Each probe recognizes a region at the 3'-end of exon 13 which is significantly different between the mouse and rat. Total RNA was isolated from mouse liver or rat hepatocytes. RNA $(25 \mu \mathrm{g})$ from each species was hybridized to both probes and analyzed using a ribonuclease protection assay. Digested and undigested lanes represent the probes hybridized with $25 \mu \mathrm{g}$ of yeast RNA with or without RNase digestion, respectively. 
protected fragments resulting from these three probes were separated on a polyacrylamide gel. This allowed us to measure the pcDNA gene construct, the endogenous rat G6PD gene and a control for transfection efficiency (CAT) all in one tube. Because RSV-CAT was a control for transfection efficiency, we first determined that CAT expression was not regulated by arachidonic acid. In 3 separate experiments the amount of CAT mRNA was not changed by the addition of fatty acids to the hepatocytes (Fig. 5B). Thus, expression of CAT mRNA reflected the amount of DNA taken up by the hepatocytes and expressing the amount of G6PD transgene mRNA per the amount of CAT mRNA corrected for differences in uptake between dishes of hepatocytes.

The $\beta$-galactosidase transgenes produced from the 3'-UTR constructs were detected using a $\beta$-galactosidase probe from Ambion. This probe protected a $300 \mathrm{nt}$ fragment in ribonuclease protection assays. The endogenous gene was detected using the rat exon 9-intron 9 probe and protected a $165 \mathrm{nt}$ fragment in total RNA and the expression of pRSV-CAT was measured with the CAT probe from Ambion which protected a $152 \mathrm{nt}$ fragment as described above. Thus, all three probes were measured in a single aliquot of RNA just as for the pcDNA assay. We chose the $24 \mathrm{~h}$ time point to isolate RNA from all experiments because at this time point we observed the maximal stimulation of endogenous G6PD expression due to glucose and insulin and the maximal inhibition due to fatty acids (17). In addition, the expression of the transgenes appeared to be at steady state at this time (data not shown). Thus a decrease in the amount of a mRNA produced from any of these constructs in hepatocytes incubated with arachidonic acid would indicate the presence of a putative regulatory domain.

\section{CMV promoter is not regulated by fatty acids}

The CMV promoter was used in all constructs. In order to ensure that any regulation observed with the transgenes was not due to regulation of the CMV promoter, we measured the expression of pCMV- $\beta$ (Clontech) in hepatocytes incubated with and without arachidonic acid. Both $\beta$-galactosidase activity and mRNA were readily detectable in the transfected hepatocytes (Fig. 5). Neither the activity nor the accumulation of the mRNA were different in hepatocytes incubated with glucose and insulin plus or minus arachidonic acid (Fig. 5A and B, experiments 1 and 2). In the same experiments endogenous G6PD mRNA levels were measured using the ribonuclease protection assay with the rat exon 13 probe in experiment 1 and the rat exon 9-intron 9 probe in experiment 2. A 4- and 7-fold increase relative to Time 0 in G6PD mRNA was observed due to glucose and insulin in experiments 1 and 2, respectively (Fig. 5C, 


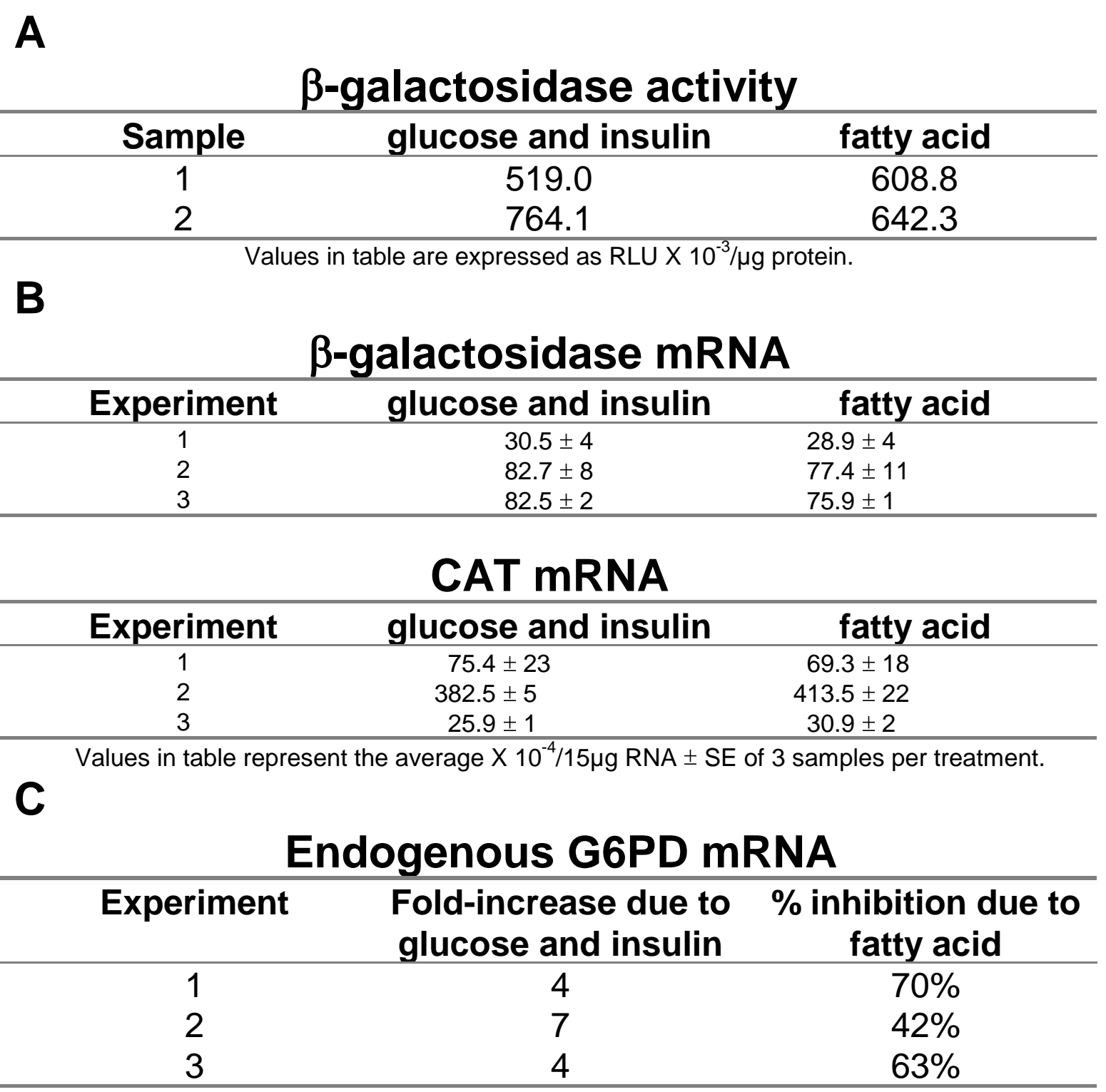

Values in table represent the average of 3 samples per treatment. 
Figure 5. The cytomegalovirus (CMV) promoter is not regulated by arachidonic acid. A) $\beta$-galactosidase activity measurements: Hepatocytes were isolated as described. $4 \mathrm{~h}$ after plating, the cells were transiently transfected with $\mathrm{pCMV} \beta$ by liposome-mediated uptake. The cells were incubated for $14 \mathrm{~h}$ in the presence of the DNA/liposome complexes. After the $14 \mathrm{~h}$ incubation, $27 \mathrm{mM}$ glucose and $0.1 \mu \mathrm{M}$ insulin with or without $250 \mu \mathrm{M}$ arachidonic acid was added to the cells and incubated an additional $72 \mathrm{~h}$. The medium was changed every $24 \mathrm{~h}$. After $72 \mathrm{~h}$ with the indicated treatments, cell extracts were prepared from 2 plates per treatment. The results are expressed as relative light units (RLU) $X 10^{-3}$ per $\mu \mathrm{g}$ protein and 2 samples per treatment are shown. B) $\underline{\beta \text {-galactosidase }}$ mRNA measurements: Hepatocytes were isolated and cotransfected with pCMV $\beta$ and pRSV-CAT in experiments 1 and 2. In experiment 3, hepatocytes were cotransfected with pCMV-GL3-gal and pRSV-CAT. Treatments were added as described above for the activity measurements. Total RNA was isolated from 3 plates $(60 \mathrm{~mm})$ per treatment after $24 \mathrm{~h}$ with the indicated treatments. The RNA $(15 \mu \mathrm{g})$ was analyzed using a ribonuclease protection assay with probes for $\beta$-galactosidase and CAT. Quantitation was done using ImageQuaNT analysis. The actual numbers from ImageQuaNT are shown. For ease of reporting, all values were multiplied by $10^{-4}$. Values represent the average \pm SE of 3 samples per treatment. C) To ensure that the population of cells from these experiments were responsive to fatty acids, endogenous G6PD mRNA was measured in experiments 1 and 2 using a ribonuclease protection assay with the exon 13 rat probe (experiment 1 ) the exon 9 -intron 9 rat probe (experiment 2 ). In experiment 3 , endogenous G6PD mRNA was measured using Northern analysis. Results are expressed as the calculated fold-increase due to glucose and insulin and the $\%$ inhibition due to fatty acid and are the average of 3 samples per experiment. 
experiments 1 and 2). A 70\% and 42\% inhibition of G6PD mRNA due to the addition of arachidonic acid was observed in experiments 1 and 2, respectively. Thus the cells used in these two experiments were responding to the indicated treatments and the lack of regulation of $\mathrm{pCMV} \beta$ was because it is not regulated by these treatments and not a reagent or cell viability problem.

As an additional control to ensure that the sequences of the parent vector used for the pcDNA construct were not mediating this regulation, the pGL3-Basic vector with the CMV promoter and $\beta$-galactosidase gene in place of the G6PD gene (pCMV-GL3-Gal) was transfected in hepatocytes along with pRSV-CAT. Expression of the $\beta$-galactosidase or RSV-CAT transgenes was not regulated with any of the experimental treatments (Fig. 5B, experiment 3). Endogenous G6PD regulation was also observed in this population of cells and is shown in Fig. 5C, experiment 3. Thus, any regulation observed with thetransgenes would be mediated via a G6PD specific sequence, not the promoter or vector sequences.

pcDNA transgene $m R N A$ is found in the same nuclear fractions as the endogenous G6PD $m R N A$

During the first 48-72 $\mathrm{h}$ after transient transfection, transcription of the foreign DNA occurs in the nucleus but the transfected plasmid may not be integrated into the genome. In the case of the endogenous gene, we hypothesize that dietary fat blocks the association of the newly transcribed G6PD RNA with the nuclear matrix or increases its degradation on the matrix during processing. Thus, we determined if the transgene mRNAs also follow this same intranuclear processing pathway. If negative results are obtained in the transfection experiments, this could be because a cis-acting element is not present or because transient transfection does not allow the transgene to follow the same processing pathway as for the endogenous gene. If the latter is the case, then stable transfection which results in the integration of the transgene into the genome of the host cell would be necessary for these studies.

To test this, we fractionated hepatocytes following transfection into five fractions: cytoplasmic, nuclear membrane, DNase soluble, salt soluble and the nuclear matrix fractions. We examined the endogenous gene using probes to detect both precursor and mature forms of the endogenous gene. Pre-mRNA should be in the nuclear matrix fraction and after processing, the mature mRNA should be found in the nuclear membrane and cytoplasmic fractions. G6PD specific RNA was found in all fractions except the DNase soluble fraction (Fig. 6A). When analyzed on a denaturing agarose gel stained 
A

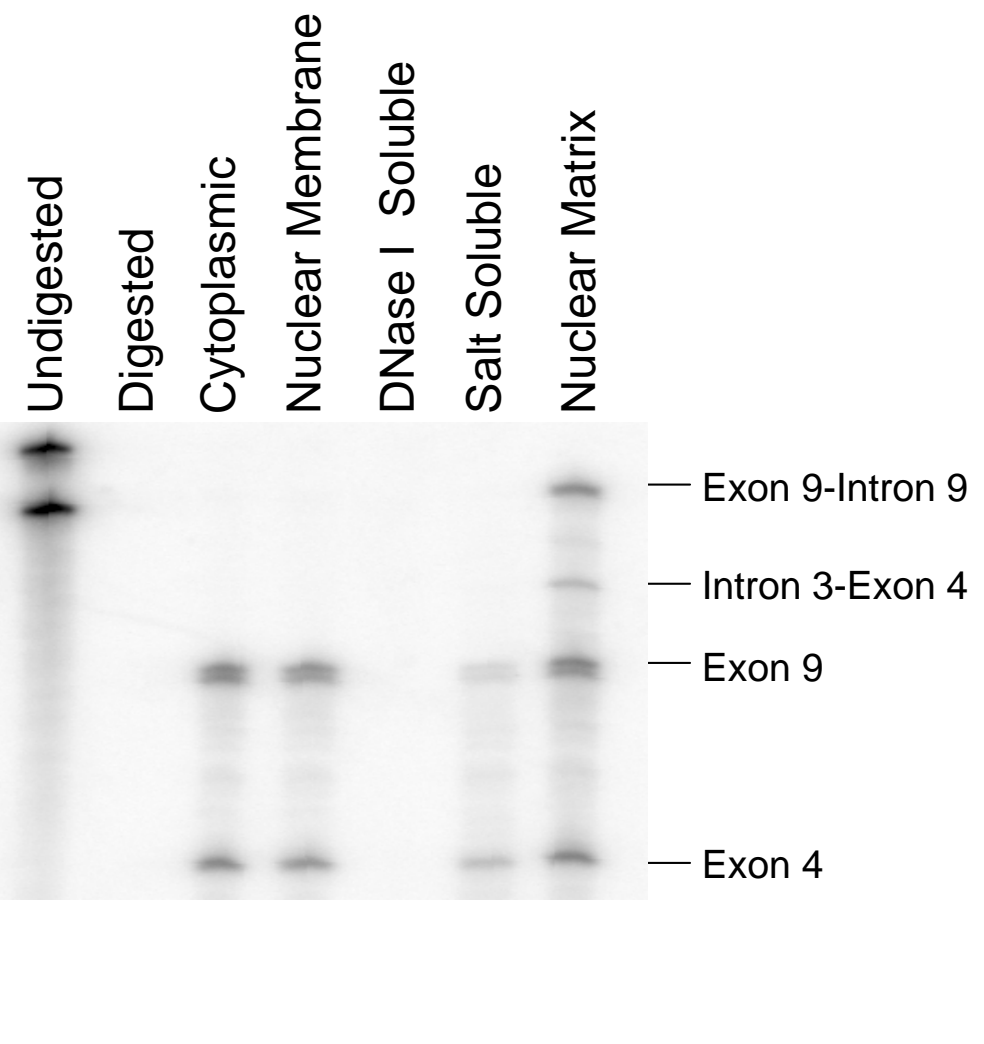

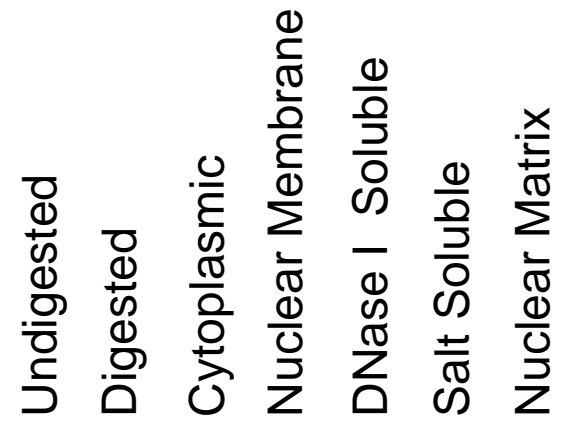

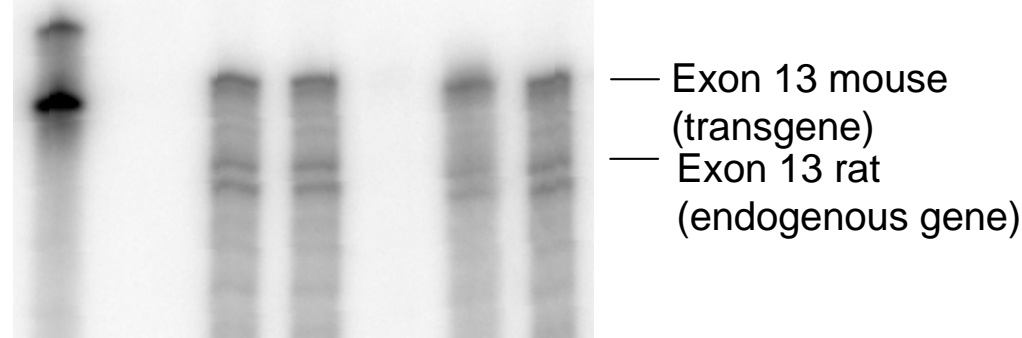


Figure 6. The pcDNA transgene colocalizes with the endogenous gene in subcellular fractions. A) Hepatocytes were isolated as described and cultured in the presence of glucose $(27 \mathrm{mM})$ and insulin $(0.1 \mu \mathrm{M})$ for $24 \mathrm{~h}$. Cellular fractionation was performed as described in Materials and Methods. RNA $(20 \mu \mathrm{g})$ from each cellular fraction was analyzed using a ribonuclease protection assay with two G6PD specific probes, exon 9intron 9 and intron 3-exon 4. B) Hepatocytes were isolated as in Part A). After the $4 \mathrm{~h}$ attachment period, the cells were washed and transfected with the pcDNA construct. Fourteen hours after transfection, the DNA/liposome complexes were removed and glucose $(27 \mathrm{mM})$, insulin $(0.1 \mu \mathrm{M})$ and a Matrigel overlay $(0.3 \mathrm{mg} / \mathrm{ml})$ were added to the cells. The cells were incubated for an additional $24 \mathrm{~h}$ in the presence of this treatment. Cellular fractionation was performed from 80 plates and $20 \mu \mathrm{g}$ of RNA from each fraction was analyzed using a ribonuclease protection assay with the exon 13 mouse probe to detect transgene expression and the exon 13 rat probe to detect endogenous G6PD expression. Digested and undigested lanes represent the probes hybridized with 20 $\mu \mathrm{g}$ of yeast RNA with or without RNase digestion, respectively. 
with ethidium bromide (EtBr), the RNA from the DNase soluble fraction was degraded (data not shown) which explains the lack of G6PD signal in this fraction. The RNA from the salt soluble fraction was also somewhat degraded. Consistent with the hypothesized role of the nuclear matrix, pre-mRNA for G6PD was detected in this fraction (Fig. 6A). Onlymature mRNA was found in the cytoplasmic, nuclear membrane and salt soluble fractions. Thus, the distribution of G6PD mRNAs in the rat hepatocytes is similar to the distribution observed in the intact mouse.

Fractionation was next done with hepatocytes transfected with the pcDNA construct and with a single treatment, glucose and insulin. The amount of G6PD transgene sequences in each fraction was compared to that of the endogenous gene using a ribonuclease protection assay and the exon 13 probe (Fig. 6B). Expression of mRNA from the transgene as measured by the mouse exon 13 probe was found in the same nuclear fractions as the endogenous gene. Again, no G6PD transgene or endogenous gene signal was observed in the DNase soluble fraction, consistent with degradation of this sample as observed on an EtBr stained denaturing agarose gel (data not shown). In this experiment, the cytoplasmic, nuclear membrane and nuclear matrix all showed similar amounts of G6PD mRNA levels. The salt soluble fraction had $40 \%$ less mRNA than the other fractions in both the transgene and the endogenous gene. These probes do not distinguish between the unspliced and spliced species of RNAs. The additional band observed beneath the rat exon 13 band is due to the single base pair difference in the mouse exon 13 probe which results in an extra cut in the hybrid during the RNase digestion. Thus, RNA produced from transiently transfected DNA is in the same fractions as the endogenous gene and therefore transient transfection is an ideal way to rapidly screen the functional activity of the chimeric constructs.

\section{G6PD mature sequences contain a fatty acid response element}

The specificity of this unique nuclear posttranscriptional regulatory mechanism for G6PD must be achieved via cis-acting elements within the pre-mRNA for G6PD. In order to test for the presence of cis-acting elements in the G6PD gene, it was necessary to design chimeric constructs to look at portions of the gene. The primary transcript is $18 \mathrm{~kb}$ in length, therefore, we chose to start with the cDNA which is $2.3 \mathrm{~kb}$ and a $1 \mathrm{~kb}$ fragment of the 3'-UTR. These regions have been shown to contain regulatory elements for other genes.

A representative ribonuclease protection assay is shown in Fig. 7A. There was more robust expression of the transgenes as measured by the mouse exon 13 probe and 
A

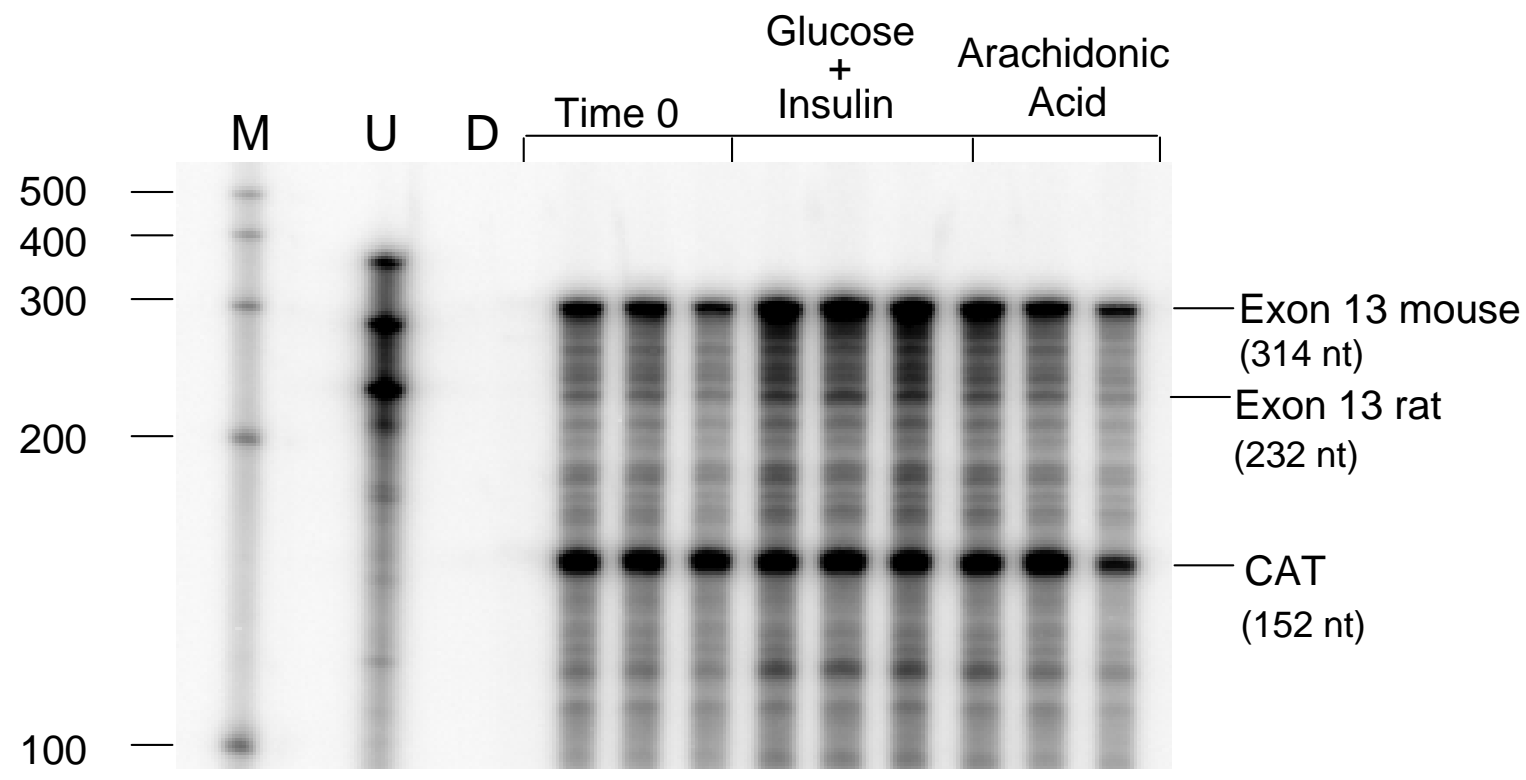

B

Transfected mouse exon 13 mRNA/CAT mRNA

\begin{tabular}{cccc}
\hline & Time 0 & Glucose and Insulin & Fatty acid \\
\hline Expt 1 & $0.60 \pm 0.1$ & $1.20 \pm 0.1$ & $0.66 \pm 0.1$ \\
Expt 2 & $0.86 \pm 0.1$ & $2.07^{*}$ & $1.07 \pm 0.2$ \\
& & $(2.31,1.84)$ & \\
\hline
\end{tabular}

Results in table represent average of 3 samples per treatment \pm SE.

* Represents average of 2 samples per treatment. Value from each sample is shown in parenthesis below the average value.

\begin{tabular}{ccc}
\hline & $\begin{array}{c}\text { Fold-increase due to } \\
\text { glucose and insulin* }\end{array}$ & $\begin{array}{c}\text { \% inhibition } \\
\text { due to fatty acid }\end{array}$ \\
\hline $\begin{array}{c}\text { mouse exon 13 } \\
\text { (transfected) } \\
\text { rat exon 13 } \\
\text { (endogenous) }\end{array}$ & - & $46 \%$ \\
\hline
\end{tabular}

${ }^{\text {* }}$ Results in table represent average of 2 separate experiments. 
Figure 7. The mature G6PD mRNA sequences contain a putative fatty acid response element. A) Hepatocytes were isolated as described. Four hours after plating, the cells were cotransfected with the pcDNA test construct and pRSV-CAT as a control for transfection efficiency. Fourteen hours later, the medium was changed to one containing glucose $(27 \mathrm{mM})$ and insulin $(0.1 \mu \mathrm{M})$ with or without arachidonic acid $(250 \mu \mathrm{M})$ with a $0.3 \mathrm{mg} / \mathrm{ml}$ Matrigel overlay. Total RNA was isolated from each individual plate (3 plates/treatment) after $24 \mathrm{~h}$ with the indicated treatments or before any treatments were added (Time 0$)$. Each RNA sample $(20 \mu \mathrm{g})$ was hybridized with 3 probes in the same tube: mouse exon 13, rat exon 13 and CAT. Analysis was done using a ribonuclease protection assay. A representative blot is shown. $\mathrm{U}=$ Undigested control; $\mathrm{D}=\mathrm{Digested}$ control; $M=$ Marker. Part (B) shows the quantitative results of 2 separate experiments. Results are expressed as mouse exon 13 mRNA divided by CAT mRNA for 2 separate experiments and are the average of 3 samples per treatment \pm SE except for the glucose and insulin value in experiment 2 with only two samples, the separate values are provided in parenthesis. The average fold-increase due to glucose and insulin is only calculated for the endogenous gene. The $\%$ inhibition due fatty acid are shown for both the transgene and the endogenous gene as an average of 2 separate experiments. 
CAT probe versus the endogenous gene as measured by the rat exon 13 probe. In subsequent experiments, we have confirmed that the band for endogenous G6PD is indeed the correct band (data not shown). CAT mRNA expression remained relatively constant in all samples with all treatments. Expression of the G6PD transgene showed the same regulatory pattern as endogenous gene expression. Fig. 7B shows the quantitative data of two separate experiments expressed as mouse exon 13 mRNA divided by CAT mRNA in the top panel. The calculated percent inhibition due to arachidonic acid was 45 and $46 \%$ for experiments 1 and 2, respectively. The foldincrease due to glucose and insulin cannot be calculated for the transgene because expression of the transgene varies with time independent of treatment in transient transfection. Expression of the endogenous gene was increased 2.5- and 6.5-fold in experiments 1 and 2, respectively. A 44 and 55\% inhibition of this stimulation was observed due to arachidonic acid. RNA from nontransfected cells was also analyzed from the same hepatocyte populations. Based on Northern analysis, endogenous G6PD mRNA expression was increased an average of 6-fold due to incubation with glucose and insulin. This stimulation was inhibited by an average of $47 \%$ due to the addition of arachidonic acid to the cells. Thus, transfection did not alter the responsiveness to fatty acids. The similar inhibition in both the transgene and the endogenous gene due to arachidonic acid suggests that the transgene contains a fatty acid regulatory sequence. Thus, we have localized a PUFA regulatory region within $2.3 \mathrm{~kb}$ of the G6PD mature sequence.

Next, hepatocytes were isolated and transfected with each of the three 3'-UTR constructs and pRSV-CAT. The results of three independent experiments showed no consistent pattern of regulation of any of the transgenes (data not shown). Regulation of the endogenous gene was observed within the same experiments. Thus, the cells were responding to fatty acids but we could not make any conclusions regarding the role of the 3'-UTR.

\section{Discussion}

Posttranscriptional regulation at a nuclear level by dietary polyunsaturated fat has not been previously described for other genes and thus represents a very novel mechanism of regulation. The ultimate question then leading to the design of these experiments is how does regulation of this gene occur without changes in the half-life of the pre-mRNA? Identification of these processes is of interest not only to understanding the intracellular actions of fatty acids but also to understanding novel mechanisms of gene regulation.

Our hypothesis is that the specificity of the nuclear posttranscriptional effect must be achieved via a cis-acting regulatory element within the G6PD precursor mRNA 
sequence to which a trans-acting protein may bind. We did a series of experiments to localize a PUFA regulated cis-acting element that may be responsible for this unique form of regulation by fat. The mouse G6PD cDNA transgene demonstrated the same regulation as the endogenous rat G6PD gene, thus a fatty acid regulatory element resides in the $2.3 \mathrm{~kb}$ region. To determine the validity of our results, we first determined that the CMV promoter, which was used to drive the expression of all constructs, and the parent vector sequences were not regulated by arachidonic acid. Second, we demonstrated that the pcDNA transgene is found in the same nuclear compartments as the endogenous gene, indicating the RNA from the transgene used a common processing pathway. Third, we cotransfected with RSV-CAT to ensure that changes in transgene expression were not due to differences in transfection efficiency. Not only was regulation of pcDNA still observed after correction for transfection efficiency but there was little difference in the transfection efficiency between plates. Fourth, inhibition of the endogenous gene expression by arachidonic acid was identical to that observed with the transgene. This was observed in both transfected and nontransfected hepatocytes within the same experiment. Thus, we have localized a PUFA response element to $2.3 \mathrm{~kb}$ of the mature G6PD sequences.

It is unclear whether the carbohydrate stimulation achieved by refeeding a starved animal and the fatty acid inhibition achieved by consumption of a high-fat diet will follow the same molecular mechanism. Both dietary regimens are regulated at a nuclear posttranscriptional step (6); however, the cis-acting elements and trans-acting proteins may be different in each case. We were unable to calculate the fold-increase due to glucose and insulin for the pcDNA transgene due to the experimental design. Time 0 RNA was isolated at $18 \mathrm{~h}$ into the culture whereas the RNA from samples treated with glucose and insulin was isolated at $42 \mathrm{~h}$ into the culture. Expression of the transgenes vary with time independent of treatment (data not shown). Insulin response elements could be localized by comparing hepatocytes treated with glucose alone versus insulin alone. The search for glucose response elements would be more difficult since most cell culture media contain small amounts of glucose and the cells do not survive in a complete absence of glucose. Although this has not been directly tested, polyunsaturated fat does not appear to induce the synthesis of another protein because the effect of dietary fat and arachidonic acid is very rapid ( $4.5 \mathrm{~h}$ in the intact animal and $2 \mathrm{~h}$ in cells in culture). In addition, when hepatocytes are incubated with glucose alone (no insulin) we do not observe inhibition by arachidonic acid. Thus, polyunsaturated fatty acids may interfere with insulin signaling which would suggest that the glucose and insulin response elements would overlap with the PUFA response element in the G6PD pre-mRNA. 
There are several possibilities for how this regulation may occur. The first possibility is that regulation of G6PD expression occurs very early in the processing pathway, either on entry of the pre-mRNA into the pathway or very early in the processing reactions. Pre-mRNA which enters the processing pathway, as may be the case with a low-fat diet (in the presence of glucose and insulin), is stable; pre-mRNA that does not enter the pathway, as may be the case with a high-fat diet (in the presence of arachidonic acid) is degraded in the nucleus by RNases. This mechanism could involve the binding of a trans-acting protein to a cis-acting element within the pre-mRNA. On binding, this protein could target the RNA for processing perhaps by association with the nuclear matrix, the location of processing of many transcripts (11-14). A protein may be induced during high-carbohydrate, low-fat feeding (in the presence of glucose and insulin) which allows attachment to the nuclear matrix to occur. Conversely, in animals fed a high-fat diet (in the presence of arachidonic acid), the amount of this protein may be reduced resulting in either a block in entry of pre-mRNA into the processing pathway or enhanced degradation during processing. Another possibility is that fat may alter the conformation of the putative regulatory protein so that it cannot bind to the regulatory sequence. Preliminary data from our laboratory supports this model. In this regard, in livers of mice fed a high-carbohydrate, low-fat diet, G6PD pre-mRNA copurifies with the nuclear matrix and more processed mRNA accumulates on the nuclear matrix. Starvation or high-fat feeding results in less pre-mRNA in the matrix and a block in accumulation of more processed RNA (Amir-Ahmady and Salati, unpublished). Fig. 8 summarizes this model for regulation of G6PD by polyunsaturated fat.

There are two other genes which are thought to be regulated through enhanced stability of the nuclear pre-mRNA, perhaps through processing on the nuclear matrix. Regulation of fibronectin by transformation with H-ras (30) or treatment with dexamethasone (31) occurs by changes in accumulation of nuclear precursor mRNA in the absence of changes in the rate of transcription, polyadenylation, or alternative splicing of the fibronectin transcript. Tissue-specific expression as well as regulation by retanoic acid of the liver/bone/kidney alkaline phosphatase gene also involves small changes in the amount of nuclear precursor mRNA without changes in transcriptional activity (32). Enhanced stability of these nuclear RNAs is the hypothesized mechanism however these conclusions are not based on measurements of changes in pre-mRNA half-life. Exact identification of the cis-acting sequences and trans-acting factors have not yet been elucidated.

The second possibility is that regulation of G6PD occurs through a pathway similar to that described for nonsense codon containing mRNAs. Nuclear mRNAs can be 


\section{Model for G6PD Posttranscriptional Regulation}

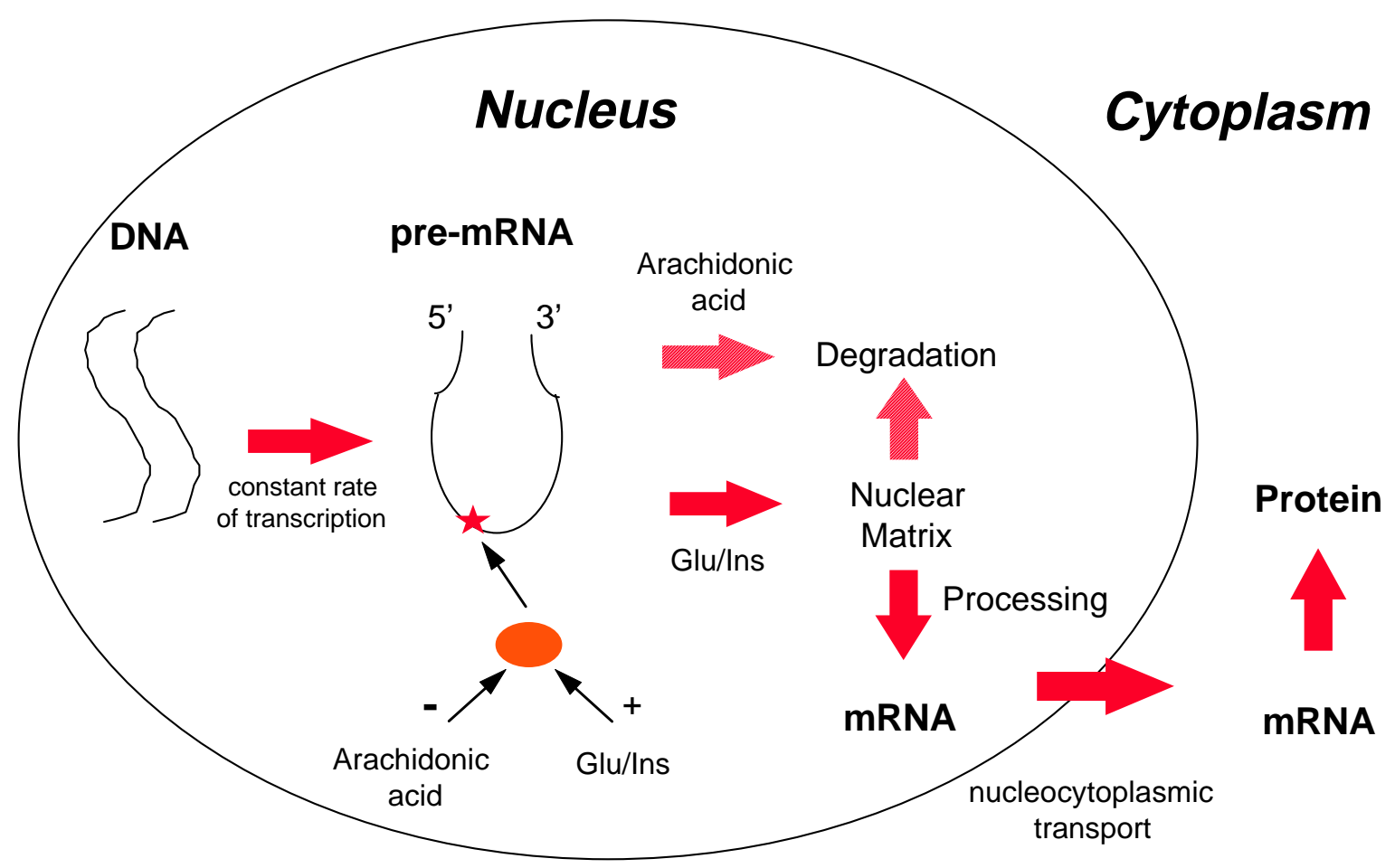

Figure 8. Proposed model for G6PD regulation by polyunsaturated fatty acids. Nuclear posttranscriptional regulation of G6PD occurs early in processing by differential accumulation of the pre-mRNA in the processing pathway. This mechanism may involve the binding of a trans-acting factor to a cis-acting element within the pre-mRNA. Perhaps a protein is induced during high-carbohydrate, low-fat feeding which allows attachment to the nuclear matrix and facilitates the movement of the pre-mRNA through the nuclear processing reactions thus protecting it from degradation. In the animal fed a high-fat diet, the activity or amount of this protein may be decreased and thus association with the nuclear matrix would not occur. Alternatively, binding to the nuclear matrix may occur but the pre-mRNA may not enter any further into the processing pathway. Pre-mRNA not associated with the nuclear matrix would then be susceptible to degradation by RNases in the nucleus. 
destabilized by the presence of nonsense codons, also called premature termination codons, as has been reported for the triosephosphate isomerase (TPI) gene (33). The nonsense mutation in TPI is caused by a genetic mutation, not regulation by diet or hormones (34). RNA produced with the nonsense codon undergoes rapid decay either within the nucleus or during transport through the nuclear pore (15). Nonsense-mediated decay requires the presence of at least one intron after the premature termination codon which implicates nuclear splicing as an effector of this pathway (35). According to the accepted model for nonsense-mediated decay, all exon-exon junctions within a multiintron gene may be "marked" with a remnant of the splicing machinery. This "mark" must be positioned at least $50 \mathrm{nt}$ downstream but less than $550 \mathrm{nt}$ downstream of the nonsense codon in order to be recognized by the proposed nuclear scanner (36). This scanner within the nucleus or at the nuclear pore recognizes and degrades mRNAs containing premature stop codons. This may be a component of the translation termination complex or a completely distinct mechanism.

At first glance it seems that we do not have the structural elements required for this pathway since the PUFA regulation is observed with the pcDNA construct which does not contain an intron sequence and second there are no nonsense codons in the G6PD coding region. It is possible that G6PD is regulated by a variation of this nonsense-mediated decay pathway. For example, it is possible that a splicing factor such as a serine-arginine (SR) protein may bind to the putative regulatory sequence that we have localized in an exon under all dietary conditions. SR proteins recognize sequences within the exons of mRNA (14). In the presence of glucose and insulin, an additional regulatory protein may be induced which binds to this SR protein to mediate the entry of the mRNA into the processing pathway. In the presence of arachidonic acid, this proteinprotein interaction may not occur. The presence of the SR protein alone on the G6PD exon may "mark" the message for decay by an unknown mechanism. A similar scanning mechanism may be responsible for decay, similar to that described for nonsensecontaining messages (15). One possibility for the putative trans-acting protein is an SR kinase which may phosphorylate the SR protein to allow the pre-mRNA to enter the processing pathway. It will be necessary to distinguish whether glucose and insulin induces a stimulatory protein or induces the decay of an inhibitory protein. If the later is the case, then arachidonic acid may block the decay of the inhibitory protein.

To date, polyunsaturated fatty acid response elements have been conclusively identified in three other genes: L-PK (37), S14 (38), and SCD1 (39). G6PD is the fourth example of a polyunsaturated fatty acid response element. However, this is the only element which has been found in the coding sequence. All others have been found in the 
promoter region of genes and are involved in regulation at a transcriptional level. It is possible that there is more than one class of polyunsaturated response element in the genes that are regulated transcriptionally. In fact, posttranscriptional mechanisms have been found to occur coincidentally with transcriptional mechanisms in some genes (8-10). It is possible that all of the other lipogenic genes possess some components of this posttranscriptional pathway which would allow more rapid changes in their expression in response to nutritional stimuli. This pathway has not been studied with these genes because of the difficulty of distinguishing between transcriptional and posttranscriptional mechanisms for changing pre-mRNA accumulation. G6PD may have adapted this exclusive posttranscriptional mechanism due to its roles in maintenance of redox state and cell growth. In this way, the organism maintains uniform expression of G6PD in all tissues but can increase expression in certain tissues when the needs for lipogenesis are great.

Our long term goal is to determine if cis-acting elements identified in the rat hepatocyte culture model are the same elements used by dietary fat in the intact animal. These experiments will require transgenic approaches. The presence of different cisacting elements would suggest that PUFA-regulated factors do not have generalized effects on regulatory pathways, but are rather gene specific. The trans-acting proteins still need to be identified to determine if there is a general pathway for all genes. Most likely there will be multiple factors involved. This is the first example of a PUFA-regulatory region found in a coding region and that is part of an exclusively posttranscriptional regulatory mechanism. Future work includes analysis of the deletion constructs to further localize the response element followed by characterization of an RNA binding protein that interacts with this region. An ultimate goal of this laboratory is to trace the signal transduction pathway within hepatocytes by which fatty acids cause a change in gene expression.

\section{References}

1. Clarke, S. D., M. K. Armstrong, and D. B. Jump. 1990. Nutritional control of rat liver fatty acid synthase and S14 mRNA abundance. J. Nutr. 120: 218-224.

2. Vaulout, S., A. Munnich, J-F. Decaux, and A. Kahn. 1986. Transcription and posttranscriptional regulation of L-type pyruvate kinase gene expression in rat liver. J. Biol. Chem. 261: 7621-7625.

3. Ntambi, J. M. 1992. Dietary regulation of stearoyl-CoA desaturase I gene expression in mouse liver. J. Biol. Chem. 267: 10925-10930. 
4. Clarke, S. D., D. R. Romsos, and G. A. Leveille. 1976. Specific inhibition of hepatic fatty acid synthesis exerted by dietary linoleate and linolenate in essential fatty acid adequate rats. Lipids. 11: 485-490.

5. Clarke, S. D., D. R. Romsos, and G. A. Leveille. 1977. Differential effects of dietary methyl esthers of long-chain saturated and polyunsaturated fatty acids on rat liver and adipose tissue lipogenesis. J. Nutr. 107: 1170-1181.

6. Hodge, D. L., and L. M. Salati. 1997. Nutritional regulation of the glucose-6phosphate dehydrogenase gene is mediated by a nuclear posttranscriptional mechanism. Arch. Biochem. Biophys. 348: 303-312.

7. Stabile, L. P., D. L. Hodge, S. A. Klautky, and L. M. Salati. 1996. Posttranscriptional regulation of glucose-6-phosphate dehydrogenase by dietary polyunsaturated fat. Arch. Biochem. Biophys. 332: 269-279.

8. Burmeister, L. A., and C. N. Mariash. 1991. Dietary sucrose enhances processing of mRNA-S14 nuclear precursor. J. Biol. Chem. 266: $22905-22911$.

9. Walker, J. D., L. A. Burmeister, A. Mariash, J. F. M. Bosman, J. Harmon, and C. N. Mariash. 1996. Insulin increases the processing efficiency of messenger ribonucleic acid-S14 nuclear precursor. Endocrinology . 137: 2293-2299.

10. Song, M. K., B. Dozin, D. Grieco, J. E. Rall, and V. M. Nikodem. 1988. Transcriptional activation and stabilization of malic enzyme mRNA precursor by thyroid hormone. J. Biol. Chem. 263: 17970-17974.

11. Nickerson, J. A., B. J. Blencowe, and S. Penman. 1995. The architectural organization of nuclear metabolism. Int. Rev. Cytol. 162: 67-123.

12. Huang, S., and D. L. Spector. 1996. Dynamic organization of pre-mRNA splicing factors. J. Cell. Biochem. 62: 191-197.

13. Mortillaro, M. J., B. J. Blencowe, X. Y. Wei, H. Nakayasu, L. Du, S. L. Warren, P.A. Sharp, and R. Berezney. 1996. A hyperphosphorylated form of the large subunit of RNA polymerase II is associated with splicing complexes and the nuclear matrix. Proc. Natl. Acad. Sci. USA . 93: 8253-8257.

14. Blencowe, B. J., J. A. Nickerson, R. Issner, S. Penman, and P.A. Sharp. 1994. Association of nuclear matrix antigens with exon-containing splicing complexes. J. Cell. Biol. 127: 593-607.

15. Maquat, L. E. 1995. When cells stop making sense: effects of nonsense codons on RNA metabolism in vertebrate cells. RNA. 1: 453-465.

16. McKusik, V. A. (with the assistance of C. A. Francomano, S. E. Antonarakis, and P. L. Pearson). 1994. Mendelian inheritance in man: A catalog of human genes and genetic disorders. John Hopkins University Press, Baltimore, MD. (Web site http:/www.ncbi.nlm.nih.gov/Omim/).

17. Stabile, L. P., S. A. Klautky, S. M. Minor, and L. M. Salati. 1998. Polyunsaturated fatty acids inhibit the expression of the glucose-6-phosphate dehydrogenase gene in primary rat hepatocytes by a nuclear posttranscriptional mechanism. J Lipid Res. 39: 1951-1963. 
18. Zollo, M., M. D’Urso, D. Schlessinger, and E. Y. Chen. 1993. Sequence of mouse glucose-6-phosphate dehydrogenase cDNA. J. DNA Sequencing \& Mapping. 3: 319322.

19. Hodge, D. L., T. Charron, L. P. Stabile, S. A. Klautky, and L. M. Salati. 1998. Structural characterization and tissue-specific expression of the mouse glucose-6phosphate dehydrogenase gene. DNA \& Cell Biol. 17: 283-291.

20. Mortensen, R. J., D. Chesnut, J. P. Hoeffler, and R. E. Kingston. 1997. Selection of transfected mammalian cells., p9.5.1-9.5.19. In F. M. Ausubel, R. Brent, R. E. Kingston, D.. Moore, J. G. Seidman, J. A. Smith, and K. Struhl (ed.), Current Protocols in Molecular Biology. John Wiley \& Sons, New York.

21. Weber, M., K. Moller, M. Welzeck, and J. Schorr. 1995. Effect of lipopolysaccharide is a frequent contaminant in eukaryotic cells. Biotechniques. 19: 930-940.

22. Felgner, P. L., T. R. Gadek, M. Holm, R. Roman, H. W. Chan, M. Wenz, J. P. Northrop, G. M. Ringold, and M. Danielsen. 1987. Lipofectin: a highly efficient, lipidmediated DNA-transfection procedure. Proc. Natl. Acad. Sci. USA 84: 7413-7417.

23. Shih, H. M., and H. C. Towle. 1995. Matrigel treatment of primary hepatocytes following DNA transfection enhances responsiveness to extracellular stimuli.

Biotechniques. 18: 813-816.

24. Bradford, M.M. 1976. A rapid and sensitive method for the quantitation of microgram quantities of protein utilizing the principle of protein-dye binding. Anal. Biochem. 72: 248-254.

25. Leppard, K. N., and T. Shenk. 1989. The adenovirus E1B 55 kd protein influences mRNA transport via an intranuclear effect on RNA metabolism. EMBO J. 8: 23292336.

26. Chomczynski, P., and N. Sacchi. 1987. Single-step method of isolation by acid guanidinium thiocyanate-phenol-chloroform extraction. Anal. Biochem. 162: 156-159. 27. Gough, N. M. 1988. Rapid and quantitative preparation of cytoplasmic RNA from small numbers of cells. Anal. Biochem. 173: 93-95.

28. Mortensen, R. J., D. Chesnut, J. P. Hoeffler, and R. E. Kingston. 1997. Preparation and analysis of RNA., p4.3.2. In F. M. Ausubel, R. Brent, R. E. Kingston, D. Moore, J. G. Seidman, J. A. Smith, and K. Struhl (ed.), Current Protocols in Molecular Biology. John Wiley \& Sons, New York.

29. Dixon, D. A., D. L. Vaitkus, S. M. Prescott. 1998. DNase I treatment of total RNA improves the accuracy of ribonuclease protection assay. Biotechniques. 24: 732-734.

30. Chandler, L. A., C. P. Ehretsmann, and S. Bourgeois. 1994. A novel mechanism of Ha-ras oncogene action: Regulation of fibronectin mRNA levels by a nuclear posttranscriptional event. Mol. Cell. Biol. 14: 3085-3093.

31. Ehretsmann, C. P., L. A. Chandler, and S. Bourgeois. 1995. A nuclear posttranscriptional mechanism mediates the induction of fibronectin by glucocorticoids. Mol and Cell Endo. 110: 185-194. 
32. Zhou, H., S. S. Manji, D. M. Findlay, T. J. Martin, J. K. Heath, and K. W. Ng. 1994. Novel action of retanoic acid. Stabilization of newly synthesized alkaline phosphatase transcripts. J. Biol. Chem. 269: 22433-22439.

33. Cheng, J., and L. E. Maquat. 1993. Nonsense codons can reduce the abundance of nuclear mRNA without affecting the abundance of pre-RNA or the half-life of cytoplasmic mRNA. Mol. Cell. Biol. 13: 1892-1902.

34. Daar, I. O., and L. E. Maquat. 1988. Premature translation termination mediates triosphosphate isomerase mRNA degradation. Mol. Cell. Biol. 8: 802-813.

35. Zhang, J., X. Sun, Y. Qian, J. P. LaDuca, and L. E. Maquat. 1998. At least one intron is required for the nonsense-mediated decay of triosephosphate isomerase mRNA: a possible line between nuclear splicing and cytoplasmic translation. Mol. Cell. Biol. 18: 5272-5283.

36. Nagy, E., and L. E. Maquat. 1998. A rule for termination-codon position within intron-containing genes: when nonsense affects RNA abundance. TIBS. 23: 188-189.

37. Liimatta, M., H. C. Towle, S. D. Clarke, and D. B. Jump. 1994. Dietary polyunsaturated fatty acids interfere with the insulin/glucose activation of L-type pyruvate kinase gene transcription. Mol. Endocrinol. 8: 1147-1153.

38. Jump, D. B., S. D. Clarke, O. MacDougald, and A. Thelen. 1993. Polyunsaturated fatty acids inhibit $\mathrm{S} 14$ gene transcription in rat liver and cultured hepatocytes. PNAS. 90: 8454-8458.

39. Waters, K. M., C. Wilson Miller, and J. M. Ntambi. 1997. Localization of a polyunsaturated fatty acid response region in stearoyl-CoA desaturase gene I. Biochim. Biophys. Acta. 1349: 33-42. 


\section{APPENDIX}

Hepatocyte isolation. The following is a more detailed procedure for the isolation of rat hepatocytes. This is a very intricate procedure and requires precise timing of certain steps in order to achieve viable cells. Thus, I will describe all of the steps in detail from injection of the animal to the end of the purification steps.

Rats used as hepatocyte donors were injected interperitoneally with $250 \mu \mathrm{l}$ of Nembutal $(50 \mathrm{mg} / \mathrm{ml})$ per $200 \mathrm{~g}$ animal immediately before surgery. It was necessary to secure the animal to a styrofoam support with autoclave tape and place this support in a metal tray to collect the perfusion buffer. The abdominal region was wet with $70 \%$ ethanol to avoid contamination from animal hair; shaving this region was not necessary. A midline incision was made starting above the pelvis and up to the sternum. Lateral cuts were then made so that the skin flaps could be pushed to the side exposing the abdominal region. The esophagus was clamped just above the stomach with a hemastat. A cut was made above the clamp so that the intestines and the stomach could be pushed to the right so as to expose the portal vein. To help expose the abdominal cavity, the barrel from a 30 $\mathrm{ml}$ syringe was placed under the back of the animal. Three pieces of surgical silk (approximately 6 inches each; Harvard Apparatus Cat \# 51-7706) were inserted around the portal vein. The silk furthest from the liver was tied very loosely around the vein. A 16 gauge 1.88 inch catheter (Angiocath ${ }^{\text {TM }}$ Cat \# 330017; Central Supply, Ruby Hospital, WV) was inserted into the vein, over the lower piece of silk. As the needle was pulled out of the catheter, blood flowed down the needle, indicating proper insertion. The perfusion tubing, which contained the $\mathrm{Ca}^{2+}$-free buffer $(500 \mathrm{ml})$, was attached immediately. It was necessary to ensure that no bubbles were present in the tubing and buffer was allowed to drip from the tubing at a rate of $1-3 \mathrm{ml} / \mathrm{min}$. Any air entering the liver through this manner would ruin the cell viability. The flow rate was increased to 20 $\mathrm{ml} / \mathrm{min}$ and the inferior vena cava was cut to allow the buffer to flow out. The point from pulling out the needle to cutting the inferior vena cava should take a maximum of $5 \mathrm{sec}$. The first sign of perfusion is that the liver becomes tan immediately as the blood is pushed out. The other surgical silk ties were knotted down, the lower one to cut off blood supply to the vein, and to tie down the catheter, the upper two to tie the catheter to the portal vein. This was followed by cutting through the diaphragm and cutting the superior vena cava. The flow rate was increased to $40 \mathrm{ml} / \mathrm{min}$ and the ties were double-checked for tightness. The point from pulling out the needle to the increase in flow rate to 40 $\mathrm{ml} / \mathrm{min}$ should take no longer than 1 min to complete. This perfusion was continued until $350 \mathrm{ml}$ of perfusion buffer was used. At that time, the collagenase solution $(100 \mathrm{ml}$ 
filtered into a $150 \mathrm{ml}$ glass bottle) was released into the perfusion tubing and the $\mathrm{Ca}^{2+}$ free buffer was stopped. Collagenase releases the cells from the matrix within a few minutes; this is easily observed upon visual inspection. After $100 \mathrm{ml}$ of collagenase buffer was perfused, the tubing was removed from the catheter. The liver was then cut away from the body cavity and transferred to a sterile petri dish. The cells were combed away from the intestinal string and the purification steps were begun.

The initial cell suspension after the collagenase digestion contains intact parenchymal cells, variable nonparenchymal and damaged cells, cell clumps, pieces of connective tissue and vascular tissue, and subcellular debris. The purpose of the purification was to remove all contaminants and end up with intact parenchymal cells. All purification steps were carried out at $4{ }^{\circ} \mathrm{C}$. The cell solution was brought up to $20 \mathrm{ml}$ with Williams' E medium [supplemented with $23 \mathrm{mM}$ Hepes, $\mathrm{pH}$ 7.4, $26 \mathrm{mM}$ sodium bicarbonate, penicillin $(100 \mathrm{U} / \mathrm{ml})$, streptomycin $(100 \mu \mathrm{g} / \mathrm{ml})$ and gentamicin $(50 \mu \mathrm{g} / \mathrm{ml})$ ] and filtered through $105 \mu \mathrm{m}$ mesh (Spectra/Mesh ${ }^{\circledR}$ ) to remove the connective tissue and cell clumps. The cells were gassed with $95 \% \mathrm{O}_{2} / 5 \% \mathrm{CO}_{2}$ for $1 \mathrm{~min}$ and centrifuged at 50 $\mathrm{X} g$ for $3 \mathrm{~min}$. The supernatant was removed and the pellet was resuspended in $20 \mathrm{ml}$ of media. The cells were gassed and centrifuged again exactly as before.

At this point, the cells were observed under a microscope for viability using trypan blue exclusion. When cells are incubated with trypan blue, a non-viable cell has a blue cytoplasm; a viable cell has a clear cytoplasm. In a $15 \mathrm{ml}$ tube, $1.2 \mathrm{ml}$ media, 0.15 $\mathrm{ml}$ cells and $0.15 \mathrm{ml}$ trypan blue (Gibco-BRL Cat \# 15250-061) is added and mixed. A few drops of cells are added under the cover slip of a hemacytometer. The hemacytometer is placed on the microscope and lined up under a grid of $4 \mathrm{X} 4$ boxes. Both live and dead cells are counted in the 4 X 4 area. Cells from 3 different 4 X 4 areas should be counted to get a better estimate of the number of cells. If 100 total cells are in the $4 \times 4$ area, this means that there are $10.0 \times 10^{6}$ cells $/ \mathrm{ml}$. The number of dead cells divided by the number of total cells multiplied by 100 gives the percentage of dead cells. This number is subtracted from 100 to give the percentage of viable cells. If cells were greater than $90 \%$ viable based on trypan blue exclusion, $25 \mathrm{ml}$ of the cell solution was added to $24 \mathrm{ml}$ of a pre-prepared Percoll solution [9:1 mixture of Percoll (Sigma Cat \# P4937) and 10X Hanks Balanced Salt Solution]. This was mixed well by inversion and centrifuged $50 \mathrm{X} g$ for $10 \mathrm{~min}$. The supernatant was removed and the cell pellet was resuspended in $10 \mathrm{ml}$ of media. The cells were gassed as before and centrifuged at $50 \mathrm{X}$ $g$ for $2 \mathrm{~min}$. This step was repeated one time. The cells were counted using a hemacytometer and trypan blue exclusion as described above and adjusted to $8 \times 10^{6}$ cells $/ \mathrm{ml}$. $0.5 \mathrm{ml}$ of cells at this density were added to each $60 \mathrm{~mm}$ plate that was 
preconditioned with $2.5 \mathrm{ml}$ of media containing 5\% newborn calf serum (Gibco-BRL Cat \# 26010-074). The cells were incubated for $4 \mathrm{~h}$ in the presence of serum to allow attachment to the plates. At this point the media containing serum was removed and replaced with one without serum. The remainder of the steps concerning the maintenance of the cells was determined based on the purpose of the experiment.

pcDNA deletion constructs. To more precisely locate the fatty acid response element of the G6PD gene, we have subcloned the pcDNA construct into smaller fragments. These fragments were not tested in transfection experiments due to problems that arose in the cell culture system. Plasmids containing smaller subsets of the G6PD cDNA sequence were made by digestion of the pcDNA construct using convenient restriction enzymes. Following digestion with HindIII and the indicated enzymes in the construct name, the desired fragments were gel isolated, filled in with Klenow treatment to create blunt-ends and religated. The new constructs were verified by sequencing through the deletions and by restriction digestion. The BglII construct was only digested with BgIII and therefore blunt-ends did not need to be created. These constructs are shown in Figure 1. 


\section{pcDNA Deletion Constructs}

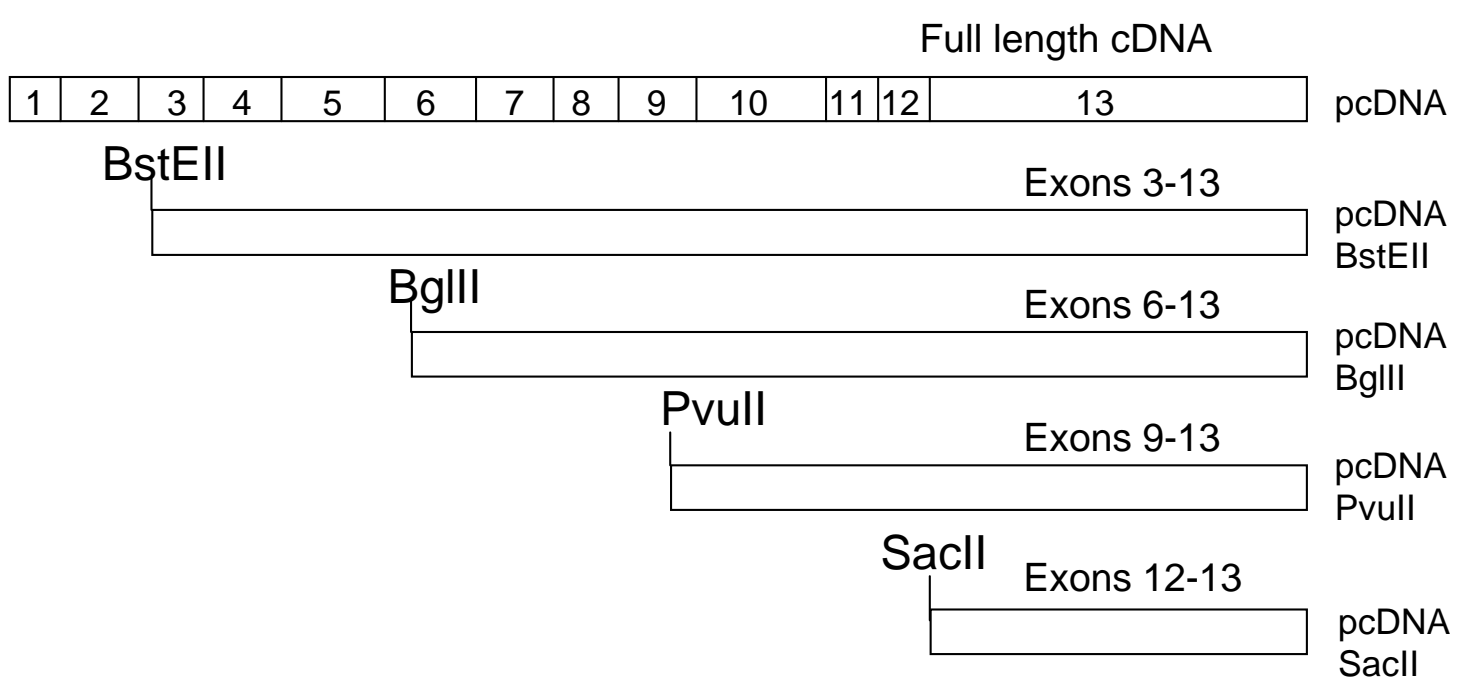

Figure 1. pcDNA deletion constructs. The full-length pcDNA construct was divided into smaller fragments using restriction enzyme digestion. The numbers represent the 13 exons of G6PD. Four deletion constructs were made: pcDNA BstEII which contains exons 3-13, pcDNA BglII which contains exons 6-13, pcDNA PvuII which contains exons 9-13 and pcDNA SacII which contains exons 12 and 13. Figure is not drawn to scale. 


\section{JOURNAL OF LIPID RESEARCH}

EDITORIAL OFFICE

\author{
FEDERATION OF AMERICAN SOCIETIES \\ FOR EXPERIMENTAL BIOLOGY \\ 9650 ROCKVILLE PIKE \\ BETHESDA, MD 20814-3998, USA \\ TEL: (301) 530-7100 \\ FAX: (301) 571.5723 \\ E-MAIL: Igidez afaseb org
}

ARTHUR A. SPECTOR, EDITOR IN-CHEF

LEWIS I. GIDEZ. EXECUTIVE EDITOR

December 9, 1998

Dr. Laura P. Stabile

Department of Biochemistry

HSC-N PO Box 9142

West Virginia University

Morgantown, WV 26506

Dear Dr. Stabile,

I am pleased to grant permission for you to reproduce "Polyunsaturated fatty acids inhibit and glucose stimulates the expression of the glucose-6-phosphate dehydroenase gene in primary rat hepatocytes by a nuclear posttranscriptional mechanism," Stabile, L. P., et al., J. Lipid Res., 39: 1951-1963 for inclusion in your dissertation.

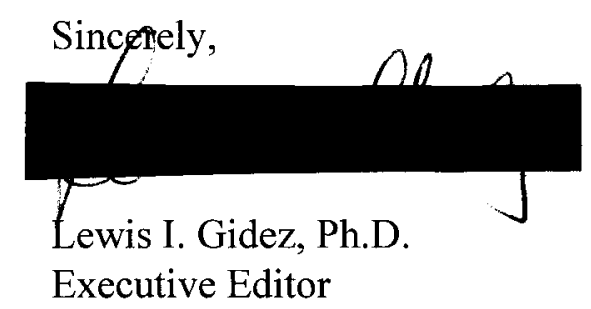




\section{CURRICULUM VITAE}

\section{Laura P. Stabile}

\section{EDUCATION}

Ph.D. (1999) Biochemistry, West Virginia University, Morgantown, WV

Advisor: Lisa M. Salati, Ph.D.

Title: Regulation of glucose-6-phosphate dehydrogenase by polyunsaturated fatty acids in cultured rat hepatocytes.

M.S. (1995) Biochemistry, West Virginia University, Morgantown, WV Advisor: Lisa M. Salati, Ph.D.

Title: Regulation of glucose-6-phosphate dehydrogenase by dietary polyunsaturated fatty acids in the intact animal.

B.A. (1993) Chemistry and Spanish, Washington \& Jefferson College, Washington, PA Advisor: Lance Funderburk, Ph.D.

Title: Spectrophotometric assays of superoxide dismutase activity.

\section{EMPLOYMENT}

8/93- 5/99

Department of Biochemistry, West Virginia University

Morgantown, WV 26506-9142

Graduate Research Assistant: Conducted research in the area of posttranscriptional gene regulation by nutritional factors. My primary goals were (1) to determine if regulation of the G6PD gene by dietary fat occurred via a transcriptional or posttranscriptional mechanism in the intact mouse, (2) to establish a cell culture system in which to study this regulation and (3) to identify a fatty acid response element within the G6PD gene. Areas of expertise include ribonuclease protection assays, transcription assays, northern and southern analysis, transfection, cell culture and sterile technique, cloning, DNA sequencing, PCR, UV-VIS spectroscopy, luminometry, gel electrophoresis, DNA/RNA isolation, cellular fractionation, enzyme kinetics.

$5 / 92-8 / 92$

Calgon Corporation

$5 / 93-8 / 93$

Pittsburgh, PA 15230

Student Internship: Worked in research and development under the guidance of Gary Matz. Tested unique combinations of monomers to develop a new hair conditioning polymer superior to others on the market. Major techniques used include polymer synthesis and reaction calorimetry. 
8/90- $5 / 93$

Department of Chemistry, Washington and Jefferson College

Washington, PA 15301

Organic Laboratory Assistant, Physical Chemistry Laboratory

Assistant: Prepared laboratory reagents, supervised experimental

work of undergraduate chemistry students, graded laboratory

notebooks, led review sessions for questions and concerns,

conducted GC, FT-IR and NMR analysis on students' laboratory

samples.

Undergraduate Research: Worked in collaboration with Dr. Bud Hayes of Allegheny General Hospital to develop two methods for analyzing superoxide dismutase activity from blood from patients with spinal cord injury using a UV-VIS spectrophotometer.

\section{AWARDS}

Sigma Xi Student Award for Research Excellence 1999

Van Liere Memorial Research Award-First Place 1999

Robert C. Byrd Doctoral Travel Award 1998

J. Adolph Schmidtz Scholar 1993

\section{PROFESSIONAL SOCIETIES}

Association of Molecular Biology and Biochemistry

Association for Women in Science

The RNA Society

Sigma Xi Honorary Research Society- inducted 1999

Sigma Delta Pi Honorary Society- inducted 1993

\section{PUBLICATIONS}

Stabile, L. P., Hodge, D. L., Klautky, S. A., and Salati, L. M. (1996)

Posttranscriptional regulation of glucose-6-phosphate dehydrogenase by dietary polyunsaturated fat. Arch. Biochem. Biophys. 332:269-279.

Hodge, D. L., Charron, T. G., Klautky, S. A., Stabile, L. P., and Salati, L. M. (1998) Structural characterization and tissue-specific expression of the mouse glucose-6phosphate dehydrogenase gene. DNA and Cell Biology, 17:283-291.

Stabile, L. P., Klautky, S. A., Minor, S. M. and Salati, L. M. (1998)

Polyunsaturated fatty acids inhibit and glucose stimulates the expression of the glucose-6phosphate dehydrogenase gene in primary rat hepatocytes by a nuclear posttranscriptional mechanism. J. Lipid Research, 39:1951-1963. 